\title{
Factors Related to the Career Intentions of Senior Athletic Training Students Approaching Graduation
}

\author{
Rae Lee Emrick \\ West Virginia University, remrick@mix.wvu.edu
}

Follow this and additional works at: https://researchrepository.wvu.edu/etd

Part of the Health and Physical Education Commons, and the Sports Sciences Commons

\section{Recommended Citation \\ Emrick, Rae Lee, "Factors Related to the Career Intentions of Senior Athletic Training Students Approaching Graduation" (2018). Graduate Theses, Dissertations, and Problem Reports. 3733. https://researchrepository.wvu.edu/etd/3733}

This Dissertation is protected by copyright and/or related rights. It has been brought to you by the The Research Repository @ WVU with permission from the rights-holder(s). You are free to use this Dissertation in any way that is permitted by the copyright and related rights legislation that applies to your use. For other uses you must obtain permission from the rights-holder(s) directly, unless additional rights are indicated by a Creative Commons license in the record and/ or on the work itself. This Dissertation has been accepted for inclusion in WVU Graduate Theses, Dissertations, and Problem Reports collection by an authorized administrator of The Research Repository @ WVU. For more information, please contact researchrepository@mail.wvu.edu. 


\title{
Factors Related to the Career Intentions of Senior Athletic Training Students Approaching Graduation
}

\author{
Rae L. Emrick \\ Dissertation submitted \\ to the College of Education and Human Services \\ at West Virginia University \\ in partial fulfillment of the requirements for the degree of \\ Doctorate of Education in \\ Curriculum \& Instruction
}

\author{
Melissa Sherfinski, Ph.D., Chair \\ James Rye, Ph.D. \\ Sam Stack, Ph.D. \\ Damien Clement, Ph.D. \\ Department of Curriculum \& Instruction
}

Morgantown, West Virginia

2018

Keywords: Athletic training, athletic training education, athletic training student, career intentions

Copyright 2018 Rae Emrick 


\title{
ABSTRACT \\ Factors Related to the Career Intentions of Senior Athletic Training Students Approaching Graduation
}

\author{
Rae L. Emrick
}

This research inquiry examined the factors that influence soon-to-be graduating senior athletic training major's decisions on their career intentions. Two research questions guided this study: What are the factors, experiences, and/or circumstances that contribute to senior athletic training students approaching graduation planning to persist in or pursue the athletic training profession? and What are the factors, experiences, and circumstances that contribute to senior athletic training students approaching graduation leading to displacement and students not planning to seek employment in the athletic training profession? Qualitative research methods employed a multiple case approach examining four different CAATE accredited athletic training programs in West Virginia. Thirteen soon-to-be graduates in their final semester of academic coursework across the four programs completed face-to-face interviews with the researcher. One institutional representative from each program also participated in a face-to-face interview. Additional program information was obtained through researcher observations and publically available program documents. Data collected was analyzed using open, axial and thematic coding. Six main themes emerged in the data that included: attractors, selection factors, initial impressions of the athletic training environment, pros of an athletic training program, cons of an athletic training program and students' impressions of challenges of the field. Results indicated that educators and professionals in athletic training need be cognizant of how students are socialized to the profession as well as programs should include additional career mentoring and advisement for students throughout the program. 


\section{Dedication}

I dedicate this work to my husband, John, who has supported me wholeheartedly in completing this portion of my doctoral requirements. He has been patient, kind and understanding in giving me the time and space to complete this.

To my daughter, Chloe, who has been with me throughout all of this process.

To my Mom, who has always been one of my biggest cheerleaders and sharing her pride in my accomplishments. 


\section{Acknowledgements}

First and foremost, I would like to thank my chair, Dr. Melissa Sherfinski. I am forever grateful for the time, effort, guidance and support that you have given to this project. I would also like to extend a thank you to her family and other students for sharing her with me during this time. Thank you to my other committee members who have provided a great amount of encouragement and assistance along the way: Dr. James Rye, who has been with me since the beginning, Dr. Sam Stack, and. Dr. Damien Clement.

I am also tremendously grateful to Dr. Vince Stilger, Dr. Steven Rinehart and last but certainly not least, Dr. Randy Wiesenmayer, who also played a large role in getting me here. Words of thanks seem an insignificant way of expressing my gratitude. I am eternally grateful to each of you.

I must also acknowledge my colleagues, faculty and staff, and students at West Virginia Wesleyan College who have been supportive, understanding and encouraging along the way. There have been so many encouraging words and acts. I am blessed to work in such a great community of people. 


\section{Table of Contents}

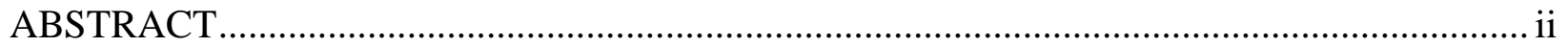

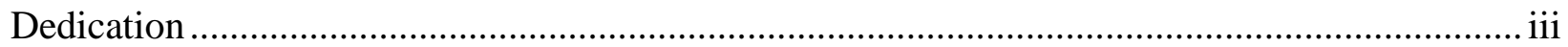

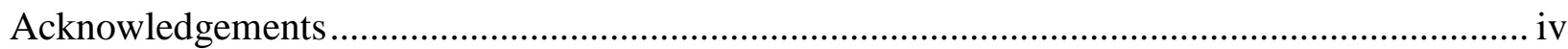

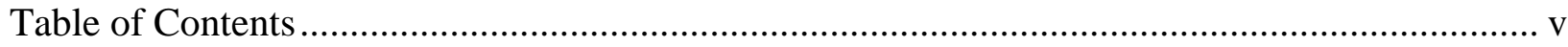

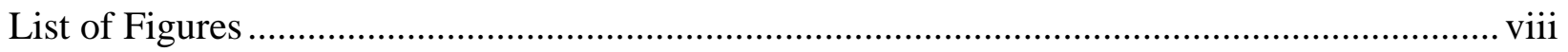

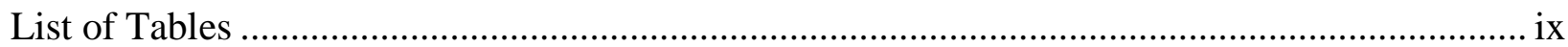

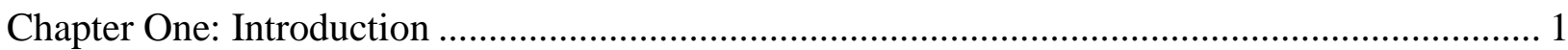

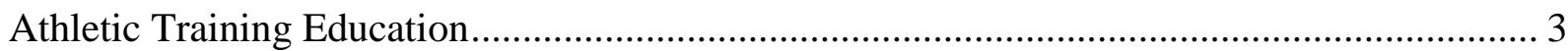

Healthcare Shortages in the United States ................................................................ 9

Statement of the Problem and Related Research Questions ................................................... 11

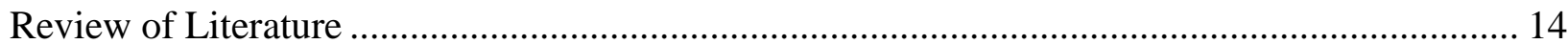

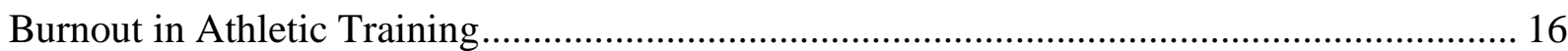

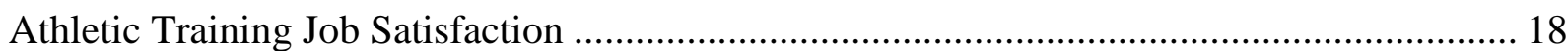

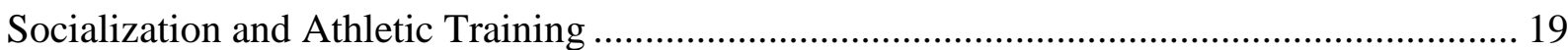

Other Potential Issues in Athletic Training ...................................................................... 22

Chapter Two: Conceptual Framework ................................................................................ 25

Eric H. Erikson's Psychosocial Theory of Development ............................................... 25

Holland's Theory of Vocational Personalities .................................................................. 29

Cultural Factors Influencing Career Choice Specific to Appalachia .................................... 36

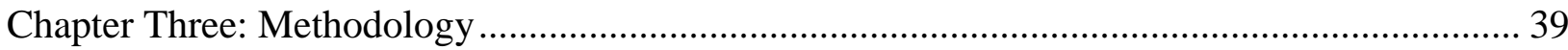

Epistemology and Conceptual Framework ..................................................................... 40

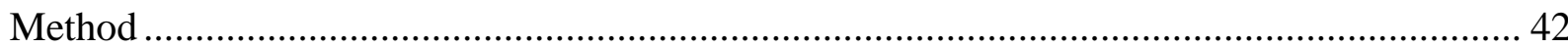

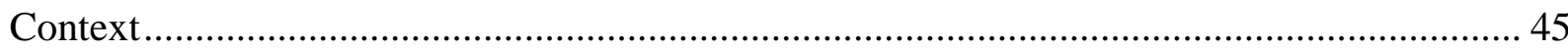

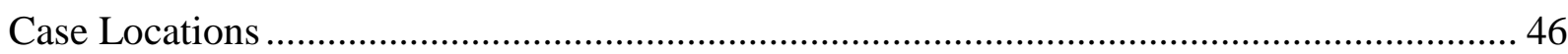

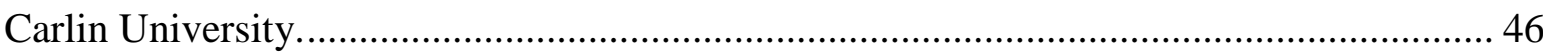

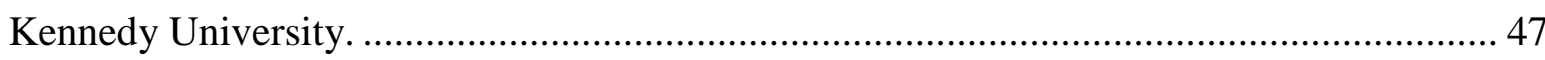

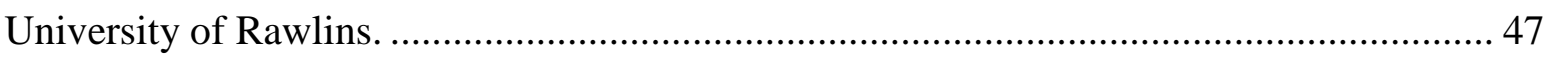

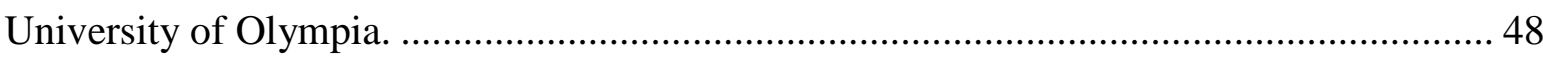

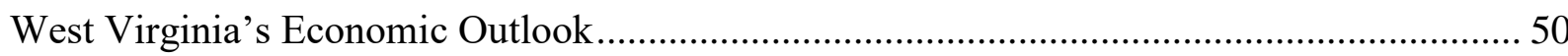

Health and Healthcare in West Virginia ................................................................... 51

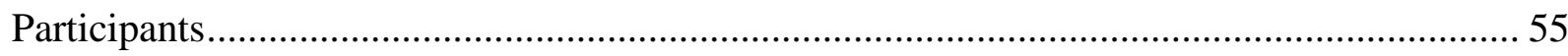

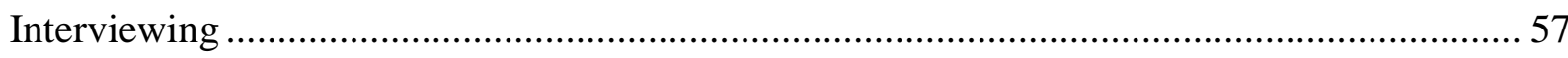

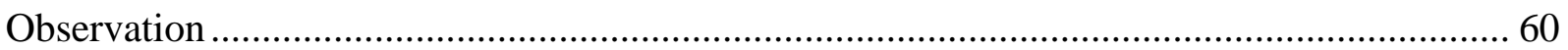




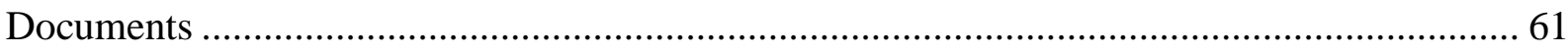

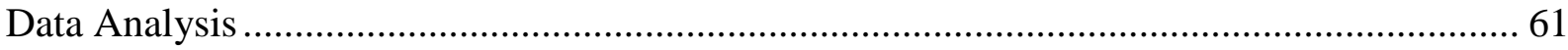

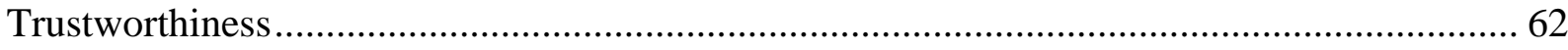

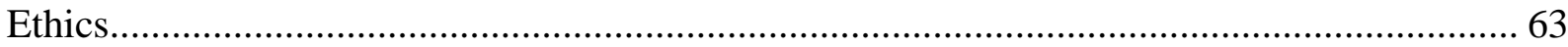

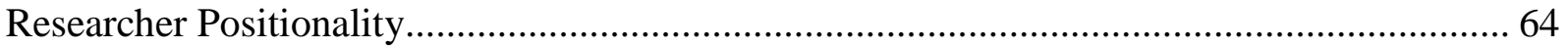

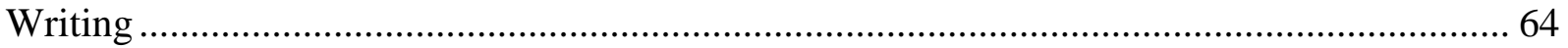

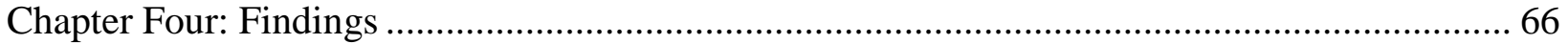

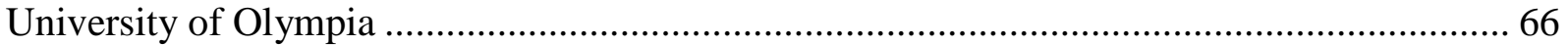

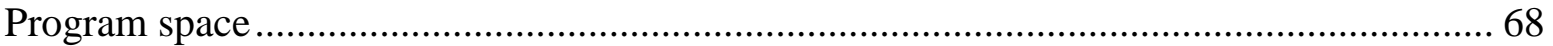

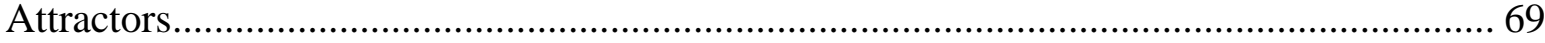

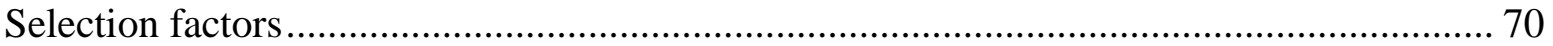

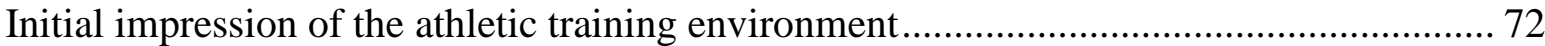

Pros of the athletic training major.................................................................................. 73

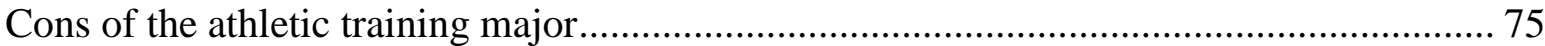

Students' impressions of challenges of the field.................................................................. 77

Kennedy University

Program space

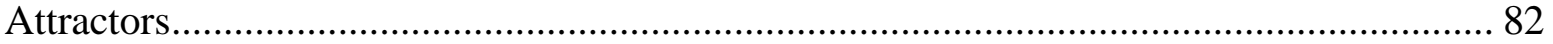

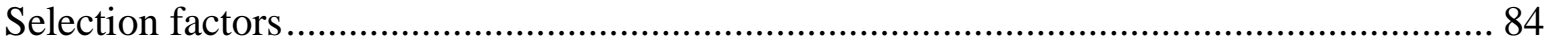

Initial impression of the athletic training environment........................................................ 88

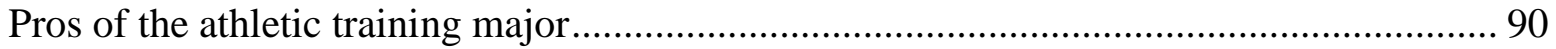

Cons of the athletic training major.................................................................................. 94

Students' impressions of challenges of the field................................................................... 96

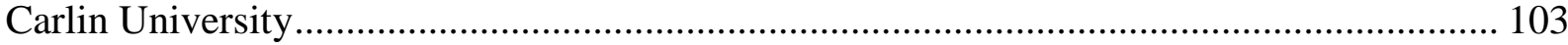

Program space

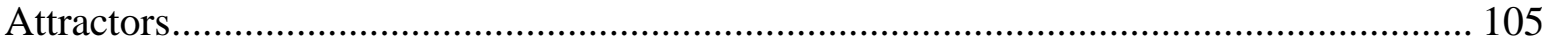

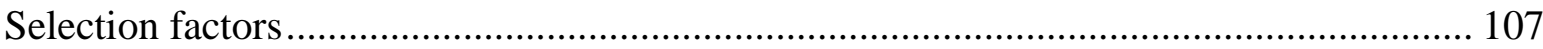

Initial impression of the athletic training environment........................................................ 109

Pros of the athletic training major...................................................................................... 110

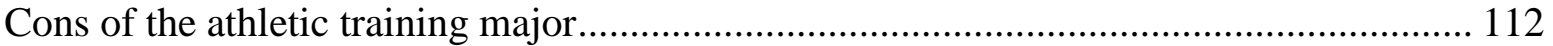

Students' impressions of challenges of the field............................................................. 114

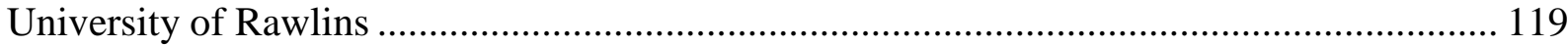

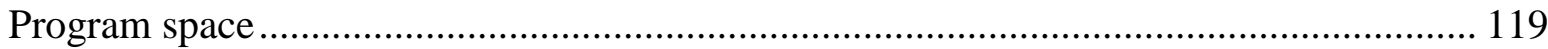

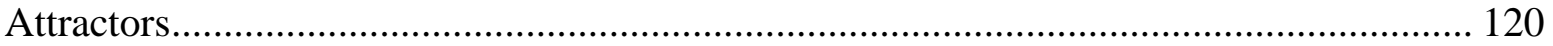




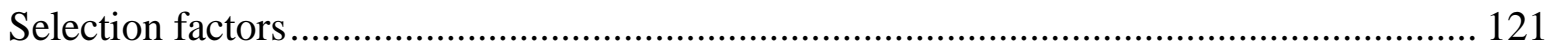

Initial impression of the athletic training environment .............................................. 122

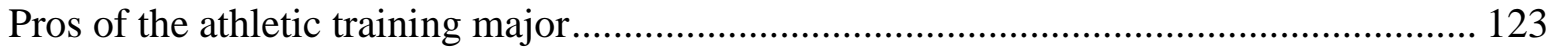

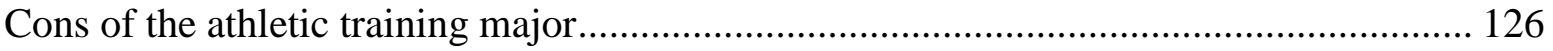

Students' impressions of challenges of the field..................................................... 127

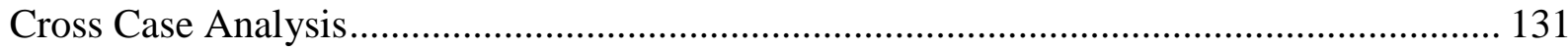

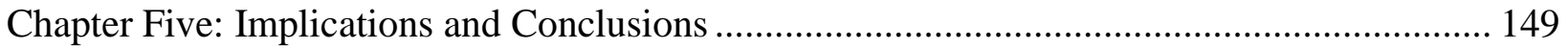

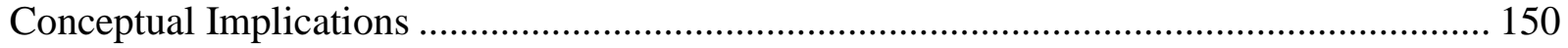

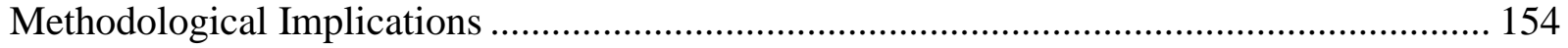

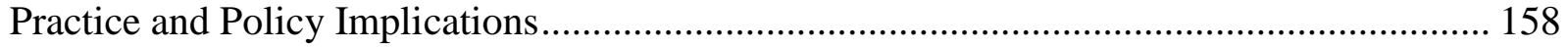

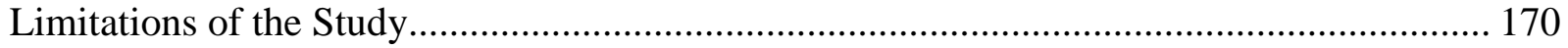

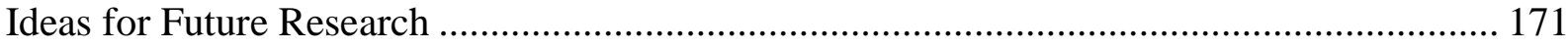

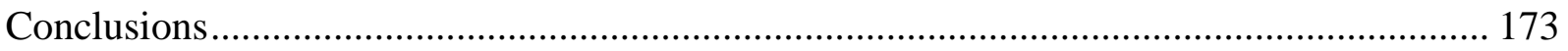

Appendix A: Student Participant Questionnaire .............................................................. 176

Appendix B: Approaching Graduation Student Interview Protocol ...................................... 178

Appendix C: Institutional Representative Pre-Interview Transcript …................................ 180

Appendix D: Institutional Representative Interview Protocol ........................................... 184

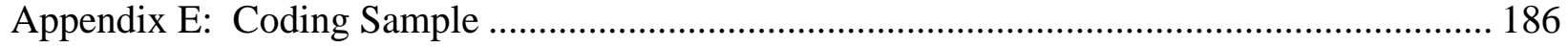

Appendix F: Sample AT Position Descriptions.............................................................. 193

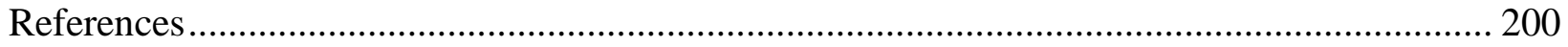




\section{List of Figures}

Figure 1. Holland's hexagonal model illustrating psychological resemblances among personality types and environments and their interaction.................................................................. 31

Figure 2. West Virginia 's Unemployment Rates .............................................................. 50

Figure 3. US Employment of Athletic Trainers ........................................................................ 53

Figure 4. Annual Mean Wage of Athletic Trainers .................................................................... 54 


\section{List of Tables}

Table 1: Erikson's Stages of Psychocial Development ......................................................... 26

Table 2: Characteristics of Holland's Personality Types and Environment Models.................. 33

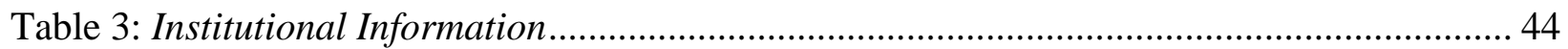

Table 4: Case Location Institutional Demographics ......................................................... 49

Table 5: WV Employment of Athletic Trainers and Wage Data ............................................ 52

Table 6: Soon-to-be Graduate Participant Demographic Information ...................................... 55

Table 7: Attractors to Athletic Training .......................................................................... 133

Table 8: Factors in Selecting College/University to Attend ................................................ 137

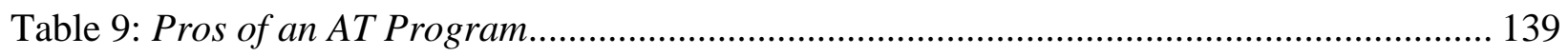

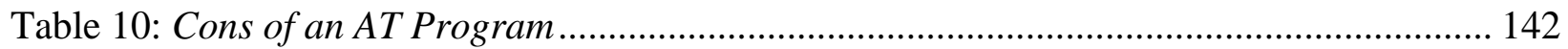

Table 11: Initial Impressions of the AT Environment ....................................................... 143

Table 12: Students' Impressions of Challenges in AT ...................................................... 145

Table 13: NATA Job Posting Qualifications...................................................................... 159 


\section{Chapter One: Introduction}

Athletic training is a relatively young profession. The history and creation of athletic training education and growth of the profession ultimately began in 1950 at a meeting involving 200 athletic trainers in Kansas City. The National Athletic Trainer's Association (NATA) developed at this time. This national organization's goals were to facilitate growth, to exchange ideas, and to strengthen the profession of athletic training (Delforge \& Behnke, 1999).

The NATA has been the leading force behind the recognition of the athletic training profession. Members and leaders of the NATA, since its inception, have recognized the necessity for a set of professional standards. Formalization of this national organization helped to unify athletic trainers across the United States. The NATA has set and maintained a standard for professionalism, education, certification, research, and practice settings (NATA, 2015a).

What began as an organization of 200 members in 1950 has experienced steady, continual growth in numbers to memberships of 5735 in 1978, 11834 in 1988, 24,292 in 1998, 31,718 in 2008, 41,418 in 2014 and over 39,000 in 2015 (NATA, 2015b). The number of individuals possessing the ATC (Certified Athletic Trainer) credential increased correspondingly with the growth in members supporting the profession of athletic training. One holding the professional credential has successfully completed a certification examination administered by the National Athletic Trainers Association Board of Certification (NATABOC), currently known as the Board of Certification (BOC). These individuals have demonstrated areas of competence in all five practice areas or domains of athletic training:

- Injury/Illness Prevention and Wellness Protection

- Clinical Evaluation and Diagnosis

- Immediate and Emergency Care 
- Treatment and Rehabilitation

- Organizational and Professional Health and Well-being (BOCATC, 2016a)

The number of individuals holding the ATC credential has grown from 7,913 in 1994 to 26,237 in 2004, 35,249 in 2009, and 45,991 in 2015 (BOC personal communication, April 17, 2015).

Athletic Trainers (ATs) are healthcare professionals who work closely with and under the direction of physicians, as prescribed by state licensure requirements. ATs provide services that consist of injury prevention, emergency care, clinical diagnosis, therapeutic intervention and rehabilitation of injuries and medical conditions (NATA, 2015c). The American Medical Association (AMA) recognizes athletic training as a healthcare profession (BOCATC, 2016b).

Today, Athletic Trainers typically provide services to the following populations:

- Olympic, professional, amateur and recreational athletes

- Individuals who have suffered musculoskeletal injuries

- Individuals seeking strength, conditioning, fitness and performance enhancement

- Others delegated by a physician

Common settings where athletic training services are available are:

- Professional and Collegiate Sports

- Secondary and Intermediate Schools

- Sports Medicine Clinics

- Hospital ER and Rehab Clinics

- Occupational Settings

- Fitness Centers

- Physician Offices (BOCATC, 2016a) 
Through the evolution and growth of athletic training, athletic training education has undergone many changes. Education programs have gone from NATA recognized programs to NATA approved curriculums to the evolution of the athletic training major. In 1990, the American Medical Association (AMA) recognized athletic trainers as healthcare professionals, which allowed athletic training curricula accreditation by the Committee on Allied Health Education and Accreditation (CAHEA). Allied health describes a large cluster of health-related professions that fulfill crucial roles in the healthcare system (Gupta, 1991). Allied healthcare professionals facilitate, assist and complement the work of physicians and other healthcare specialists (Gupta, 1991). In the mid-1990s, the accrediting body became the Commission on Accreditation of Allied Health Education Programs (CAAHEP) as CAHEA was disbanded (Delforge \& Behnke, 1999). CAAHEP along with the Joint Review Commission in Athletic Training (JRC-AT) accredited programs for a period of time after CAHEA disbanded. In July 2006, the JRC-AT legally separated from CAAHEP and became the Commission on Accreditation of Athletic Training Education (CAATE) (CAATE, 2006). This new independent accrediting body allowed for the ownership of the educational standards that govern athletic training by the profession, instead of another accrediting body that must address the needs of multiple healthcare professions (Koehneke, 2003).

\section{Athletic Training Education}

For a profession to withstand time, it must have a formal education structure in place. Beginning in 1956, the Committee on Gaining Recognition, authorized by the NATA Board of Directors, began to develop a curricular model for athletic training education and preparation. By 1959, the Board of Directors approved this model. During the 1950s and early 1960s, athletic training curriculums housed in schools of education/physical education placed emphasis on the 
completion and attainment of a secondary-level teaching credential. This would allow individuals to teach at a high school, primarily in health or physical education, and serve as the school's athletic trainer. During this era of athletic training education, athletic training students were also encouraged to complete prerequisites for acceptance into physical therapy school. Athletic trainers were encouraged to pursue further study in physical therapy as a means of professional growth and employability (Delforge \& Behnke, 1999; Perrin, 2007).

As time moved forward into the 1960s, only a few colleges and universities responded to the call for curriculum development. However, as time continued, a renewed effort took place to spread the word to institutions of higher education. In 1969, the Committee on Gaining Recognition divided. One subdivision became the Professional Education Committee. This new committee and the NATA began formally to recognize undergraduate athletic training programs. Only four institutions held this recognition in 1969: Mankato State University, Indiana State University, Lamar University and the University of New Mexico. As NATA recognition was occurring for curricular programs, the movement towards a national certification examination was occurring as well. Administration of the first certification examination was in 1970. Four routes to certification existed at this time: (1) the NATA approved athletic training program, (2) an internship, (3) physical therapy school, or (4) five years as an actively engaged athletic trainer (Delforge \& Behnke, 1999; Perrin, 2007).

The 1970s proved to be an era of tremendous growth and continued evolution of athletic training education curriculum. During this time and into the early 1980s, the number of NATA approved academic programs grew from four to sixty-two. The NATA also began to recognize graduate athletic training programs. Nine NATA approved graduate programs were developed. 
The NATA published guidelines for both undergraduate and graduate curricular models (Delforge \& Behnke, 1999).

At this time, notable curricular modifications started to give athletic training an identity separate from physical therapy. Physical therapy school prerequisites were not as strongly emphasized, although a required course of study leading to a secondary level teaching certificate remained. Curricula that were irrelevant or minimally relevant to athletic training content were eliminated. Additions made to the curriculum in the 1970s required students to complete a minimum of 600 total clock hours of laboratory or clinical experience under the direct supervision of a NATA-Certified Athletic Trainer (Delforge \& Behnke, 1999).

Also during the 1970s, the NATA Professional Education Committee began to develop a list of behavioral objectives for required courses within the curriculum. A skill competency checklist monitored the progression of a student's clinical skills. Through the curricular eliminations, clinical experience addition, behavioral objectives development and athletic training skills checklist, athletic training education continued to emerge as a unique body of knowledge (Delforge \& Behnke, 1999).

The 1980s brought greater advancement to athletic training education. During this period, amidst numerous changes in the Professional Education Committee leadership, athletic training education was still able to advance significantly. The requirement of athletic training as a major or program of study constituting a major equivalent for NATA approval was instituted. The policy allowing for a major equivalent was essentially a compromise from the NATA with programs or institutions that had limitations on receiving institutional approval as a degreegranting program. During this period of development, athletic training was beginning to 
formulate a distinct identity eliminating the graduate of a physical therapy school route to BOC certification (Delforge \& Behnke, 1999).

In 1982, the NATA Board of Certification conducted its first role delineation study. This led to an additional major advancement in athletic training education. Newly developed competencies in athletic training derived from the study replaced the behavioral objectives previously developed and implemented during the 1970s. The goal of the newly developed competencies was to promote the development of a true competency-based athletic training program. This also allowed for the inclusion of a specified subject matter requirements instead of specific courses (Delforge \& Behnke, 1999).

In the summer of 1990, the profession of athletic training and athletic training education reached a major milestone. The American Medical Association (AMA) formally recognized athletic training as a healthcare profession. This newly attained recognition in the medical arena now allowed athletic training education to seek CAHEA accreditation of educational programs. AMA policy prevented CAHEA accreditation of any non-recognized healthcare education program (Delforge \& Behnke, 1999; Perrin, 2007).

The Professional Education Committee and CAHEA met to formulate a new review committee, the Joint Review Committee on Educational Programs in Athletic Training (JRCAT). This committee would be responsible for review and accreditation of athletic training programs by CAHEA. Representatives from the American Academy of Family Physicians, the American Academy of Pediatrics, the AMA, the NATA, and the American Orthopaedic Society for Sports Medicine all comprised the JRC-AT (Delforge \& Behnke, 1999).

CAHEA and the JRC-AT worked together to develop accreditation requirements and standards for athletic training curriculum programs. In the summer of 1993, the NATA 
discontinued the approval process for the undergraduate curriculum. By February of 1994, CAHEA accredited the first two entry-level athletic training programs. Former NATA-approved programs and additional education programs were reviewed and accredited by CAAHEP. By June of 1998, 82 entry-level programs held this status. The transition from NATA approval to CAAHEP accreditation of entry-level educational programs was complete in the fall of 1998 as additional programs were scheduled for review (Delforge \& Behnke, 1999).

During the 1990s, the BOC was also making policy changes that affected entry-level education programs and graduate athletic training education. The first implemented policy stated that only NATA approval of graduate athletic training education would be for those programs that offered "advanced" learning experiences beyond that required of CAAHEP accreditation. The second policy that was established was to no longer offer the completion of an NATA approved graduate program as a route to certification. This would mean that NATA approval of graduate education programs required that admitted students be certification exam eligible or have BOC certification. CAAHEP accreditation of entry-level programs and NATA approval of graduate education led to a greater distinction between the two (Delforge \& Behnke, 1999).

The defined distinction between entry-level and graduate education within athletic training initiated a new component to the profession of athletic training. Graduate education and research typically go hand in hand. Some believed that research in athletic training had been missing up to this point in time. The National Athletic Trainers Association Research and Education Foundation (NATA-REF) gave research a tremendous boost as well. A strong fundraising campaign sponsored numerous research projects. By the end of the 1990s, research and scholarly work was no longer a missing component evidenced by the number of publications in 
the Journal of Athletic Training and other scholarly works during the 1990s and continuing until the present (Delforge \& Behnke, 1999).

In 1996, the BOC continued moving forward in an effort to standardize the education requirements of certified athletic trainers. A new policy was in effect that stated that by 2004 BOC exam eligibility required candidates to possess a baccalaureate degree and successful completion of a CAAHEP-accredited entry-level athletic training program. Implementation of this policy in 2004 would eliminate the internship route to certification. With the elimination of multiple routes to certification, now only completion of a CAAHEP-accredited entry-level program would serve as an acceptable pathway (Delforge \& Behnke, 1999; Perrin, 2007).

The Professional Education Committee was no longer in effect as of June 1998. The development of a new group, the National Athletic Trainers Association Education Council (NATAEC), emerged. The Education Council was tasked with addressing entry-level education, advanced graduate education, and continuing education. The Education Council provided continued leadership in the professional preparation of certified athletic trainers (Delforge \& Behnke, 1999).

CAAHEP and JRC-AT accreditation of entry-level athletic training education continued until July of 2006. At this time, the JRC-AT legally separated from CAAHEP and became known as the Commission on Accreditation of Athletic Training Education (CAATE). CAATE was the new independent specialized accreditor of athletic training education. All CAAHEP accredited programs were automatically now denoted as CAATE accredited programs. Programs retained the same accreditation status and review cycle (CAATE, 2006). Presently, CAATE accredits 339 Bachelor's and 59 Master's professional entry-level athletic training programs in the United States (CAATE, 2016). 
In the fall of 2015, CAATE announced a change to CAATE Standard 2. Standard 2 stated that essentially accredited programs must offer a degree in Athletic Training. Programs had two options of degree levels, professional Bachelor or entry-level Master. After the Strategic Alliance (BOC, CAATE, NATA, and NATA Foundation) determined the professional degree should be at the master's level in the spring of 2105, CAATE announced the change to Standard 2. The change to Standard 2 eliminates the bachelor's degree route for institutions and students in the future. All entering students enrolled or admitted beginning in the fall of 2022 must enter a professional master's level athletic training program (CAATE, 2015).

\section{Healthcare Shortages in the United States}

As previously stated, increases in the number of athletic trainers have been noted. In 1986, as reported by the BOC, there were 4,736 athletic trainers. In 1998, there were 13,105, in 2009, there were 35,249 , and in 2015 , there were 45,991 certified athletic trainers (BOC, personal communication, April 3, 2006; BOC personal communication, November 10, 2009; BOC personal communication, April 17, 2015). An increased awareness of athletic healthcare has also led to an increased interest in the athletic training profession. This increased awareness and the shortages of qualified healthcare professionals have placed even greater demands on the numbers of skilled healthcare providers entering the workforce. Graduate displacement from the profession will lead to greater shortages and place increased stresses on the United States healthcare system.

Currently there are 6,100 Primary Care Health Professional Shortage Areas (HPSAs) designated by the United States Department of Health and Human Services. An HPSA is defined 
A geographic area, population group, or healthcare facility that has been designated by the Federal government as having a shortage of health professionals. HPSAs may be geographic (a county or service area), demographic (low-income population) or institutions (comprehensive health center, federally qualified health center or other public facility). (HRSA, 2014, para. 7).

Adequately serving the 65 million residents in these areas would take 16,000 practitioners (HRSA, 2014). Although traditionally, employment of athletic trainers is in the athletic arena, athletic trainers serve on the front lines of primary healthcare each day. The athletic training profession is expanding into more and more settings than athletic healthcare, such as performing arts facilities, the military, physician's offices, industrial and manufacturing settings, and police and fire departments (BOCATC, 2016b). Athletic trainers possess a clinical skill set working in collaboration with other healthcare providers that could enhance the primary medical care available to residents or individuals in underserved HPSAs.

The United States Department of Labor Bureau of Labor Statistics projects that the employment of athletic trainers will grow 21 percent from 2014 to 2024 . Obviously, this growth is dependent on retaining and producing competent qualified individuals. This projected growth rate is much faster than the average for other healthcare practitioners and technical occupations, which is an average of 10 percent and for all occupations, for which the total projected overall increase is seven percent. This greater increase for athletic training is due to the fact that people are becoming more aware of sports-related injuries at younger ages, thus driving the demand (BLS, 2015, para. 1).

The demand for healthcare should grow dramatically as a result of technological advances, increased emphasis placed on preventative care, and the increasing number of active 
middle aged and aging citizens in the United States. Sports programs available to all ages and all athletic levels will increase the demand for athletic trainers as education on various injuries, especially concussions, continues to advance. Athletic trainers will be able to benefit from this expansion. Athletic trainers provide a cost-effective way to increase the number of health professionals in an office or other setting (BLS, 2015). They are healthcare professionals who can assist in alleviating the shortage and strain currently placed on the U. S. healthcare system.

\section{Statement of the Problem and Related Research Questions}

Since the formalization of the profession in 1950, two grossly understudied areas have been retention in the field and the attrition of degree holding graduates. To date only two studies dealing with the loss of trained individuals from the profession, Capel 1990 and Goodman 2007, have been conducted and shared with the athletic training profession. In 1990, Capel indicated that the two most enjoyable aspects of entering athletic training were: (1) contact with athletes, and (2) professional activities such as rehabilitation, safety, taping and treatment. The desire for additional education, the time consuming nature of the work, the lack of professional advancement, the lack of time for family, the low compensation, and interest in another professional field were all reasons for leaving the profession of athletic training.

Goodman (2007) examined retention and attrition of female Certified Athletic Trainers in the National Collegiate Athletic Association Division I (NCAA D-1) football bowl subdivision setting. Goodman found through interviewing 23 currently employed female athletic trainers that the reasons for persisting in the profession were (1) increased autonomy, (2) increased social support, (3) enjoyment of job/fitting the NCAA D-I mold, and (4) kinship responsibility. Two sub-factors were also present: the NCAA D-I atmosphere and positive dynamics with the athletes. In interviewing participants that voluntary left the NCAA D-I arena, Goodman found 
that there were three main contributory factors: (1) life-balance issues, (2) role conflict/role overload, and (3) kinship responsibility. Sub-factors present in were supervisory/coach conflict and decreased autonomy. Neither of these studies examined the decisions of senior athletic training students approaching graduation to stay and pursue a career in athletic training (persistence) and/or choose another professional path (displacement).

In 2010, Neibert, Huot and Sexton began to investigate the career decisions of senior athletic training students and recent graduates of ATPs. A web-based survey analyzed 1,792 responses. This study found that the majority (82.4\%) of participants elected to pursue a career in AT while the remainder (17.6\%) had decided not to seek employment opportunities as ATs. Clinical experience hours, variety of clinical experiences, the roles/functions of the clinical instructor, preparation to enter the field, a level of confidence, clinical instructor attitudes toward their work settings, clinical instructor demonstrations of professionalism, and clinical instructor/faculty encouragement were reasons for persistence. Salary, work hours per week, interest in other professions, and changing work schedules were the most influential factors found for displacement or not choosing to pursue a career as an AT. Benes and Mazerolle (2014) found similar positive and negative perceptions of senior athletic training students. Long hours, low compensation, family conflict issues, the projected future and dynamism of the profession, professional enjoyment, public misconceptions about the profession, and a lack of respect for the profession were perceptions found. Students' clinical experiences and interactions with AT professionals influenced these perceptions.

In 2011, Bowman and Dodge examined 14 students enrolled in a post-professional graduate education program to determine factors of persistence among ATP graduates. This qualitative study examined the factors of persistence among graduates of athletic training 
programs. Bowman and Dodge found four factors that led to persistence. These were positive interactions with faculty, quality clinical instructors and peers, the environment of the ATP (small class sizes and family atmosphere), learning a great deal in the classroom and clinical education, and students' visualization of themselves practicing a career in athletic training. Athletic training has shown continual growth since 1950 from 200 to nearly 46,000 athletic trainers. For this growth to continue, displacement of graduates from ATPs and preparation to enter the profession must be closely examined. Athletic training students, in many cases, undergo a separate formal application process to be admitted to an athletic training program. Program standards must then be maintained through program completion. Students are electing a program of study that has higher academic requirements (i.e., minimum grade requirements, GPA requirements, or exit exam requirements) than most other academic majors. The purpose of this study is to determine factors (consistent factors with those previously found and/or additional factors) that influence athletic training graduates' decisions to persist in or be displaced from the athletic training profession. The findings of this study may be helpful to athletic training educators and CAATE in making program or curricular changes that encourage more graduates to pursue careers within the profession of athletic training. Specifically, this study seeks to examine:

1. What are the factors, experiences, and/or circumstances that contribute to senior athletic training students approaching graduation planning to persist in or pursue the athletic training profession?

2. What are the factors, experiences, and circumstances that contribute to senior athletic training students approaching graduation leading to displacement and students not planning to seek employment in the athletic training profession? 


\section{Review of Literature}

The following review of literature will provide an overview of existing research and related issues to support this study of AT seniors' persistence with or displacement from AT careers. I chose studies specifically to support my research purposes and questions.

Athletic training attrition has not been widely studied since the birth of the profession in 1950. However, throughout the development of the field of AT, attrition has been a major concern (Capel, 1990). When an individual leaves AT, the clients served and the organization may suffer. The individual may experience negative effects. The continuity of relationships and care of clients may be affected. The organization will suffer from increased costs incurred for advertising, interviewing and hiring a new employee (Capel, 1990).

As mentioned in the introduction, Capel (1990) conducted a study of attrition of athletic trainers. Capel analyzed returned surveys from 82 Certified Athletic Trainers no longer employed as ATs. This was only a $45 \%$ participation rate for eligible participants. Capel found that the respondents were young and lacked significant professional experience. Seventy-five percent of respondents were under the age of 36 and had been certified for less than 10 years. According to the respondents, the two most enjoyable aspects of entering athletic training were contact with athletes and professional activities such as rehabilitation, safety, taping and treatment. The desire for additional education, time-consuming labor, a lack of opportunities for professional advancement, a desire to spend more time with family, low compensation, and an interest in another professional field were all reasons for leaving the profession of athletic training. Interestingly, Capel found that most of the respondent's employment fields were closely related to athletic training or physical activity. Roles included physical therapist, physician, nurse, orthopedic physician's assistant, exercise specialist, physical education teacher, adapted 
physical education teacher, athletic training educator or program director, coach or work in other clinical services not specified.

Also mentioned in the introduction, a study by Goodman (2007) examined the retention and attrition of female Certified Athletic Trainers in the National Collegiate Athletic Association Division I (NCAA D-1) football bowl subdivision setting. Goodman found through interviewing currently employed female athletic trainers the reasons for persisting were: (1) increased autonomy, (2) increased social support, (3) enjoyment of job/fitting the NCAA D-I mold, and (4) kinship responsibility. Two sub-factors were also present: the NCAA D-I atmosphere and positive dynamics with the athletes. In interviewing participants that voluntarily left the NCAA D-I arena, three main contributory factors arose: (1) life-balance issues, (2) role conflict/role overload, and (3) kinship responsibility. Sub-factors present in this group were supervisory/coach conflict and decreased autonomy.

There has been one other study conducted to date although this study does not specifically address the factors of attrition of practicing clinical athletic trainers or new graduates. Judd and Perkins (2004) specifically examined perceptions on job selection, job satisfaction and attrition of athletic training program directors. Through a qualitative survey of 83 program directors, Judd and Perkins concluded that the academic environment and professional advancement were positive and satisfying aspects of the positions. The least satisfying and beneficial aspects were workload, student issues and student discipline.

Current research suggests that there may be a number of professional issues needing attention within the profession of athletic training. These include stress and burnout (Capel, 1986; Campbell, Miller \& Robinson, 1985; Clapper \& Harris, 2006; Giacobbi, 2009; Hendrix, Acevedo, \& Hebert, 2000; Kania, Meyer, \& Ebersole, 2006), athletic training job satisfaction 
and work-family conflict (Barrett, Gillentine, Lamberth, \& Daughtrey, 2002; Mazerolle, Bruening, Casa, Burton, \& Van Heest, 2006; Milazzo, Miller, Bruening, \& Faghri, 2006), and professional socialization (Mensch, Crews, \& Mitchell, 2005; Pitney, 2002, 2006; Pitney, Ilsley, \& Rintala, 2002).

\section{Burnout in Athletic Training}

Burnout is emotional and physical exhaustion resulting from a combination of exposure to environmental and internal stressors and inadequate coping and adaptive skills. In addition to signs of exhaustion, the person with burnout exhibits an increasingly negative attitude toward his or her job, low self-esteem, and personal devaluation. (Medical dictionary, 2016, para. 1)

Capel's first published work in 1986 examined psychological and organizational factors related to burnout in athletic trainers. By analyzing questionnaires received from 332 participants from the Western United States, Capel (1986) concluded that while absolute levels of burnout were low, role conflict, role ambiguity, locus of control, number of hours in direct contact with athletes, and the number of athletes under that athletic trainer's care were significantly related to total burnout.

Campbell and colleagues (1985) conducted another study in the mid-1980s just prior to Capel's (1986). Campbell (1985) attempted to provide 1,500 athletic trainers questionnaires in attendance at the 1984 NATA Clinical Symposium. Two hundred twenty-one usable questionnaires were received by the researchers representing all 10 NATA Districts. The results showed that $60.3 \%$ of the respondents were experiencing burnout. In the burned out respondents, Campbell and colleagues also found a higher incidence of medical symptoms and unhappy marriages. 
Hendrix and colleagues (2000) studied the burnout of athletic trainers at NCAA Division I-A universities. This group of researchers examined burnout through the administration of five psychological inventories: the Hardiness Test, the Social Support Questionnaire, the Athletic Training Issues Survey, the Perceived Stress Scale, and the Maslach Burnout Inventory. These researchers found that individuals who reported lower levels of hardiness and social support and higher levels of athletic training issues reported higher levels of stress. Perceived stress was a predictor of emotional exhaustion. Emotional exhaustion was a primary factor of burnout. Additionally, personal accomplishment and depersonalization were significantly related to participants' perceived stress levels.

In contrast to past publications recent publications by Clapper and Harris (2006) and Kania, Meyer, and Ebersole (2009), low to average levels of burnout were found in athletic trainers employed by NCAA institutions. Low levels of burnout were consistent with the findings of Capel (1986) and Giacobbi (2009). Similarly, to Campbell and colleagues (1985) and Capel (1990), Clapper and Harris (2006) identified that young participants with relatively few years of professional experience suffered burnout due to a perceived lack of organizational support. In other words, younger ATs reported lower levels of organizational support and higher levels of burnout. Participants in Clapper and Harris' (2006) study reported an average of 2.42 years of experience. Giacobbi (2009), however, utilized 934 participants through a nationwide random sample and participants were represented fairly equally in the following groups: fewer than 5 years' experience, 5 - 10 years' experience, and greater than 10 years' experience.

Kania and colleagues (2009) also had a majority of respondents under the age of 40 with less than 10 years' work experience in athletic training. They found that stress level was predictive on three subscales of burnout (emotional exhaustion, depersonalization, and reduced 
personal accomplishment) and that leisure time was predictive of personal accomplishment. In studies published in 2006 and 2009, Kania and colleagues found that in addition to stress level, pressure from coaches to medically clear athletes for participation was predictive of burnout.

\section{Athletic Training Job Satisfaction}

Recent studies conducted about athletic training job satisfaction appear to have conflicting outcomes in regards to married athletic trainers. Bell (1989) found that married athletic trainers had greater job satisfaction while Mazerolle and colleagues (2006) and Milazzo and colleagues (2006) found that as work-family conflict increased, job satisfaction decreased. It is important to note that both of these studies used participants from National Collegiate Athletic Association (NCAA) Division I-A institutions while Bell (1989) utilized athletic trainers from various employment settings. Occupational, or job, stress (e.g., work hours, operating conditions, compensation) and role strain varied among differing athletic training employment settings and thus influenced overall job satisfaction. Mazerolle and colleagues (2006) and Milazzo and colleagues (2006) elected to study a defined population of athletic trainers. Bell (1989), however, examined a broader group of athletic trainers. A broader population may have diluted the stress and strain impacting the larger group whereas studying one specific group of athletic trainers may show greater detailed information for that particular job setting.

Barrett and colleagues (2002) conducted a descriptive study to examine perceived job satisfaction of NATABOC Certified Athletic Trainers working in NCAA Division I-A athletic training departments within the Southeastern Athletic Conference. These researchers found that the least satisfying aspects were pay, promotion, fringe benefits, contingent rewards, and operating conditions. The most satisfying aspects were coworkers, nature of the work and supervision opportunities. Just as was seen with studies conducted on burnout, Barrett and 
colleagues (2002) reported that the largest group of low job satisfaction respondents were young and lacked professional experience.

\section{Socialization and Athletic Training}

Socialization into a profession includes learning knowledge and skills, engaging in faculty and student peer interactions, and experiencing multiple learning environments (internships, fieldwork, research collaboration, and/or clinical experiences) (Hermanowicz, 2011; Mazerolle, Bowman, \& Dodge, 2014; Mensch et al. 2005). Research on the socialization of athletic trainers has received increased interest in the last decade. According to Pitney (2002), "a better understanding of socialization provides an essential first step to identifying educational strategies to improve the undergraduate education and professional development of certified athletic trainers (ATs)" (p. 63). Professional socialization is the process by which individuals learn the norms, knowledge, and necessary skills that will allow them to function in a particular role.

Socialization models are divided into a two-phase or three-phase developmental process. Pitney's research (Pitney, 2002, 2006; Pitney et al., 2002) utilizes a two-phase socialization process. Anticipatory socialization (phase one) is defined as an individual's experiences before entering the work setting such as formal education/training and prior experience. Organizational socialization (phase two), is defined as an individual's experiences after entering the work setting. Further subdivided into two periods, the organizational phase includes a period of induction followed by a period of role continuance, which focuses on one's adjustments over time to organizational demands.

Mensch and colleagues (2005) described the three-phase socialization process as follows. Anticipatory socialization, or recruitment, is the first phase. This refers to the process of 
individuals exploring professional requirements and analyzing these against their own personal attributes. Professional socialization occurs next and refers to individuals that enter formal education programs that will adjust their initial impressions of a particular field to socializing agents within the profession (i.e., university faculty, clinical supervisors). The final phase, organizational socialization, refers to the process where individuals enter the work force and adjust to the demands of the professional setting.

Klossner (2008) qualitatively examined professional socialization of twelve second-year undergraduate athletic training students and concluded that "clinical education and field experiences are components of the professional education process that are important to the socialization of preprofessional students in various fields and to the organizational socialization of entry-level ATs" (p. 384). Clinical education experiences and clinical educator interaction of knowledge application allow for the definition of role expectations within a profession. Creating learning experiences that provide students with a sense of affirmation and feelings of legitimation can facilitate socialization in developing athletic trainers.

Pitney and colleagues (2002) first conducted a qualitative investigation targeted toward describing the professional socialization process of athletic trainers in the NCAA D-I setting. Current and former full-time NCAA D-I ATs of both genders, a current part-time graduate assistant AT, and two athletic administrators comprised the participants. Utilizing a modified grounded theory approach, the authors identified a "five-phase developmental sequence: (1) envisioning the role, (2) formal preparation, (3) organizational entry, (4) role evolution, and (5) gaining stability" (p. 65).

In this group of participants, envisioning the role involved career selection and it was highly influenced by a personal identity or history with the culture of sport. During formal role 
preparation, obtaining a graduate assistant position appeared to be a rite of passage for becoming a NCAA D-I AT. The organizational entry phase involved a period of uncertainty and adjustment during this transition into the work force. Evidence of role strain, role ambiguity, a very informal induction process and 'learning by doing' were all present. In the third phase, role evolution, the athletic trainers' mission changed over time from privileging accolades and monetary recognition early on to a more comprehensive view of their role and relationships with their student-athletes as well as promoting the profession itself over time. Once the role of a professional athletic trainer was better understood, role stability could be achieved by three possible avenues: (1) stability within (personal values are congruent with organization and administrative support exists), (2) refocusing within ('picking your battles' within the organization and finding rewards in other aspects of the employment setting), or (3) role instability (removing oneself from the organization due to a lack of organization support or commitment) (Pitney et al., 2002).

Pitney conducted a similar study in 2006. In this study, organizational influences and quality of life issues were identified that affected the professional socialization of NCAA D-I athletic trainers. Fourteen athletic trainers and two athletic directors comprised the participants for this project. Bureaucratic issues within NCAA D-I athletic organizations and concerns for a diminished quality of life greatly affected the participants and emerged as the two main themes. Despite these concerns expressed by the participants, these athletic trainers were able to maintain a commitment to delivering quality athletic healthcare to the student-athletes at their respective institutions (Pitney, 2006).

Additional studies have been conducted on socialization of secondary school athletic trainers. Pitney (2002) and Mensch and colleagues (2005) conducted qualitative studies 
examining the professional socialization experiences of athletic trainers who are working or have worked in the secondary school setting. An informal learning process was the emerging theme that developed in Pitney's (2002) research. Athletic trainers reported an extremely informal process of induction and participants expressed that learning occurred by trial and error. This group of athletic trainers attempted to enhance the informal learning processes by creating networks for learning through peers, fellow secondary school ATs, and former mentors (Pitney, 2002).

Through interviewing varsity basketball coaches and the athletic trainers assigned to those teams, Mensch and colleagues (2005) investigated the perspectives of high school coaches and athletic trainers in regards to an athletic trainer's role. Three themes emerged: (1) coaches possessed a limited knowledge and understanding of athletic trainer's qualifications, professional preparation, and experience, (2) an expectation of coaches was that athletic trainers were available to complement their roles, and (3) positive communication was a critical component of a good coach-athletic trainer relationship.

\section{Other Potential Issues in Athletic Training}

Mazerolle, Eason, Nottingham, and Barrett (2016) examined athletic training students' perceptions of mentorship. Through conducting interviews with 17 athletic training students that were presently being mentored, it was concluded that the mentoring experience allowed for the development of career goals as well as the advancement of students' clinical practice. It was further suggested that mentoring is an advantageous aspect of the socialization process as well as providing a chance to cultivate a professional identity (Mazerolle et al., 2016).

Athletic training employment issues could be a potential factor of athletic training graduate attrition according to Stilger, Meador and Tsuchiya (1999). Stilger and colleagues 
(1999) suggested that information on employment opportunities, professionalism, salaries, and a saturated job market affected a graduate's opportunity or choice to practice within the profession of athletic training. This group of researchers found through the administration of a survey instrument that varying amounts of time were utilized by curriculum directors for instructing students on job search preparation, developing a resume, interview preparation, methods of locating employment opportunities, the discussion of career options, or career service centers. In the book Keeping Nurses in Nursing: The Profession's Challenge for Today, Albaugh (2003) discussed nursing graduate attrition. Nursing education is very similar to that of athletic training education when comparing multiple curricular aspects (i.e. related coursework, clinical education or accrediting bodies). Some potential reasons for attrition cited by Albaugh included a lack of involvement in policy and decision-making, problems with supervisors, poor working conditions, inadequate salaries, and a lack of job security. Some of these cited reasons for nursing attrition were in strong contrast to those that may be present in the athletic training profession, such as a lack of information on employment opportunities and a saturated job market (Stilger et al., 1999).

Much of the existing research examining athletic training has led to conclusions that provide information about characteristics, positive and negative, of the athletic training employment environment or about the athletic training educational environment. Hendrix and colleagues (2000) did examine subjects utilizing various psychological inventories when making conclusions in regards to burnout. Presently, an inquiry into the meshing of individuals with occupational environments has not been conducted. In Chapter Two: Conceptual Framework, an introduction to two related psychological theories and information about cultural influences on 
career choice provides a basis of understanding the importance of these connections between individuals and environments. 


\section{Chapter Two: Conceptual Framework}

The conceptual framework of this inquiry centers around two different psychological theories as well as the impact of culture. Eric Erikson provides a psychosocial theory of development while John Holland offers a theory of vocational personalities. Both theories relate to the research questions by providing a deeper understanding of the subject's respective developmental periods of psychosocial development and vocational development. An understanding of where a student may be in these periods and the influencing factors, including cultural influence, can aid in a greater understanding of a student's decision to persist or displace themselves from athletic training.

\section{Eric H. Erikson's Psychosocial Theory of Development}

Eric Erikson, a German born developmental psychologist and psychoanalyst, developed an eight stage theory of human psychosocial development. Table 1 below provides descriptions of the stages. 
Table 1

Erikson's Stages of Psychosocial Development (McLeod, 2013).

\begin{tabular}{|c|c|c|c|}
\hline Stage & Age & Characteristics & Virtue \\
\hline $\begin{array}{l}\text { Trust vs } \\
\text { Mistrust }\end{array}$ & $\begin{array}{l}\text { Birth to } 1 \\
\text { yr. }\end{array}$ & Trust in primary caregiver & Hope \\
\hline $\begin{array}{l}\text { Autonomy } \\
\text { vs Shame, } \\
\text { Doubt }\end{array}$ & $\begin{array}{l}18 \mathrm{~m} \text { to } 3 \\
\text { yrs. }\end{array}$ & Child learns self-care skills & Will \\
\hline $\begin{array}{l}\text { Initiative vs } \\
\text { Guilt }\end{array}$ & 3 to $5 \mathrm{yrs}$. & Becoming more goal oriented; assertive & Purpose \\
\hline $\begin{array}{l}\text { Industry vs } \\
\text { Inferiority }\end{array}$ & 5 to 12 yrs. & $\begin{array}{l}\text { Social and cultural norms, development of school } \\
\text { skills and use of tools }\end{array}$ & Competence \\
\hline $\begin{array}{l}\text { Identity vs } \\
\text { Identity } \\
\text { Confusion }\end{array}$ & $\begin{array}{l}12 \text { to } 18 \\
\text { yrs. }\end{array}$ & $\begin{array}{l}\text { Sense of self, learning who one is; begins to } \\
\text { assume adult roles; personal values and attitudes } \\
\text { emerge }\end{array}$ & Fidelity \\
\hline $\begin{array}{l}\text { Intimacy vs } \\
\text { Isolation }\end{array}$ & $\begin{array}{l}18 \text { to } 40 \\
\text { yrs. }\end{array}$ & $\begin{array}{l}\text { Intimate relationships beyond family and } \\
\text { adolescent love }\end{array}$ & Love \\
\hline $\begin{array}{l}\text { Generativity } \\
\text { vs } \\
\text { Stagnation }\end{array}$ & $\begin{array}{l}40 \text { to } 65 \\
\text { yrs. }\end{array}$ & $\begin{array}{l}\text { Become parents, raise children; occupational } \\
\text { achievement, educate those younger }\end{array}$ & Care \\
\hline $\begin{array}{l}\text { Integrity vs } \\
\text { Despair }\end{array}$ & 65 yrs. + & $\begin{array}{l}\text { Self-acceptance, evaluation of life; can define } \\
\text { one's identity }\end{array}$ & Wisdom \\
\hline
\end{tabular}

Each stage as defined by Erikson is an experience of crises, or a turning point, that leads to the development of a virtue. The growth of the personality characterizes these crises. Each stage is a challenge to the ego, a threat, as well as an opportunity for personal growth and improvement (Erikson, 1968).

Trust vs. Mistrust, the first stage, occurs from approximately birth to one year. Trust as defined by Erikson is an essential trustfulness of others as well as a fundamental sense of one's own trustworthiness. The second stage, Autonomy vs. Shame/Doubt, generally occurs between ages 18 months and three years. Children begin to learn to assert their independence, choosing toys for play, selecting clothing to wear, or food to eat. Initiative vs. Guilt, stage three, continues from the age of three to five. The child learns to move with greater independence, walking freely and with vigor. This establishes a wider and unlimited radius of goals. Stage four is Industry 
versus Inferiority and occurs during the ages of 5 to 12 years. Children are learning to read and write, do mathematics and complete tasks on their own. Greater influence by those other than parents impact the child's development. Identity versus Identity Confusion, ages 12 to 18 years, comprises stage five. The sixth stage, Intimacy versus Isolation, occurs during young adulthood, 18 to 40 years. Stages five and six are discussed in detail shortly as these two stages are the most relevant developmental periods for this research inquiry. During middle adulthood, ages 40 to 65 years, the seventh stage called Generativity versus Stagnation, occurs in which careers and longterm relationships are established, families are built, and individuals begin to develop a sense of being part of something bigger. Integrity vs. Despair, the final and eighth stage, occurs during late adulthood (65 years plus). This is a time of reflection, a time of looking back and evaluating one's life and accomplishments (Erikson, 1968).

During stage five, Identity versus Identity Confusion, a critical transition from childhood to adulthood is occurring. Children begin to look at the future in terms of career, relationships, families, housing, etc. as they are becoming more independent. The individual is working through how to belong to a society and 'fit in'. Often during this stage, the individual can be preoccupied with what they feel they are in the eyes of others as compared to what they feel they really are inside, constantly seeking how to mesh the roles and skills planted earlier with the ideals of the day. Finding out who exactly he or she is and determining one's identity is what the adolescent will re-examine. This stage involves determining which opportunity to decide freely on in terms of duty and service while avoidance of an activity that leaves them feeling exposed to ridicule or self-doubt. Not being sure about himself or herself or place in society leads to identity confusion. Identity confusion may lead one to experiment with different work or educational activities (Erikson, 1968). Traditionally, the age of 18 is a transition period of 
students from high school to college, the period at which a decision on which occupational opportunity shall the individual seek and pursue typically occurs. The level of development of this stage can have a significant impact on the student's academic and occupational decisions as they continue to define the boundaries of who they are and what they wish to become.

A psychosocial moratorium, as termed by Erikson, can occur between the transition from stage five to six. This moratorium is a granted delay to the individual that is not ready to meet an obligation or may be forced on the individual that should give oneself time. This psychosocial moratorium delays the implementation of adult commitments. This time allows an individual the opportunity to examine societal roles, career possibilities, and values. At some circumstances, this is free from the expectation of commitments and long-term responsibilities. Each society has in essence institutionalized a moratorium for its young people (Erikson, 1968). One could look at college and possibly graduate school as a type moratorium in US society. A permissive selectiveness and provocative playfulness of youth characterizes this period. This time, though, often leads to a deep commitment on the part of the youth but a more or less ceremonial confirmation of commitment from society (Erikson, 1968).

Sharing oneself with greater intimacy is the focus of the sixth stage, Intimacy versus Isolation. Identity formation must be well established for true intimacy to occur. An individual that is not secure in their identity will shy away from interpersonal intimacy. Exploring relationships with someone other than a family member for a long-term commitment occurs. A sense of commitment, safety and comfort develops within the intimacy component of this stage. Fear of commitment and relationships may lead to loneliness, isolation, or acts of promiscuity without true fusion of intimacy with another (Erikson, 1968). 
This research inquiry seeks to examine college-aged seniors, a group of individuals that are essentially between stages five and six. Their psychosocial development during this segment of life can vary, as these youth are experiencing a transition period. Depending on the level of identity development and the impact of familial, peer and/or societal influence, this transition from adolescence to adult responsibilities, or commitments, may affect their academic pursuits and success in academic, personal, occupational and personal choices, and ultimately occupational or career choices.

\section{Holland's Theory of Vocational Personalities}

John Holland, an American psychologist, developed a theory of careers and their application to vocational life. The development of this theory was to explain vocational behavior and suggest practical ideas to the young, middle-aged and older individuals in job selection, changing of jobs, and the attainment of vocational satisfaction. Holland developed six personality types: Realistic, Investigative, Artistic, Social, Enterprising, and Conventional. Essentially, Holland's theory states that the more one resembles a type, the more one will exhibit the personal traits and behaviors of that type. Holland also believes that there are six model environments, correlated to the six personality types: Realistic, Investigative, Artistic, Social, Enterprising, and Conventional. The pairing of personality type and environment is what allows one to predict outcomes such as vocational choice, vocational stability and achievement, educational choice and achievement, personal competence, social behavior, and susceptibility to influence (Holland, 1997).

The pairing of personality type and environment could be very helpful for Athletic Training educators, as well as other educational professionals, as students are entering and progressing through their academic preparation. Athletic training educators and professionals 
understand characteristics of the athletic training environment. Identifying personality types of students expressing an interest in athletic training early in the process and continuing through the educational program may allow educators to better predict, advise and mentor students on individual vocational choice, thus creating a more synergistic pairing of the two in the end.

Holland (1997) acknowledges four working primary assumptions of the theory. These assumptions are:

1. In our culture, most persons can be categorized as one of six personality types: Realistic, Investigative, Artistic, Social, Enterprising, and Conventional.

2. There are six model environments: Realistic, Investigative, Artistic, Social, Enterprising, and Conventional.

3. People search for environments that will let them exercise their skills and abilities, express their attitudes and values, and take on agreeable problems and roles.

4. Behavior is determined by an interaction between personality and environment. (p. 3-4)

Secondary assumptions are also incorporated into the theory. Those assumptions are: consistency, differentiation, identity, congruence, and calculus. Within a personality type or environment, some types have more in common than others. Consistency is the level of relatedness between types or models. Differentiation is the degree to which a type or environment is well defined. Identity is the possession of well-defined and established goals, interests, talents, tasks or rewards. The matching of personality type and model environment is congruence. Lastly, calculus describes the relationship within and between personality types and environment models represented in hexagonal form (Holland, 1997). 


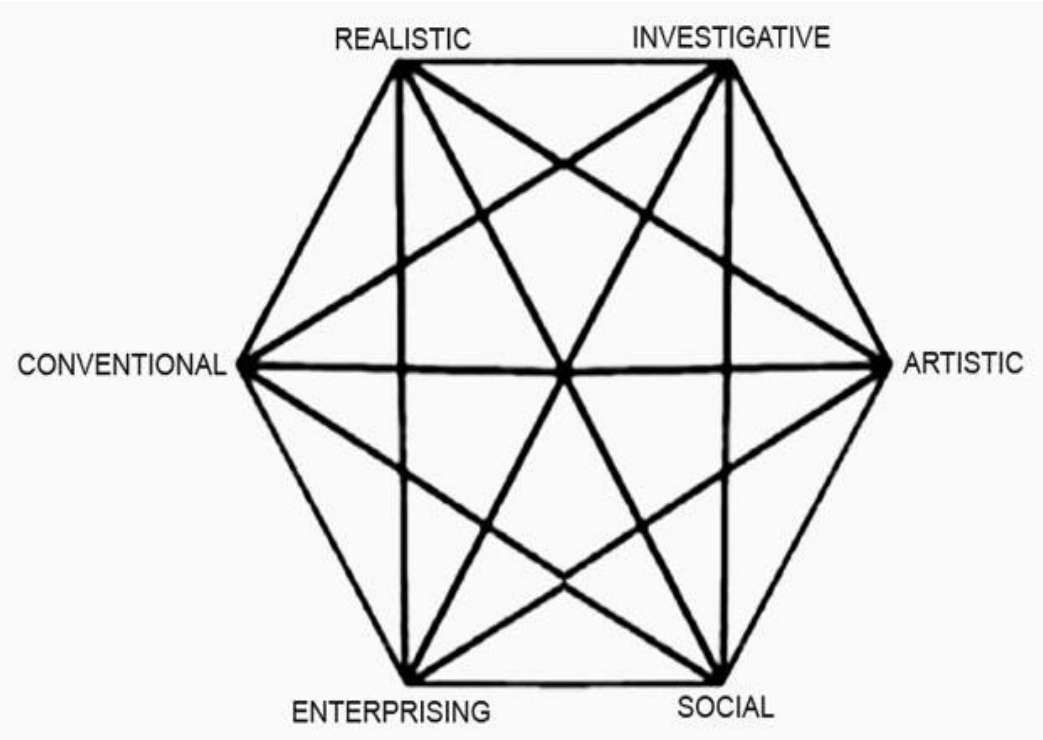

Figure 1. Holland's hexagonal model illustrating psychological resemblances among personality types and environments and their interaction (Careerpatri, 2016)

Holland utilizes a hexagonal model to demonstrate the interaction and relationships among personality types. The distance between types helps to illustrate the similarity or difference, whichever it may be, among defined types. A shorter distance represents similarity, whereas, a greater distance represents variance (Holland, 1997). Identifying personal characteristics and matching those to one's environment creates an improved synergistic interaction with like items attracting (shorter distance, similarity) and different (greater distance, difference) items repelling. For example, a realistic personality is best suited for a realistic environment, is moderately well suited for a conventional environment and least suited for a social environment.

Individuals possess a dominant personality type but will also possess characteristics of additional related or opposing types to varying degrees, developing an overall personality profile. Each defined personality type is the product of multiple aspects of the individual's life and experiences. Examples of influences are peers, heredity, parents, social class, activities, interests, competencies, culture and physical environment. The dominant personality type is that which 
will determine the primary direction of one's occupational choice. Secondary and tertiary subtypes making up the personality profile will define one's choice in a more specific manner. For example, the Social type may be dominant and that individual will aspire to social occupations but it may be more specifically directed in Social-Artistic or Social-Investigative domains (Holland, 1997). 
Table 2

Characteristics of Holland's Personality Types and Environment Models (Holland, 1997)

\begin{tabular}{|c|c|c|c|}
\hline & Realistic & Investigative & Artistic \\
\hline $\begin{array}{c}\text { Personality } \\
\text { Type }\end{array}$ & $\begin{array}{c}\text { Prefers realistic } \\
\text { occupations } \\
\text { (electrician/mechanic/ } \\
\text { agricultural/technical) } \\
\text { Conforming, Materialistic, } \\
\text { Realistic, Reserved, } \\
\text { Uninsightful, Practical, } \\
\text { Persistent, Hardheaded, } \\
\text { Genuine, Inflexible }\end{array}$ & $\begin{array}{c}\text { Prefers investigative } \\
\text { occupations } \\
\text { (biologist/medical } \\
\text { technology) Analytical, } \\
\text { Cautious, Complex, } \\
\text { Critical, Curious, } \\
\text { Independent, Intellectual, } \\
\text { Pessimistic, Precise, } \\
\text { Rational, Reserved, } \\
\text { Unassuming, Radical }\end{array}$ & $\begin{array}{c}\text { Prefers artistic } \\
\text { occupations } \\
\text { (writer/interior } \\
\text { decorator) Complicated, } \\
\text { Imaginative, Disorderly, } \\
\text { Emotional, Expressive, } \\
\text { Nonconforming, } \\
\text { Idealistic, Impractical, } \\
\text { Impulsive, Independent, } \\
\text { Intuitive, Open, Original }\end{array}$ \\
\hline $\begin{array}{c}\text { Environment } \\
\text { Model }\end{array}$ & $\begin{array}{l}\text { Encourages performance } \\
\text { of realistic activities } \\
\text { Stimulates technical } \\
\text { competencies \& } \\
\text { achievements } \\
\text { Encourages mechanical } \\
\text { ability Rewards the } \\
\text { display of traditional } \\
\text { values \& attitudes }\end{array}$ & $\begin{array}{c}\text { Encourages performance } \\
\text { of investigative activities } \\
\text { Stimulates scientific } \\
\text { competencies \& } \\
\text { achievements Encourages } \\
\text { scholarly ability. Rewards } \\
\text { the display of scientific } \\
\text { values \& attitudes }\end{array}$ & $\begin{array}{c}\text { Encourages performance } \\
\text { of artistic activities } \\
\text { Stimulates artistic } \\
\text { competencies \& } \\
\text { achievements } \\
\text { Encourages expressive } \\
\text { ability Rewards the } \\
\text { display of independent } \\
\text { values \& attitudes }\end{array}$ \\
\hline & Social & En & Conventional \\
\hline $\begin{array}{c}\text { Personality } \\
\text { Type }\end{array}$ & $\begin{array}{c}\text { Prefers social occupations } \\
\text { (teacher/counselor) } \\
\text { Agreeable, Cooperative, } \\
\text { Helpful, Empathetic, } \\
\text { Friendly, Generous, } \\
\text { Idealistic, Kind, Patient, } \\
\text { Persuasive, Tactful } \\
\text { Responsible, } \\
\text { Understanding, Warm, } \\
\text { Sociable }\end{array}$ & $\begin{array}{c}\text { Prefers enterprising } \\
\text { occupations (sales } \\
\text { person/management) } \\
\text { Acquisitive, Ambitious } \\
\text { Forceful, Sociable, } \\
\text { Energetic, Adventurous, } \\
\text { Assertive, Enthusiastic, } \\
\text { Self-confident, Optimistic, } \\
\text { Resourceful }\end{array}$ & $\begin{array}{c}\text { Prefers conventional } \\
\text { occupations (banker/ } \\
\text { bookkeeper) Careful, } \\
\text { Conscientious, Efficient, } \\
\text { Inflexible, Inhibited, } \\
\text { Thrifty, Methodical, } \\
\text { Obedient, Orderly, } \\
\text { Persistent, Practical, } \\
\text { Thorough, } \\
\text { Unimaginative }\end{array}$ \\
\hline $\begin{array}{c}\text { Environment } \\
\text { Model }\end{array}$ & $\begin{array}{l}\text { Encourages performance } \\
\text { of social activities } \\
\text { Stimulates social/helping } \\
\text { competencies \& } \\
\text { achievements } \\
\text { Encourages cooperative } \\
\text { ability Rewards the } \\
\text { display of empathetic } \\
\text { values \& attitudes }\end{array}$ & $\begin{array}{c}\text { Encourages performance } \\
\text { of enterprising activities } \\
\text { Stimulates assertive/self- } \\
\text { confident competencies \& } \\
\text { achievements } \\
\text { Encourages leadership } \\
\text { ability Rewards the } \\
\text { display of } \\
\text { personal/organizational } \\
\text { enterprising values \& } \\
\text { attitudes }\end{array}$ & $\begin{array}{c}\text { Encourages performance } \\
\text { of organizational } \\
\text { activities } \\
\text { Stimulates operational } \\
\text { competencies \& } \\
\text { achievements } \\
\text { Encourages nonartistic } \\
\text { ability } \\
\text { Rewards the display of } \\
\text { conforming values \& } \\
\text { attitudes }\end{array}$ \\
\hline
\end{tabular}


Athletic training is a social environment model. Dominant social personality types are mainly found in this environment. This social environment values social personality types who are helpful, friendly and trustworthy. Individuals in this environment excel at teaching, counseling, nursing, and medicine, providing information and solving social problems. Social personalities, known as "The Helpers", possess the following personal characteristics: friendly, helpful, outgoing, cooperative, patient, empathetic and kind. These individuals also like to work in groups, help with problems, provide service to others, or plan and supervise activities. The social type generally avoids using machines, tools or animals to achieve a goal. Social types are most like artistic or enterprising types and least like realistic types (Western Reserve, 2011).

Other recognized factors that lead to expected occupational choices are level of aspiration and achievement, career involvement and satisfaction, jobs shifts and unemployment, educational behavior, social behavior and environmental responsiveness. Levels of aspiration and achievement are applied to the personality types as such. High vocational aspirations and vocational achievement are positively associated with personality types in this order: ESAICR or Enterprising, Social, Artistic, Investigative, Conventional and Realistic. The accomplishments of an individual in a field are positively associated with consistency, differentiation, and identity when the type is congruent with the field. Congruence is positively associated with career involvement and satisfaction. Coping with job changes and unemployment, with all things being equal, associates with the SEAICR personality pattern. Greater coping competence is associated with a pattern that most resembles that particular personality pattern order. High educational aspirations and achievement follow the pattern of ISACER. In regards to social behavior, like personality patterns will be attracted to one another. Dissimilar personality patterns are more likely to dislike each other and potentially result in conflict. Social and enterprising types are 
more likely to participate and be in leadership roles. Personality patterns also influence one's choice of non-vocational activities. Higher levels of interpersonal relations follow the pattern of SEAICR. Lastly, individuals that possess consistent, differentiated personality patterns and a high level of identity have increased resistance to external influences. Those with inconsistent, undifferentiated patterns and a low level of identity possess lesser resistance to external influences. Personality patterns can also predict one's susceptibility to environmental stresses. For example, a conventional type should have difficulty dealing with problem solving or vague, undefined tasks (Holland, 1997). This particular research inquiry will attempt to identify the factors just discussed through the face-to-face interview process that will be used to evaluate the connections among personality, associated factors and the environment.

Environmental models are not immune to influence. These influences include vocational behavior, personal effectiveness, educational behavior, social behavior, sensitization, and organizational behavior. In the area of vocational behavior, each model attracts its associated personality type. Consistency and differentiation of an environment promotes vocational choice stability. An environment's identity promotes stability of vocational aspiration. The influence of personal effectiveness, educational behavior, and social behavior is apparent in that each model environment reinforces its own characteristic group of activities, competencies, achievements, educational and social behaviors. Personality types in each environment model are sensitized to characteristic attitudes, beliefs, values, and roles. Organizational behavior influence considers the degree of similar or varying characteristics of differing organizations. Organizations with similar characteristics are more likely to interact in mutually beneficial relationships. Well-defined organizations are more likely to have individuals with higher levels of involvement, satisfaction, and economic productivity (Holland, 1997). 
Given that personality types and environmental models share a common set of foundational principles, it is then possible to predict the outcome of pairing people and environments. The interaction of a Realistic type and a Realistic environment, for example, should produce desirable outcomes in the areas of vocational stability, work satisfaction and work achievement. The relationship between individual and environment should be a synergistic one (Holland, 1997).

\section{Cultural Factors Influencing Career Choice Specific to Appalachia}

A number of factors, such as psychosocial development, personality traits, environmental traits, life context, personal aptitude, and educational attainment can influence occupational choice. In U.S. society, the process of a young adolescent beginning to formulate career decisions or choices typically occurs in high school. Think about how many times you yourself were asked or have asked young adults nearing the end of high school what their post high school plans were, college bound or work-bound. Meeting the challenge and formulating a career plan is a critical developmental milestone in an adolescent's life (Ferry, 2006).

Cultural influence in career choice is multifactorial involving familial, school and community culture as found by Ferry (2006) when studying rural Pennsylvania. In these contexts, youth learn and explore careers and the opportunities available to them. Youth look to those who are role models (parents or other family members) in their lives and often want to emulate them. Those from communities that are more affluent tend to have more family, school support, and career counseling resulting in a wider range of career options. Individuals from lower income communities experience a lack of career-decision making and often the expectation is that the school instead of the family will help the individual make career decisions. The transition from high school to career can vary by social and economic context. College 
bound youth tend to view the college years as a time to 'test' what they want to choose as a career with the focus being on graduation. Skill development and educational attainment that direct their career expectations drive work-bound youth. Communal location, rural versus urban, also influences career choice. Migration out of rural areas for youth can bring a conflict. The struggle to remain close to friends and family while believing urban areas offer more opportunity and income is the dilemma faced (Ferry, 2006; Russ, 2006).

Russ (2006) studied the impact of family background and trust on career self-efficacy and career interests of Appalachians and non-Appalachians. Family background factors (income, parents' educational levels, and prestige level of career choice) was slightly higher in the Appalachian group studied. It impacted career self-efficacy among both groups (Russ, 2006). Individuals in Appalachia often have a strong commitment to family and community, which supports the findings of Ferry (2006). Appalachian culture often is seen to exhibit an inherit mistrust of outsiders or persons and organizations/institutions outside their circle. This concept of trust and commitment to kinship can influence career self-efficacy in Appalachians. For example, career self-efficacy among individuals in Appalachians was lower in the areas of Business and Management, an area of careers that involves organizations or institutions that may not be fully trusted, while a positive influential relationship was present in Health Services and Industrial/Engineering models. This influence was not present outside of Appalachia (Russ, 2006).

Other factors of cultural influence on career choice to consider that are non-specific to Appalachia are the impact of race and ethnicity. Race or ethnicity does not seem to influence career aspirations or decision-making attitudes, but does influence perceptions of career opportunities and barriers (Fouad \& Byars-Winston, 2005). This should be an important aspect 
of career counseling, guidance, mentoring and professional socialization of individuals into a career field. 


\section{Chapter Three: Methodology}

As discussed, current research suggests that there may be a number of professional issues needing attention within the profession of athletic training. These include stress and burnout (Capel, 1986; Campbell et al., 1985; Clapper \& Harris, 2006; Giacobbi, 2009; Hendrix et al., 2000; Kania et al., 2006), athletic training job satisfaction and work-family conflict (Barrett et al., 2002; Mazerolle et al., 2006; Milazzo et al., 2006), and professional socialization (Mensch et al., 2005; Pitney, 2002, 2006; Pitney et al., 2002).Other issues such as information on employment opportunities, professionalism, salaries, and a saturated job market affect a graduate's opportunity or choice to practice within the profession of athletic training. As suggested by Stilger and colleagues (1999), this could be a potential factor of athletic training graduate attrition. It is unknown what impact these professional issues and/or other unknowns (e.g., a student's desire to gain additional knowledge or advancement of skills through pursuing additional education or self-confidence levels) have on senior athletic training students approaching undergraduate graduation, a critical point of potential entry into/exit out of the profession.

This research project sought to explore factors affecting the career intentions of senior athletic training students approaching graduation from an Athletic Training Program (ATP) that led the researcher to an explanatory conclusion; therefore, qualitative methods were employed. Qualitative research allows the investigator to gain insight into and understand the meaning of a particular experience (Patton, 2002). Qualitative research also allows the researcher to gain firsthand experience of how the participants derive meaning from their surroundings and environment as well as how these influence decisions and behavior. In this particular research inquiry, qualitative research methods helped the researcher to investigate past and present 
experiences and influences of senior athletic training students approaching graduation (Hancock \& Algozzine, 2011). To date, no qualitative research examining factors influencing persisting and becoming displaced from athletic training of senior athletic training students approaching the benchmark of undergraduate graduation exists. Even though Athletic Training is presently undergoing a degree transition, educators and professionals must have a solid understanding of influences and factors that impact the professional. We must understand current dynamics of athletic training to be able to implement useful, effective change in the future. Thus, the purpose of this study was to gain insight and understanding into the factors and circumstances affecting senior athletic training students' intentions to pursue or not pursue the athletic training profession. The following research questions guided this study:

1. What are the factors, experiences, and/or circumstances that contribute to senior athletic training students approaching graduation planning to persist or pursue the athletic training profession?

2. What are the factors, experiences, and circumstances that contribute to senior athletic training students approaching graduation being displaced and not planning to seek employment in the athletic training profession?

\section{Epistemology and Conceptual Framework}

This research inquiry utilized a constructivist perspective. As described by Crotty (2015), research in a constructivist vein... requires that we not remain straitjacketed by the conventional meanings we have been taught to associate with the object. Instead, such research invites us to approach the object in a radical spirit of openness to its potential for new or richer meaning. It is an invitation to reinterpretation. (p. 51) 
The researcher used information gathered during interactions with participants through interviews, participant responses and shared experiences as well as the data collected through non-participant observations to consider the influences on athletic training students' choices to persist in or displace themselves from the profession of athletic training. It is the belief of the researcher that each participant's experience and influences on their decisions is unique in nature. The researcher used the basis of constructivism to determine how meaning was created as participants interacted, interpreted, and made sense of their individual experiences in the area of athletic training (Crotty, 2015).

Interpretivism with a symbolic interactionism approach guided this study. Symbolic interactionism involves three basic principles:

1. human beings act towards things on the basis of the meanings that things have for them

2. the meaning of such things is derived from, or arises out of, the social interaction that one has with one's fellows

3. the meanings are handled in, and modified through, an interpretative process used by the person in dealing with things that he encounters (Blumer, 1969, p. 2)

These three closely connected principles apply to this research inquiry in the following ways. In making our occupational choices or decisions, we choose jobs or careers that we relate to, connect to, value or find purpose within. The decisions that we make, as previously discussed, are impacted by interaction or influences of our family, environment, and culture, our lived life experiences. Lastly, we derive meaning from our lived life experiences and interactions that then influence and affect our future decisions and life path. 


\section{Method}

A multiple case study approach used. As explained by Yin (2014), case study research methods are appropriate when an exploratory inquiry is being conducted and it provides an advantageous methodology for research questions with a "how" or "why" context. In examining the factors, experiences, and circumstances of senior athletic training students approaching graduation and their impact on their decisions to persist or become displaced from athletic training, the "why" was explored.

Case study research differs from other types of research because these studies occur thorough analyses and accounts of a single element or organization defined or "bounded" by space and time. The intention of the researcher was "to gain in-depth understanding of situations and meaning for those involved" (Hancock \& Algozzine, 2011, p. 11). Case study issues suggest multifaceted, positioned, challenging relationships pulling attention both to the ordinary experience and to the disciplines of knowledge (Stake, 2006).

A multiple case approach was proposed for this particular research inquiry to be able to examine the intricate similarities and differences among four WV ATPs that influenced the career intentions of athletic training students approaching graduation. Each selected respective WV ATP was treated as an individual case; this led to the multiple case approach. An in-depth examination of more than one WV ATP allowed the researcher to broaden the lens and investigate additional factors that were potentially present within and across various programs. The researcher recognized that not all factors were present within each case and each case has their own unique specific factors. However, the benefit of a cross-case analysis afforded the results of all of these factors. Each case was examined and analyzed within itself but each case and its findings were also analyzed against, or across, the other three studied cases. 
Eight Commission on Accreditation of Athletic Training Education (CAATE) programs presently exist within the state of West Virginia (CAATE, 2016). For the purposes of this inquiry, four of the eight programs were selected for in-depth study. Using pseudonyms to protect participants' identities, these have been labeled as Carlin University, Kennedy University, University of Rawlins, and University of Olympia. These four programs included three of the longest standing accredited athletic training programs within West Virginia. The selection of these four institutions and programs allowed for diversity among program size, institution size, institution type, athletic competition level and demographic location within West Virginia. Table 3 shows institutional information regarding the four institutions. 
Table 3

Institutional Information

\begin{tabular}{|c|c|c|c|c|c|c|}
\hline $\begin{array}{c}\text { Name of } \\
\text { Institution }\end{array}$ & $\begin{array}{l}\text { Institution Size } \\
\text { (Fall FTE 2014) }\end{array}$ & $\begin{array}{c}\text { Institution Type; } \\
\text { Carnegie } \\
\text { Classification }\end{array}$ & $\begin{array}{c}\text { Program } \\
\text { Accreditation } \\
\text { Date }\end{array}$ & Location & $\begin{array}{c}\text { Athletic } \\
\text { Competition } \\
\text { Level }\end{array}$ & $\begin{array}{l}\text { Athletic } \\
\text { Conference } \\
\text { Affiliation }\end{array}$ \\
\hline $\begin{array}{c}\text { Carlin } \\
\text { University }\end{array}$ & 13,390 & $\begin{array}{l}\text { Bal/HGC } \\
\text { Master's L } \\
\text { Public }\end{array}$ & 4/18/1997 & Medium City & $\begin{array}{c}\text { NCAA } \\
\text { Division I }\end{array}$ & $\begin{array}{c}\text { Conference USA } \\
(\mathrm{FBS})\end{array}$ \\
\hline $\begin{array}{l}\text { Kennedy } \\
\text { University }\end{array}$ & 1895 & $\begin{array}{c}\text { Bal/SGC } \\
\text { Baccalaureate/ } \\
\text { Diverse Fields } \\
\text { Private, } \\
\text { not-for-profit }\end{array}$ & 10/17/1997 & Medium City & $\begin{array}{c}\text { NCAA } \\
\text { Division II }\end{array}$ & Mountain East \\
\hline $\begin{array}{l}\text { University } \\
\text { of Rawlins }\end{array}$ & $\begin{array}{c}29,175 \\
\text { (main campus) } \\
31,976 \\
\text { (UR system) }\end{array}$ & $\begin{array}{c}\mathrm{Bal} / \mathrm{HGC} \\
\mathrm{Ru} / \mathrm{H} \\
\text { Public }\end{array}$ & 9/16/1995 & Small City & $\begin{array}{c}\text { NCAA } \\
\text { Division I }\end{array}$ & Big 12 (FBS) \\
\hline $\begin{array}{l}\text { University } \\
\text { of Olympia }\end{array}$ & 1377 & $\begin{array}{c}\text { Prof+A\&S/SGC } \\
\text { Baccalaureate/ } \\
\text { Diverse Fields } \\
\text { Private, Catholic } \\
\text { not-for-profit }\end{array}$ & 05/03/2010 & Small City & $\begin{array}{c}\text { NCAA } \\
\text { Division II }\end{array}$ & Mountain East \\
\hline
\end{tabular}


The remaining four CAATE institutions not selected for in-depth study are Cowen University, the University of Winchester, Sunnyside University, and Clark University. Reasons for exclusion of in-depth study are as follows. Cowen University located in Homestead, WV will be electing to voluntarily withdraw CAATE accreditation in the near future and no longer offer an athletic training education program. The University of Winchester located in Winchester, WV is a small, public, primarily residential university that is highly undergraduate with an enrollment of 2,545 offering undergraduate instruction in the balanced arts \& sciences/professions that competes athletically at the NCAA Division II level within the Mountain East Conference. Sunnyside University in Sunnyside, WV only recently in January 2016 was granted accreditation status from CAATE and is also a small, public institution with an enrollment of 2,694 offering undergraduate education in diverse fields that competes athletically within NCAA Division II and the Mountain East Conference. Clark University is a small, private, not-for-profit, primarily residential institution in Townsend, WV that is also highly undergraduate with an enrollment of 1,511 offering undergraduate instruction in balanced arts and sciences that competes athletically at the NCAA Division II level within the Mountain East Conference. The University of Winchester, Sunnyside University or Clark University do not add to greater diversity among institution, athletic or program characteristics nor do these programs aid in maintaining a balance of selected institutions among private, not-for-profit and public.

\section{Context}

Deans, Department Chairs, and Program Directors (as appropriate by individual institutions' policies) gave written permission for this work, filed with the West Virginia University Institutional Review Board (IRB). Upon IRB approval, Program Directors were contacted via phone and/or email at the four selected CAATE accredited ATPs in West Virginia 
(Carlin University, Kennedy University, University of Rawlins and University of Olympia). Upon contact, information regarding the study was provided, permission to interview senior athletic training students approaching graduation was requested, and permission to observe athletic training students in a clinical setting provided by the program and an institutional representative/program official's participation in a face-to-face interview was requested.

Once an ATP agreed to participate in this study, the investigator and each Program Director agreed on a day(s) and time(s) most convenient for the volunteer, senior students and an institutional representative to complete face-to-face interviews. A cover letter for interviewees and an interview schedule for students to indicate the most convenient time for them to be interviewed was then provided to the Program Director by the investigator. Program Directors were also provided cover letters via email for all athletic training students and clinical preceptors assigned to the clinical site provided for observation explaining the study and requesting participation. Students willing to participate and thus consenting to an interview indicated on the investigator's schedule formed a convenient time for an interview. Lastly, Program Directors assisted in providing a secure location on their campus for private, face-to-face semi-structured interviews.

\section{Case Locations}

Carlin University. Carlin University is a mid-sized, West Virginia state institution of higher education. Carlin University is located in a middle-sized city in the southwestern portion of West Virginia. Carlin was founded in 1837 as Carlin Academy. Carlin Academy faced a number of challenges through the years, most financial. In 1867, the West Virginia Legislature created the State Normal School of Carlin College to train teachers. Carlin has sponsored an accredited athletic training education program since April of 1997 (CAATE, 2016). 
Carlin is specifically located on the Ohio River in a two-county area with a population of 49,138 , the second largest in the state, as of the 2010 Census. It is part of the largest inland port within the United States. It is the center of a metropolitan area spanning seven counties and three states with a population of 365,419 . In addition to convenient water travel, the economy in the area is also supported by its airport and an interstate highway system that links the area to the East Coast, Southern and Midwest markets. The metropolitan area is within a 24-hour drive of $44 \%$ of the U.S. industrial market and $37 \%$ of the U.S. consumer market.

Kennedy University. Kennedy University is located in southern West Virginia, near the state capitol. Kennedy University is a small, private, liberal arts institution that was founded originally in 1888 and originally known as a seminary. It moved to its present home during the Great Depression. Ties to the United Methodist Church were intact until 1942 when the college disaffiliated and became independent. In 1978, it was renamed Kennedy University by the Board of Trustees. Kennedy has offered students an accredited athletic training program since October 1997 (CAATE, 2016).

Its medium-sized city location, at the confluence of two major rivers, has a population of 51,400, the largest in the state as of the 2010 Census (US Census, 2016). The metropolitan area spans three counties and has a population of 240,000. The area also has access to convenient water travel, an airport and multiple interstate highways and US routes going north, south, east and west.

University of Rawlins. The University of Rawlins is the largest land grant, research institution of higher education within West Virginia. The University of Rawlins is located in a small city along a major river in North Central West Virginia. As of the 2010 Census, the city had a population of 29,660 (US Census, 2016). It is within easy traveling distance to Pittsburgh, 
PA, Washington, DC, Cleveland, $\mathrm{OH}$ and Columbus, $\mathrm{OH}$. The University of Rawlins has divisional campuses located around the state. The University of Rawlins System crosses the entire state consisting of 15,880 acres. The main campus sits on 1,892 acres and consists of 245 buildings. The University of Rawlins has offered an accredited Athletic Training Program since September 1995 (CAATE, 2016).

Its location in a 'city of distinction' offers a great deal of opportunity for business development and expansion. It has shown continual population growth for the past 20 years. Development areas include housing, manufacturing, research and commercial sectors. The University of Rawlins main campus area is easily accessible by interstate, water, air and rail.

University of Olympia. The University of Olympia is a small, private, liberal arts college also located in northern West Virginia in a small city. Founded in 1954, the University of Olympia has a strong affiliation with the Catholic Church. It has offered an accredited AT Program since May 2010 (CAATE, 2016).

Its small city is located in two counties. It had a population of 28,486 as of the 2010 Census (US Census, 2016). It is located along the Ohio River and is easily accessible to I-70. It is 55 miles from Pittsburgh, 120 miles from Columbus, $\mathrm{OH}$ and 130 miles from Cleveland, $\mathrm{OH}$. Due to its location along major transportation routes, this area became a manufacturing center in the late $19^{\text {th }}$ century. Post WWII, its industry now includes healthcare, education, law and legal services, entertainment and tourism and energy. 
Table 4

Case Location Institutional Demographics

\begin{tabular}{|c|c|c|c|c|c|}
\hline Case Location & $\begin{array}{l}\text { Minority } \\
\text { student }\end{array}$ & $\begin{array}{c}\text { Gender } \\
\text { Breakdown }\end{array}$ & $\begin{array}{c}\text { International } \\
\text { population }\end{array}$ & $\begin{array}{c}\text { Tuition Costs } \\
\text { undergraduate }\end{array}$ & $\begin{array}{c}\text { Incoming Freshman ACT, } \\
\text { GPA Averages }\end{array}$ \\
\hline $\begin{array}{c}\text { Carlin University } \\
\qquad(2014-15)\end{array}$ & $11 \%$ & $\begin{array}{l}59 \% \text { Female } \\
\text { 41\% Male }\end{array}$ & $3 \%$ & $\begin{array}{c}\text { Tuition In-state: } \\
\text { \$6914/year } \\
(' 15-16)\end{array}$ & $\begin{array}{l}\text { ACT } 22.1 \\
\text { GPA } 3.4\end{array}$ \\
\hline $\begin{array}{c}\text { Kennedy } \\
\text { University } \\
(2015-16)\end{array}$ & Not available & Not available & $\begin{array}{l}41 \text { countries } \\
\text { represented }\end{array}$ & $\begin{array}{c}\text { Tuition } \\
\$ 28,900 / \text { yearly } \\
\text { ('16-'17) }\end{array}$ & $\begin{array}{c}\text { ACT } 23 \\
\text { GPA } 3.42\end{array}$ \\
\hline $\begin{array}{l}\text { University of } \\
\text { Rawlins } \\
(\mathbf{2 0 1 5 - 1 6 )}\end{array}$ & Not available & $\begin{array}{l}52 \% \text { Male } \\
\text { 48\% Female }\end{array}$ & $\begin{array}{l}110 \text { countries } \\
\text { represented }\end{array}$ & $\begin{array}{l}\text { Tuition In-State: } \\
\text { \$3816/semester }\end{array}$ & $\begin{array}{c}\text { ACT } 24 \\
\text { GPA } 3.45\end{array}$ \\
\hline $\begin{array}{l}\text { University of } \\
\text { Olympia } \\
\text { (2015-16) }\end{array}$ & $25 \%$ & $\begin{array}{l}52 \% \text { Male } \\
48 \% \text { Female }\end{array}$ & $\begin{array}{c}6 \% \\
26 \text { countries } \\
\text { represented }\end{array}$ & $\begin{array}{c}\text { Tuition: } \\
\$ 28,030 / \text { yearly }\end{array}$ & $\begin{array}{l}\text { ACT } 23 \\
\text { GPA } 3.4\end{array}$ \\
\hline
\end{tabular}




\section{West Virginia's Economic Outlook}

The greater expectations and forecast horizon for the U.S. and broader global economy will have a significant impact on the local West Virginian economic performance. Forecasts indicate that economic recovery will continue over the next five years with a state job growth of .5 percent per year through 2020. The anticipated U.S. employment growth rate is an average of 1.2 percent per year. West Virginia's employment will lag behind national rates if forecasts hold (Deskins et al., 2015). Figure 2 illustrates recent West Virginian unemployment rates with the four case universities highlighted.

Unemployment rates by county, not seasonally adjusted, West Virginia March 2016

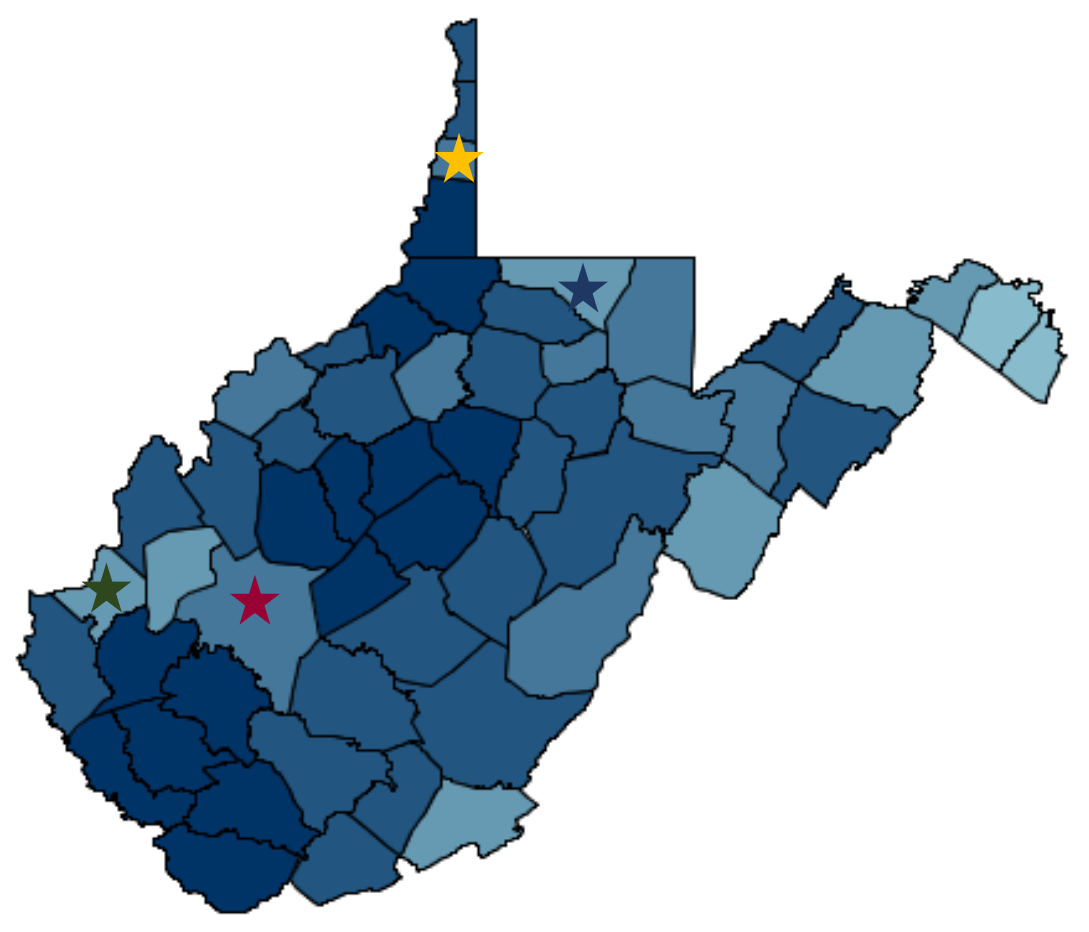

\begin{tabular}{|c|c|c|}
\hline & University & Unemployment Rate, Mar. '16 \\
\hline t & Carlin & 5.3 \\
\hline 卓 & Kennedy & 6.2 \\
\hline 文 & Rawlins & 5.0 \\
\hline$\sqrt{1}$ & Olympia & $6.4 / 9.9$ \\
\hline
\end{tabular}

Figure 2. West Virginia's Unemployment Rates (BLS, 2016a) 


\section{Health and Healthcare in West Virginia}

Access to healthcare services in West Virginia due to the nature of the terrain and facility locations has been challenging for residents. Through the construction of new roads and the expansion of healthcare services, residents are finding greater access to care (Deskins et al., 2015). According to America's Health Rankings (2016) though, West Virginia still has an overall health rank (based on 27 health indicators) of $47^{\text {th }}$ out of 50 , ranking $50^{\text {th }}$ in Smoking, $50^{\text {th }}$ in Diabetes, $49^{\text {th }}$ in Obesity and $47^{\text {th }}$ in Physical Activity. The strengths within the state are high per capita public health funding, low prevalence of excessive drinking, and low incidence of infectious disease. Present challenges faced within the healthcare system of West Virginia are a high prevalence of diabetes, low immunization coverage among children and a high prevalence of smoking (America's Health Rankings, 2016). Improved access to care and qualified providers must continue for the overall health rankings to improve within the state. West Virginia presently has 108 designated HPSAs within the state across its 55 counties (HRSA Data Warehouse, 2016). As alluded to previously, athletic trainers can assist in alleviating the strain placed on the shortage areas and improve healthcare access to residents. Table 5, Figures 3 and 4, illustrate a comparison of the employment and wage data of Athletic Trainers in West Virginia as compared nationally. While the annual mean wage in West Virginia may be in one of the higher wage brackets nationally, one can see from Figure 3 that West Virginia is not a state that presently affords a large number of athletic training jobs to prospective athletic trainers. Nor, given job growth forecasts, will West Virginia be able to 'catch up' with other states in the near future. 


\section{Table 5}

WV Employment of Athletic Trainers and Wage Data (BLS, 2016b)

Occupation: Athletic Trainers (SOC code 299091)

Period: May 2015, West Virginia

\begin{tabular}{|r|c|c|c|}
\hline Employment(1) & $\begin{array}{c}\text { Employment percent } \\
\text { relative standard } \\
\text { error(3) }\end{array}$ & $\begin{array}{c}\text { Annual mean } \\
\text { wage(2) }\end{array}$ & $\begin{array}{c}\text { Wage percent } \\
\text { relative } \\
\text { standard } \\
\text { error(3) }\end{array}$ \\
\hline 120 & 29 & 45790 & 3.1 \\
\hline
\end{tabular}

\begin{tabular}{|c|c|c|}
\hline $\begin{array}{c}\text { Annual median } \\
\text { wage(2) }\end{array}$ & $\begin{array}{c}\text { Employment per 1,000 } \\
\text { jobs }\end{array}$ & $\begin{array}{c}\text { Location } \\
\text { Quotient }\end{array}$ \\
\hline 38890 & 0.176 & 1.03 \\
\hline
\end{tabular}

Footnotes:

(1) Estimates for detailed occupations do not sum to the totals because the totals include occupations not shown separately. Estimates do not include self-employed workers.

(2) Annual wages have been calculated by multiplying the hourly mean wage by 2080 hours.

(3) The relative standard error (RSE) is a measure of the reliability of a survey statistic. The smaller the relative standard error the more precise the estimate. 


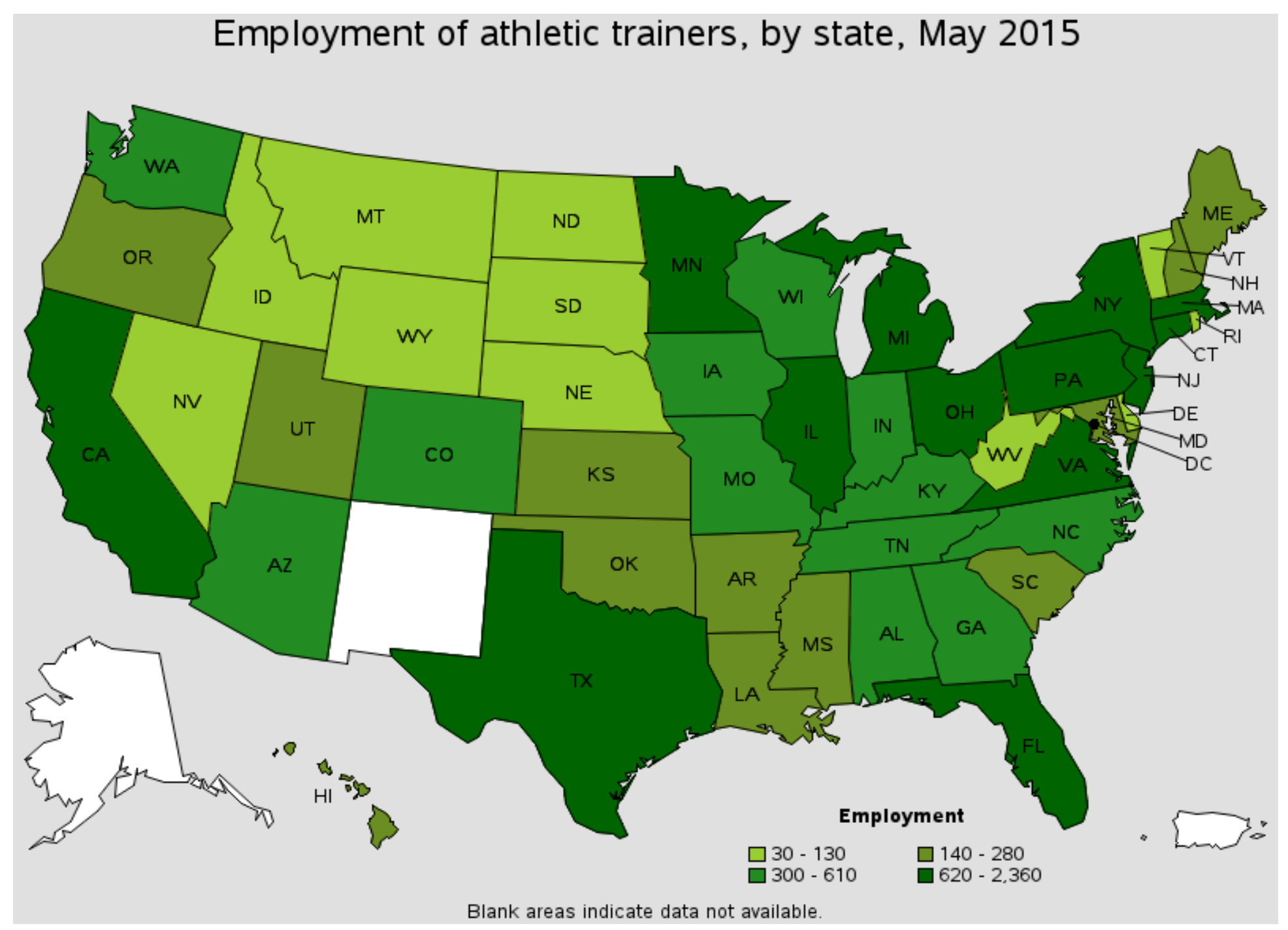

Figure 3. US Employment of Athletic Trainers (BLS, 2016c) 


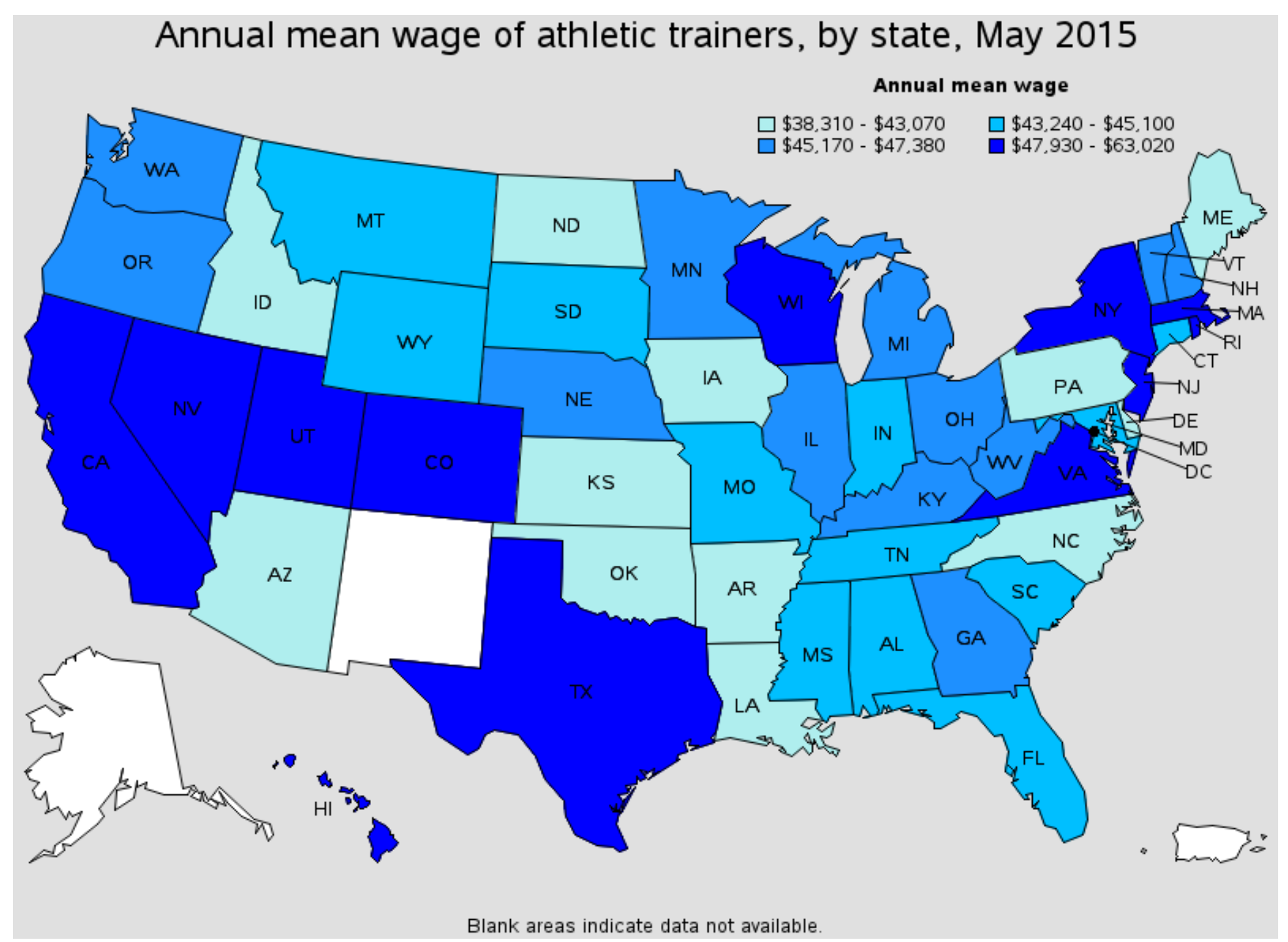

Figure 4. Annual Mean Wage of Athletic Trainers (BLS, 2016c) 


\section{Participants}

Participants for this qualitative inquiry were thirteen, volunteer senior athletic training students in the final semester of academic coursework attending one of four CAATE ATPs in West Virginia. Soon-to-be graduate participant demographics can be found below in Table 6 . ATPs included in this study are Carlin University, Kennedy University, University of Rawlins, and University of Olympia. Senior ATP students that were not in the final semester of academic coursework were excluded from the eligible participant pool. In conjunction with the Program Director of each program, 3-4 participants were recruited to participate from each athletic training program. An institutional representative from Carlin University, Kennedy University, University of Rawlins, and University of Olympia was also asked to participate on a voluntary basis.

Table 6

Soon-to-be Graduate Participant Demographic Information

\begin{tabular}{|c|c|c|c|}
\hline Participants & Gender & Home State & $\begin{array}{c}\text { Estimated Household } \\
\text { Income }\end{array}$ \\
\hline UO & M & MD & $\$ 86,000-\$ 100,000$ \\
\hline & M & WV & $\$ 25,000-\$ 40,000$ \\
\hline KU & F & OH & $\$ 86,100-\$ 100,000$ \\
\hline & M & WV & $\$ 41,000-\$ 55,000$ \\
\hline & F & WV & $\$ 56,000-\$ 70,000$ \\
\hline & F & DE & $\$ 86,000-\$ 100,000$ \\
\hline CU & F & WV & $\$ 41,000-\$ 55,000$ \\
\hline & M & WV & $\$ 56,000-\$ 70,000$ \\
\hline & F & WV & $\$ 86,000-\$ 100,000$ \\
\hline UR & F & MD & $\$ 100,000+$ \\
\hline & M & WV & $\$ 56,000-\$ 70,000$ \\
\hline & F & PA & $\$ 71,000-\$ 85,000$ \\
\hline & F & MD & $\$ 56,000-\$ 70,000$ \\
\hline
\end{tabular}

Sampling. "Purposeful sampling focuses on selecting information-rich cases whose study will illuminate the questions under study" (Patton, 2002, p. 230). Given the fact that there are 
339 bachelor's level CAATE accredited ATPs in the U.S., studying persistence or displacement of all ATP soon-to-be graduates using qualitative methods is neither practical or feasible (CAATE, 2016). Therefore, criterion and convenience sampling was used to identify participants for the study. The first criterion for selection was that participants must be students enrolled in an ATP located in West Virginia. The second criterion was that the student be a senior ATP student in the final semester of academic coursework. These criteria allowed for the greatest access to participants as well as access to senior students that had finalized or were actively in the process of finalizing immediate post-undergraduate graduation career plans.

In the recruiting volunteer participants, the Program Director at each institution assisted in securing a representative group from each program. Program Directors helped identify and secure 3-4 soon-to-be graduates that they felt represented the demographic make-up of the graduating cohort. Program Directors were instructed that participants could be from different states/countries, ethnic backgrounds, either gender, socioeconomic class, and intended career paths. Specific personality characteristics were not used as part of the selection criteria. During participant interviews and data analysis, the researcher attempted to determine the alignment of personality characteristics and environment.

Each willing student participant completed a short demographic questionnaire (Appendix A) prior to an average 40-minute long face to face interview. The demographic information requested included: name, gender, age, email contact, permanent residence, hometown, estimated cumulative grade point average, self-confidence level in athletic training skills, financing of undergraduate education, estimated household annual income, professional certifications held and sought, anticipated BOC exam date, and desired entry-level salary. The specific demographic information sought from each participant guided the researcher during the 
interview process. Program Directors were asked to provide each student participant access to his/her program file/portfolio for their review and individual reflection prior to and during completion of the questionnaire. Previous research has suggested that information on employment opportunities, professionalism, salaries, and a saturated job market affect a graduate's opportunity or choice to practice within the profession of athletic training (Stilger et al., 1999). Gaining information about a student's personal background, individual expectations and professional academic preparation assisted the researcher in probing deeper into the professional expectations that led to senior athletic training students approaching graduation planning to enter or not planning to enter the athletic training profession during the face-to-face interview.

\section{Interviewing}

In an attempt to "build theory rather than test theory" (Patton, 2002, p.127), a grounded theory design was applied in this research study. The instrument was the investigator. Information was organized by a system of coding maintained by only the investigator. Private, semi-structured interviews were completed with each participant.

The previous research of Neibert, Huot and Sexton (2010) influenced the initial development of specific interview questions. This research team used an online survey instrument to gather demographic, background information from senior athletic training students or recent AT graduates. The survey also collected clinical education information, career placement data and selected influences on those factors. Developed interview questions were first piloted with current, senior athletic training students to assure understanding and peer reviewed by two individuals with a combined experience of 59 years within the profession of athletic training and athletic training education to ensure content validity (Appendices B and D). 
The researcher subsequently concluded that the questions were easily understood by participants and others in the field as originally drafted. The interview technique of probing was successfully utilized to improve participant understanding. Interview questions were designed to allow the researcher insight into a student's academic and career journey or path. The interview questions allowed the researcher to understand what past and present experiences a participant has encountered that have influenced their decisions regarding their future professional path. Institutional representative interview questions provided additional background information on the program as a whole. Participating institutional representatives were provided a pre-interview transcript (Appendix C) prior to the face-to-face interview with the researcher. This was to allow additional time to gather information for question responses if necessary prior to the interview session.

During the completion of each participant interview, the researcher maintained a relaxed and comfortable atmosphere to keep participants at ease. The researcher began by explaining why the interview was being completed with a brief background to the nature and purpose of the study and provided participants a copy of the interviewee's cover letter. Participants were reassured that all information shared would be kept confidential. At no time were names be revealed during the reporting process. Participation was entirely voluntary, and could be stopped at any time without penalty. The researcher attempted to develop a rapport with participants that allowed each participant to feel respected in his/her athletic training experiences, influences and decisions. It is important to note though as stated by Seidman (2013) that, "The rapport an interviewer must build is an interviewing relationship needs to be controlled.....The interviewing relationship must be marked by respect, interest, attention, and good manners on the part of the interviewer" (p. 99). 
Each in-depth interview was audiotaped and field notes were maintained by the investigator. Participant responses to the demographic questionnaire were utilized by the investigator during the face-to-face interview which guided prompts and interview probing to participant responses to questions. These techniques were used for greater understanding of a participant's responses by the investigator or to gain additional information. The researcher maintained an audio journal of initial and summary impressions immediately following the conclusion of all interviews at each case site.

Upon completion of the data collection, interviews and field notes were transcribed. A student assistant selected and screened by the researcher was utilized to assist in the transcription of completed, taped interviews. The student assistant was asked to maintain participant and interview data confidentiality and act in a professional manner at all times during and post transcription. The student assistant was required to agree to and sign a confidentiality statement maintained by the researcher. The student assistant only transcribed the interviews verbatim and did not include linguistic cues. Discursive linguistic cues were added by the researcher. The researcher listened to each taped interview while reading the student assistant's transcribed document to check for accuracy of transcriptions in addition to assessing and eliminating any potential bias that could be present in the transcription.

Member checking was then utilized and transcribed interviews were emailed to all participating interviewees. Member checking was selected as a method to improve accuracy of participant data in attempt to facilitate participant compliance with the study. Given that students were in their final semester of academic coursework, the researcher realized continued access to the participants would be limited. To decrease the demand on participant time and attempt to be of greater convenience for those participating, member checking was selected. Participants then 
had the opportunity to review transcripts at their leisure and schedule as opposed to coordinating another session with the researcher.

Member checking allowed each participant to review the transcripts for accuracy and make any necessary corrections to their individual interview transcript. Transcripts were then returned to the researcher via email. All transcribed interviews (13 students, 4 institutional representative) were member checked and returned to the researcher. All data was maintained in a secure, private office in a locked closet. All electronic files were maintained on a password protected laptop computer. Participant identities were not attached to audiotapes or transcribed interviews. The investigator utilized a system of coding to protect personal identities. Pseudonyms are used in data reporting. Confidentiality of participants was protected at all times.

\section{Observation}

Program Directors provided the researcher access to athletic training students in a clinical education setting on their campus for a period of 2 to 3 hours minimum. Program Directors were sent copies of participant cover letters to provide to all enrolled ATP students explaining the purpose of the observation, and introducing the researcher and the research being conducted. The researcher also made copies of the cover letter available to participants during the observation periods. Program Directors suggested a non-obtrusive area in which the researcher positioned herself during the non-participant observation. Students were observed interacting with peers, patients, clinical preceptors, other campus faculty/staff and other healthcare professionals. The researcher signed and returned a HIPAA confidentiality statement as required by any institution given that clinician-patient interaction could be involved during the observation periods. The observations were completed in an overt manner but as to not impact or impede the natural interactions of those being observed in any manner. Observations were recorded using field notes 
containing both descriptive and reflective information from the researcher. Field notes from each observation were written up into thick descriptions within the 24 hours following the observation.

\section{Documents}

Information contained in program admission materials, brochures, and the institutional website pages for athletic training and/or other program marketing materials were examined by the researcher. Program specific materials were requested by the program director and/or the institution's admissions office.

These documents were evaluated to determine how each individual institution was attempting to attract students to the ATP. Publicly shared program successes and highlights were reviewed within each program as well as compared across programs. Student clinical education placement during completion of the program and post-graduation placements (graduate programs, employment, internships, etc.) were also collected and reviewed.

\section{Data Analysis}

Data from student interviews, student questionnaires, institutional representative interviews and program documents were analyzed within and between cases. According to Patton (2002), “Qualitative analysis transforms data into findings. No formula exists for that transformation" (p. 432). Therefore, for this particular study, three levels of coding were utilized in analyzing the data from transcribed interviews. First, transcriptions were analyzed using the open-coding technique. Open coding involved an analysis of interview transcripts to identify concepts and categories. The researcher read through each transcript twice. During a third reading of the transcript, the researcher listened to the audio tape of the original interview during the open coding process. Axial coding was then utilized to identify relationships among the open 
codes. Lastly, thematic coding formulated emerging themes. The researcher initially employed different organizational systems for the coding and identifying of emerging themes. Initially, a color coding system of organizing codes into themes was attempted both on paper and in Microsoft Word. The researcher found that this was a challenging and difficult system to maintain. An organizational system was then developed in Microsoft Excel (see Appendix E). This organizational system allowed the researcher to visualize all codes across each case simultaneously to identify emerging themes particular to that case. Emerging themes identified through the coding processes were examined across all data sources (interviews, questionnaires, and program documents) and analyzed for commonalities or differences and consistencies or inconsistencies within cases and across cases.

Analytic memos were utilized by the researcher during the coding processes. The purpose of writing analytic memos is to provide reflective notes about any or all of the following: how the researcher relates to participants; reflection of the research questions; coding choices and operational definitions; emergent concepts, categories and themes; possible linkages among themes; an emergent or related theory; problems with the research inquiry; personal or ethical dilemmas with the study; future directions of the study; the analytic memos generated themselves; and/or the final report of the research inquiry. Memoing contributes to the credibility of the qualitative research process and eliminates the need to rely on the human memory or mental notes while analyzing the data (Saldana, 2013).

\section{Trustworthiness}

The trustworthiness of this study is grounded in the use of multiple interviews at each case site, as well as interviewing both athletic training students and institutional representatives, each having a unique perspective and experience. Interviewing multiple athletic training students 
approaching graduation gave the researcher insight into the career decision making process of senior athletic training students. Member checking of the interview transcripts was also utilized. Non-participant observations took place at each case site. Documentary evidence was collected, analyzed and evaluated based on its relationship to the data collected from participant interviews. The incorporation of data source triangulation and methodological triangulation contributed to the overall trustworthiness, specifically credibility and conformability, of the study. Other components of trustworthiness are transferability and dependability. Transferability was assured by providing a detailed context of the study. Clear and detailed information about the study in a thick description is provided to address dependability (Lincoln \& Guba, 1985).

\section{Ethics}

For this research inquiry, the researcher maintained the highest level of ethical standards possible. Permission was obtained by appropriate administrators at each institution to solicit, recruit, interview and observe all volunteer participants. Participants were not harmed in any physical or psychological manner at any time during the collection of data. All individuals' privacy, anonymity, and confidentiality was protected at all times. Participation in the research inquiry was strictly voluntary and all participants were informed that withdrawal was permissible at any time. No incentives of any kind were afforded to participants by the researcher although the researcher followed-up with each participant at the conclusion of data collection with a formal thank you note for their participation, cooperation and time. The researcher remained independent and impartial during the execution of this study by acknowledging personal biases. The intricacy of the participants' experiences, challenges faced, life experiences and what the individual makes of those was appreciated and respected by the researcher (Seidman, 2013). 


\section{Researcher Positionality}

I hold a very strong passion for the profession of athletic training and athletic training education. I chose athletic training as a career choice when I was in high school, as a student trying to decide on what to study in college. I thought that Sports Medicine sounded really "fun and cool." I had been an athlete in high school, but was not going to continue participating in athletics in college and thought it would be exciting to stay in that arena. Therefore, I chose Sports Medicine as a major and really enjoyed it once introduced to the field of study. That decision has brought me to where I am today.

I have been involved in the athletic training field for the past 27 years in some capacity or another, which is the reason why I chose to study what influences students that persist/do not persist in the field of athletic training. The majority of my 27 years have been spent in the traditional collegiate athletic training setting. For the past 21 years specifically, I have been working with athletic training students and athletes at a small, private liberal arts institution located in north central, rural West Virginia. I have witnessed many students successfully complete the academic and clinical requirements of the athletic training program and then essentially choose one of three career paths: continue in the profession of athletic training, pursue a career in a different healthcare field, or choose a completely different career path. I was interested to examine the factors that influenced students' decisions on which path to take, which led to the basis of this research.

\section{Writing}

Upon the completion of data collection and analysis, information gathered through participant interviews, observations and document analysis was presented in a data chapter. It provided additional information regarding each individual case studied. Each case was reported 
in a sub-section of this chapter to provide a more in-depth, focused look at each case from an individual lens. Detail was provided on the context of each case, the results of the triangulation of the data within each case, and the details of the emergent themes, including excerpts of collected data. This chapter also included a report the findings of the cross case analysis detailing commonalities and differences across the cases. In the final chapter of the dissertation are the research implications and overall conclusions of the findings. 


\section{Chapter Four: Findings}

The researcher's aim of this study was to determine factors (consistent factors with those previously found and/or additional factors) that influence athletic training graduates' decisions to persist in or become displaced from the athletic training profession. Specifically, this study sought to examine:

1. What are the factors, experiences, and/or circumstances that contribute to senior athletic training students approaching graduation planning to persist with or pursue the athletic training profession?

2. What are the factors, experiences, and circumstances that contribute to senior athletic training students approaching graduation leading to displacement and not planning to seek employment in the athletic training profession?

In order to examine these questions in the context of the four institutions in the state of West Virginia chosen for this study, I will discuss first each individual case, and then compare and contrast the four cases in a cross-case analysis. In doing so, I aim to provide a rich, realistic, and detailed explanation of factors underlying students' decision-making as it relates to institutional contexts and supports as well as student variables. In the site-by-site description below, I start with the smallest institution and work my way towards the largest institution in the state.

\section{University of Olympia}

University of Olympia (UO) founded in 1954 is a private, liberal arts institution that is part of the 450-year history of Catholic higher education. It is the smallest institution examined. The athletic training program, however, had a healthy student enrollment of 14 seniors, 10 juniors, and 12 sophomores formally admitted into the professional phase. UO has offered a 
CAATE accredited program since 2010. UO is located in northern West Virginia, in the city of Olympia. UO's athletic training program is the most recently developed educational program examined in this research. Information from its athletic training program was collected in February 2017.

The University of Olympia utilizes Problem-Based Learning in the athletic training curriculum. UO also offers other healthcare professional programs in respiratory therapy, nursing, psychology and physical therapy. Interprofessional education (IPE) has also newly been introduced into the athletic training curriculum. Senior athletic training students were grouped together with other students representing each academic program to complete a joint capstone scenario project. Each student group was mentored by a UO faculty member (Interview, Jeff Holmes, February 10, 2017).

From a programmatic standpoint, the program at UO appeared very focused on maintaining compliance with CAATE Standard 11, which requires a minimum of a three-year aggregate first-time BOC exam pass rate of $70 \%$. Jeff Holmes, the institutional representative interviewed, stressed the importance of maintaining that standard and teaching students the necessary knowledge to become an Athletic Trainer upon graduation:

I guess from a selfish standpoint it's going to be... the passing rate... that's always going to be first and foremost in your mind because you're always worried about that 70 percent... Basically, it's just am I teaching these kids what they need to know so they can go function and work as an athletic trainer. (Interview, Jeff Holmes, February 10, 2017) The program further committed to maintaining Standard 11 by annually fund-raising dollars to pay for a student's first attempt to challenge the BOC examination. While the program provided financial assistance for initial examination fees to seniors, it had to balance that as to not result in 
negative effects as well. The program encouraged all seniors to pursue BOC certification but did not want students only to sit for the exam because it was to no cost to them on the first attempt. Mr. Holmes and others stressed to students that their level of commitment to the examination should mirror that of the program. (Interview, Jeff Holmes, February 10, 2017)

Program space. UO's athletic training program has dedicated, didactic and clinical classroom space. The faculty office suite provided ample workspace for the program's three faculty members. In the office suite, there was also ample space for interaction among faculty and students. Space was available for one-on-one interaction or small group interaction for educational opportunities, meetings or casual daily interaction.

University of Olympia provided access to one clinical education site on campus. The athletic training facility is primarily used to provide athletic training services to the student athletes of UO. The facility is a traditional, small athletic training facility. This clinical site is equipped with two private office areas, a treatment area, a taping area and a wet room (Observation, February 9, 2017). An adjacent hallway is utilized as additional space for functional activities and some rehabilitation activities (Observation, February 9, 2017).

The athletic training facility was busy with activity while the researcher was present. Multiple clinical preceptors were available to numerous athletic training students of all levels, freshman through senior. Students present appeared to be familiar, relaxed and comfortable with the function and processes of athletic training facility. Some athletic training students were engaged in working with student-athletes on the athlete's rehabilitation/treatment plan, pre athletic practice preparation, student-preceptor conversation, and facility record keeping maintenance. Other athletic training students were involved with student-student conversation, personal cell phone/laptop usage or reading a book (Observation, February 9, 2017). 
Three soon to be graduating senior athletic training students, two male and one female, participated in private, face-to-face interviews with the researcher. The emerging themes that arose from student interviews were attractors to athletic training, factors in selecting a college/university to attend, pros of an athletic training program, cons of an athletic training program, initial impressions of an athletic training environment, and challenges present in the athletic training field.

Attractors. Students reported a strong affinity to athletics either through a love of sports or participation in sport personally. Participants described their path to athletic training in this manner:

...I wanted to do physical therapy. And then, athletic training is about sports and I really love sports. So, I was, like, “that's better!” (Interview, Eric, February 9, 2017) ...I have been an athlete since I was about 10 . So, I've always grew up around sports... (Interview, Paige, February 9, 2017)

As discussed previously in the Conceptual Framework, students entering college are transitioning from Erikson's stage five, Identity versus Identity Confusion to stage six, Intimacy versus Isolation. Often during Identity versus Identity Confusion, the individual can be constantly seeking how to mesh the roles and skills planted earlier with the ideal of the day (Erikson, 1968). Through their development in stage five of a sense of self and personal values, these students have determined that sport or athletics is part of their identity. By finding athletic training as a potential career choice, these students have found a way to mesh the two aspects together.

The students noted that past exposure to an athletic trainer as well as a desire to care for or help others drew them to athletic training: 
She [Mary, an Athletic Trainer] took care of my tendonitis and deltoid, shoulder, bicep, and elbow...I found it interesting how well she knew the human body even though she wasn't a 'doctor'. I had known very little bit about the profession before I met her and she opened my eyes a bit more to it. This wasn't at the point that I decided to do it but it stuck a little. I don't know, a stinger in me. (Interview, Tony, February 9, 2017) So, I think when I started thinking about being an athletic trainer because it was like the best of both worlds where I care for people and interact with them and I could be around sports also...I never really interacted with my athletic trainer that much in high school probably, like once but I got like a scratch or something. But I think it was definitely like a good combo of both medical and sport. (Interview, Paige, February 9, 2017)

Holland's theory of personality type can help to understand how these students were attracted to Athletic Training. Athletic training fits within the social environment model. This social environment draws individuals that desire to be helpful, friendly and trustworthy. Social personalities, known as "The Helpers", possess the following personal characteristics: friendly, helpful, outgoing, cooperative, patient, empathetic and kind. "The Helpers" also like to work in groups, help with problems, provide service to others, or plan and supervise activities (Western Reserve, 2011). Athletic training as a career choice allows individuals to assist and provide service to others within a team environment.

Selection factors. Participating students were from three different states, West Virginia, Ohio, and Maryland. Their hometown locations ranged from two hours driving distance to fiveand-a-half hours away from the University of Olympia. The following factors influenced students' decisions in selecting a college/university to attend: the affordability, size, proximity to home, community/welcoming spirit of the institution, and demographics of the school were 
more important to students than the reputation of the Athletic Training program. In other words, the choice of college was primary for these students, and the choice of major was secondary. As the cost of higher education continues to rise, affordability is often a component of the college decision-making process. This characteristic did not escape the students of UO as an important factor in college choice:

I got an athletic scholarship so that's definitely a big help! But I got the academic and a volleyball scholarship. So, that definitely helped the cause (laughs). (Interview, Paige, February 9, 2017)

Yes, before I came here I was a student at the University of the Rylands. Then, once I got my financial aid back I was like, "this Catholic school doesn't sound that bad" (laughs). (Interview, Eric, February 9, 2017)

Appalachian cultural influences on youth, as we have learned from the research of Russ (2006) and Ferry (2006), creates a strong commitment to family and community. This sense of commitment was reflected in the desire to stay somewhat close to home and family as an important factor guiding students' college choice decisions. The students also desired a welcoming sense of community and family feel as important factors influencing their college choices:

It was kind of close to home but at the same time far away, so I got like a little college experience. And at the time Jeff and Terri, they were very considerate and down to Earth. They came with open arms and it was really cool because, you know, little freshman not knowing anyone at the school. It's kind of nerve racking but they were always there. (Interview, Eric, February 9, 2017) 
I'm from kind of a small hometown. ...And this definitely has a small town feel, small campus. Everyone knows everyone...I met with Terri on my initial visit when I was here and she was so nice and so welcoming... And then my coach was, 'they're like family' and they were so nice. And I think that family, close hometown feel definitely drew me to the University of Olympia. (Interview, Paige, February 9, 2017)

Not only does Appalachian culture influence a student's decision on college choice as seen in symbolic interactionism, students are carrying defined aspects of their past lived experiences with them as they make these individual decisions that are of value to them (Blumer, 1969). Students connect with the small size and closeness of the community present at the University of Olympia and have included those components into their college choice.

Initial impression of the athletic training environment. The athletic training arena at the University of Olympia can initially be intimidating for some students and especially young high school graduates entering college as they navigate an entirely new environment and surroundings. Soon-to-be graduates recounted their initial impressions of the athletic training environment as chaotic, "Very fast paced. Extremely fast paced. A lot going on" (Interview, Tony, February 9, 2017) and stressful, "At first, for me it was nerve-wracking because it was a whole new experience I never really discovered" (Interview, Eric, February 9, 2017). Entering students often assumed the role of observer:

As a freshman, you have to do a couple hours just, like, get out on the field. I just like stood there in the corner and didn't talk to anyone 'cause I didn't know what to do. I couldn't really help either. (Interview, Paige, February 9, 2017)

However, students gained greater confidence in clinical skill sets, which ranged from a selfreported 5 (above average) to 5.5 (between above average and very confident) and comfort with 
the new environment through clinical preceptor support, community support, and classroom learning as they matriculated through the program. An initially intimidating environment became a fun and enjoyable one while also maintaining a professional, serious atmosphere.

They [preceptors] helped out a lot and now I love the atmosphere especially the people here. The athletes are really nice and chill. They like to joke around. I mean, sometimes you have to take it serious but at the same time you can goof around a little bit, make a couple friends. And then, my clinical skills have greatly improved because of the preceptors' help and classwork. (Interview, Eric, February 9, 2017) ...definitely senior year I'm so much more confident. I feel comfortable going up to patients I don't know asking them like what their injury is, what sport they play. I feel comfortable talking to preceptors about, if even if it's like a preset that I forgot... And I feel like at practice say if someone gets injured and you run out in the field. I was timid at first but now I'm just like zooming towards them. So, definitely confidence level has skyrocketed since freshman year. I think I'm definitely more comfortable with everyone in the athletic training room. (Interview, Paige, February 9, 2017)

As students became oriented to their new environment and acquired new vocational skills by learning athletic training specific skills, it is clear they felt more at ease and relaxed within the athletic training environment. This involves a better pairing of personality and environment as outlined by Holland (1997).

Pros of the athletic training major. Interviewed students cited many pros of the athletic training program. Positive aspects of the athletic training program ranged from exposure to a variety of clinical experiences/settings, meaningful relationships with peers/faculty/athletes, 
faculty/preceptors creating positive, fair, and challenging learning experiences, travel experience, and gaining skills for all of life.

Tony, a soon-to-be graduate from Maryland and one of nine children, appreciated the close-knit group of his senior class and the variety of clinical experiences he was exposed to through the clinical education rotations:

[I] enjoyed, I must say, my classmates... seeing how much my class gels together. I think that's a good word for it. It's amazing how close as a class we've gotten, we've become. That's one of the things that I enjoyed the most. I enjoy the clinical aspect... the clinical setting, I really like downstairs. When I've had to do my gen med rotations, my rotations at the hospital.... I love that. I absolutely love that. It showed me a total different aspect. (Interview, February 9, 2017)

Eric spoke positively of the life skills he has gained by completing the program in addition to the opportunity of travel experiences that give him a broader view and insight of how things can be done differently in athletic training facilities:

Helped me a lot with my personal skills, my people skills because, especially being on a small campus here there's a good bit of people here who are athletes. So, you get to know them. So, this is definitely not a profession if you don't talk to anyone because you' re kind of forced to talk to everyone... I got to travel a couple of times, which was really cool because I got to see what other athletic training rooms look like. (Interview, February 9, 2017)

A sense of fairness in the academic program and classes was also expressed as a positive component of UO. Students were able to connect classroom content and information and learning assessment methods in a way that they feel is reasonable and appropriate: 
I think they do a very good job of teaching all aspects of athletic training, really hitting every single subject and fair grades. I think it's very important in college if you're teaching one thing and your tests are on something completely different. What are you really getting out of it? You know what I mean? So, I think they do a good job of correlating teaching and test taking in fair grades. I think they do a really good job with that. (Interview, Paige, February 9, 2017)

Overall, students of OU appeared to be satisfied with their choice of academic major and the program. The soon-to-be-graduating seniors expressed contentment with the educational content and design of the curriculum, the manner in which they were treated by faculty, preceptors and peers, and how the experience assisted with individual personal growth outside of the context of Athletic Training. The nature of the students' lived experiences, social relationship development and effect these have on the students overall individual development is reflective of symbolic interactionism (Blumer, 1969). Students additionally gained an appreciation of how they were treated and interacted with others related to the program as they continued to mature themselves developing a stronger sense of personal and professional identity and aspects of that they want to include in their future lives. This can be related to Erikson's theory and the transition between stages (Erikson, 1968).

Cons of the athletic training major. While soon-to-be graduates expressed content with the program requirements, this did not occur without concern, adjustment or sacrifice to some degree. As mentioned, travel experience was stated as a positive of the program. However, lack of the same or similar travel experience was noted as a con, along with the clinical hours requirement, burnout potential, and time management: 
I wanted to travel with volleyball but the trainer wasn't as open for me doing that... Hopefully, this spring semester I'll be able to travel with the baseball trainer, which I think will be a very unique experience. Because as a junior last year, I couldn't travel with wrestling but, hopefully... But I hope that I can this semester a little bit. (Interview, Tony, February 9, 2017)

Although lack of travel experiences rose as a con, the more concerning cons in the students' eyes revolved around time management and the clinical hours' demand:

Sometimes the amount of hours that we need to get... Especially when I've worked with the volleyball team and I work four hours a day five days a week. It's not that much. But you couple that on top with work and a few other things and studying and it adds up. (Interview, Tony, February 9, 2017)

And then the hours (pause). The hours are kind of, hmm, not really coordinated because one-time practice might be at six in the morning and then the next one. So, you can't really make plans. I can see why athletic training kind of has, like, a burnout because of hours especially with the pay. But as a young kid, I want to go out and travel. So, doesn't really bother me yet... It's definitely hard. I feel like it's one of the harder majors on campus because you do have clinical hours along with your classwork. (Interview, Eric, February 9, 2017)

One interesting point to note regarding the cited cons of the AT program is that travel experiences and time management and the clinical hours' demand could all be contradictory to some. Travel experiences would pose a greater demand on the students' time management ability. Additional time away from campus and other normal daily activities would necessitate the student to prepare and plan more efficiently to be able to keep up with their academic 
requirements and demands of life. It appears that students may value the variation of the experience and exposure to new or different things that may be inherent in a travel experience more than the repetition of what they have already been exposed to and experienced.

Students' impressions of challenges of the field. As the senior athletic training students approach a nearing graduation date, they are acutely aware of challenges facing athletic training presently. This group of seniors made reference to a lack of understanding by those outside of athletic training as to what the job entails. Students have been witness and experienced an underappreciation and lack of recognition for work performed by athletic trainers. Students expressed frustration of the misconception of 'trainer' - personal trainer versus athletic trainer. Lastly, participants recognized lower compensation for athletic trainers as compared to other similar professions.

Paige's passion and respect for the profession of athletic training and those that do the job was evident as she described her impression of challenges facing athletic training presently:

I think athletic trainers are not as, maybe not respected as they should be. But I think they work so incredibly hard. I think they know so much about athletes and injuries that people don't actually realize. And they spend all of their day worrying about athletes and working overtime and they just don't get their respect and pay that they should... So, I think that athletic trainers should be more recognized as a health profession... Like, you work a ton but I don't think that you get... not that it's not rewarding to be. I think it's very rewarding to be an athletic trainer... seeing your athlete be successful. I think like pay-wise it's not very; it doesn't give the most motivation. (Interview, February 9, 2017) 
Despite past and continuing efforts of the NATA to educate, the public on what athletic training is and the differences between personal training and athletic training, challenges are still ever-present:

[Athletic training is] not getting the credit it deserves. Like I said earlier, I feel like athletic training is very important to rehabilitation because you're the first one there and then you finish off with the athlete. So, you know what happens. Physical therapists don't know what happens, doctors don't know. They're not on the field but you're the first responder. But, at the same time, I feel like we're kind of, not really mocked. We are just not getting the credit we're deserved. And a lot of people still think that we're personal trainers. So, that's kind of irritating. (Interview, Eric, February 9, 2017)

Acute awareness of the burnout rate in athletic training was not overlooked by Tony. He listed burnout as the number one challenge faced by athletic trainers at the present time and added this summary as his perception, "Not enough athletic trainers to cover all the sports. The profession as a whole is getting overworked, underpaid" (Interview, February 9, 2017).

All three soon-to-be-graduates interviewed planned to persist in athletic training to some degree although that varied from student to student. Eric expressed the strongest desire to persist in athletic training as he intended to pursue a master's in athletic training or education. He stated that possibly using a degree in education might allow him to be employed in athletic training education at a college in the future or as his plan B should he experience burnout later in his athletic training career (Interview, Eric, February 9, 2017). Paige's initial plans were to work in athletic training for a couple of years while completing any remaining admission pre-requisites to Physician Assistant (PA) School and pursuing graduate education in that field to become a PA (Interview, Paige, February 9, 2017). Although Tony expressed an intention of working in 
athletic training, it was only initially on a part-time basis. Tony planned to pursue employment in the area of emergency medical services by working two different EMS jobs and then hoped to also be able to work as an AT on a part-time basis at a local high school. Tony's largest concern was creating financial stability for himself and felt that he could do that quicker with being employed in EMS than as an AT (Interview, Tony, February 9, 2017).

In interviewing the institutional representative of UO, Jeff Holmes, he expressed concern of the job outlook for graduating seniors in the local area and region. Jeff reported limited employment opportunity with those jobs being located in a small number of regional high schools, limited clinical AT positions, and very limited professional team opportunities. Employment within the college setting afforded the greatest opportunity in the area with three different colleges within an hour of each other (Interview, Jeff Holmes, February 10, 2017).

In taking a historical view of the program, the three soon-to-be-graduates appear to be representative of past graduates in their plans. One-third of program graduates persisted in athletic training, forty-one percent pursued physical therapy school and the remaining graduates pursued career options in a variety of areas including, physician assistant school, prosthetics, occupational therapy, medical sales, medical school, and chiropractic school. In 23 years of working in the profession of athletic training and with athletic training students, Jeff has been witness to what he feels are numerous factors that influence new program graduates on their career paths. Specifically, he discussed factors ranging from limited AT job availability in a specific region/location, or even in a particular AT setting, coupled with a desire to return home after college with this especially being true for graduates from West Virginia, a desire to earn a higher salary. Some graduates that persist find a true love for AT while completing the program and just wanting to do it (Interview, Jeff Holmes, February 10, 2017). 
As an athletic training educator and one with experience in the field, Mr. Holmes acknowledged different challenges facing athletic training today. Jeff's concerns regarding the future of athletic training centered around the transition to the entry-level master's requirement by CAATE and the impact that will have in terms of lost jobs for other educators, as some schools may find it necessary not to make the degree transition and eliminate programs. Although from a programmatic standpoint, work-life balance and family was modeled for athletic training students by multiple preceptors, Jeff remained concerned over students' perceptions of that balance and their own self-efficacy in their ability to achieve it. Like the students though, Jeff also expressed concerns over compensation for athletic trainers that leads to displacement or attrition from the profession.

In connecting the three soon-to-be graduates and their initial career decisions regarding athletic training to the theories of Erikson (1968) and Holland (1997), it appears that the students are active in the transition from Erikson stage five to stage six and they are also continuing to seek a better match to their personality type and vocational environment. The application of both theories together provides a greater understanding of where students are in the process of individual development, career exploration and career choice. The students have begun to align realized characteristics of their personality with career choice while they are still defining their personal identities into adulthood.

\section{Kennedy University}

Kennedy University (KU) is another small, private, liberal arts institution with a history of past religious affiliation. It has remained independent for the last 76 years. Kennedy University was originally founded in 1888 and has offered students an accredited athletic training program since October of 1997 (CAATE, 2016). KU also offers degree programs in 
nursing, radiologic technology occupational therapy assistant, health promotion, movement science, radiologic science, and physician assistant. Kennedy University's metropolitan area spans three counties and has a population of 240,000. Information from its athletic training program was collected in March of 2017.

Program space. Kennedy University's athletic training program includes a faculty office suite of three offices with an adjacent clinical athletic training classroom that is used for small didactic or laboratory athletic training classes. The program faculty and students also have access to a nearby conference room that can be utilized for faculty-to-faculty or faculty-to-student interaction. The program is housed within the School of Health Sciences, which also affords the program access to a nearby health science assessment laboratory.

The researcher was granted access to observe one clinical education site on the campus of $\mathrm{KU}$. The athletic training clinical facility is primarily used to provide athletic training services to the student athletes of $\mathrm{KU}$ and is located in their primary athletic building. The facility is a medium sized athletic training facility. This clinical site is equipped with three private office areas, a treatment area, a taping area, a storage area and a wet room (Observation, March 1, 2017).

The athletic training facility was busy with patient treatments and evaluation while the researcher was present. Three clinical preceptors were available to numerous athletic training students of varying levels in the program. KU offers a very structured clinical experience for students enrolled in the athletic training program. Students reported to their clinical assignments appropriately dressed as per the program uniform policy. There was no cell phone usage by students or athletes present as per the athletic training facility rules. Students were constantly engaged in patient care or activities of facility operation during the time the researcher was 
present for observation of the clinical education component of the program. Students were comfortable approaching the preceptors to practice or review athletic training skills if they were not engaged in other activity. It was apparent that there was very little down time for the students present (Observation, March 1, 2017). The program of Kennedy University stresses the quality of clinical education and hours over the quantity (Interview, Dallas Moore, March 1, 2017).

Four soon-to-be graduating senior athletic training students, one male and three female, participated in private, face-to-face interviews with the researcher. The emerging themes that arose from student interviews were: attractors to athletic training, factors in selecting a college/university to attend, pros of an athletic training program, cons of an athletic training program, initial impression of the athletic training environment, and students' impressions of challenges present in the athletic training field.

Attractors. Students at KU reported personal past experience in athletics and at least limited previous exposure to an AT through those experiences. All four students also had interests in healthcare upon entrance to college ranging from nursing, physical therapy and athletic training. Students also expressed a continued desire to be involved in sports or a team environment. Interviewed students shared with the researcher their experience with athletic training prior to attending college and their own path to find athletic training as a field of study. Students explained their experience as:

My freshman year I did play college basketball... I actually got to work with Tom [Athletic Trainer] some before I came here. I had like a partially torn meniscus... And Tom kind of explained it to me like what was going on. And it was coming from there that I took interest and started the typical athlete research. (laughter) I started doing that and started realizing how in-depth things are and just like that it would probably fit me 
more because I always wanted to be around an athletic population... I was studying biology at the time and I wanted to go to PT school. (Interview, Michael, March 1, 2017) My official name was a water girl. But I worked with the football team at Rich Creek High School for all four years of my high school career. There was the EMT obviously that was supervising. He kind of introduced me to athletic training and told me about it and got me interested in it. Unfortunately, my first year, I went to a different college...to do nursing. And then I still wanted to do athletic training. So I said, "Let's not do this. Let's not do this." So, I transferred here after that to do athletic training. (Interview, Abbey, March 1, 2017)

... I went to a vocational high school so it was like a trade school and athletic training was actually a major that you could take there. I didn't take it. I guess, I didn't know that's what I wanted to do at the time. But I wish I did. There was a lot of background knowledge that could help me. But we had an athletic trainer that would teach that class throughout the day and then we had an athletic trainer that would work on the sports... It was nice we got a touch of all of it. (Interview, Lexi, March 1, 2017)

One unique component to the program at KU was that it appears from the students that were interviewed, KU's program consisted of more students moving from other fields of study to AT. Of the four participating students, two had originally started their college studies in biology and one had begun in nursing. Of those three students, two had transferred to KU from other institutions. Only one student, Lexi, had initially started college as an AT degree-seeking student. By examining Erikson's psychosocial theory of development and the movement from stage five to stage six, individuals are constantly seeking how to intertwine roles and abilities acquired in one stage into the next (Erikson, 1968). Lexi seemed to have a more direct path to 
Athletic Training than the other interviewed students. This could be attributed to her experience at a vocational high school as opposed to the others whose high school careers were more traditional in nature thus creating a slight delay in students finding their best-suited academic field of study. Blumer's symbolic interactionism could also be employed in Lexi's case, specifically (1969). Lexi had the unique experience of attending a vocational high school as opposed to her peers. This experience gave her a better opportunity to inform her decisions on career choice by having an opportunity for greater career exploration prior to entering college. This opportunity also allowed Lexi an earlier insight into the social norms of an athletic training environment for more efficient assimilation.

All four students from KU expressed a path to Athletic Training through an initial interest in a healthcare field, i.e. athletic training, nursing or physical therapy. In Holland's theory of personality type, the social personality characteristics include: friendly, helpful, outgoing, cooperative, patient, empathetic and kind. Those in healthcare fields also value these characteristics. Social personalities like to work in groups and provide service to others (Western Reserve, 2011). Athletic training is a social environment and attracts social personalities. The application of both Erikson's and Holland's theories in this case can help to understand the attraction of Athletic Training as a career choice. Athletic training allowed the students of KU to mesh aspects of their identity and personality with a career path.

Selection factors. Students interviewed originated from hometowns as close as 20 minutes from Kennedy University to as far away as 7 hours 20 minutes. Three of the students were from West Virginia, while one was from Delaware. Three of the four students reported matriculating through the program through a fast track option, transferring into the program from another major/institution or graduating in three versus four years with their undergraduate 
degrees. The fast track option permitted students to complete two years of the program in essentially one year by 'doubling' up coursework requirements to some degree. Factors that affected the students' choice to attend this institution included proximity to home, financial aid packaging, recruitment by the institution (athletics/program), school/class size, and the reputation of the Kennedy University.

A desire to attend a college that is close to home appears to be inherent in the students from Appalachia. All three students from West Virginia selected Kennedy University due to in part to its proximity to their home. This is consistent with the research conducted by Russ (2006) and Ferry (2006). Appalachian culture creates a strong commitment to family and community. These students elected to remain close (20 minutes to one hour) to their families while attending college. Conversely, the one student from Delaware was more comfortable with being a greater distance (7 hours 20 minutes) away from home while attending college.

Cori grew up in the small town of Leeville, West Virginia. Therefore, a school that was affordable, close to home and of a small size was essential for the comfort of both she and her family, as she states:

[What aspects specifically of Kennedy University helped you choose to come to college at KU?] The financial resources and being recruited for sports. And close to home... I am on the track team... Part of why I chose KU is because of the size... I came from a very small high school and I had a lot of small classes and I knew that I needed to speak one on one with some of my professors if I ever had a struggle and I wanted to make sure that in my college education I would be able to do that with my professors. (Interview, Cori, March 1, 2017)

Distance from home and size of institution were also very important factors to Michael: 
The proximity to home [was important]. I'm from about an hour away here. So, that was big. The professor to student ratio was also very [important], because it was 14:1, I think... I would get more one on one time and I felt that I could really where I was weak I could find one of the clinicians that were maybe strong in that area and spend time with them and learn from them and try to help strengthen my weak spots with some more, the one on one interaction... Its [cost] was one of the reasons to not come (laughter). I'll be honest but when I spoke with admissions, they did show that... "OK, maybe it might be a little more doable"... (Interview, March 1, 2017)

Like Cori, Lexi also appreciated the availability of financial aid resources at KU in addition to selecting a quality institution to attend. Her father, who did not attend college himself, impressed the importance of education on his three children and actually chose this institution for his daughter based on his own research. He got her started early, with a foot in the door, by having her attend soccer camps while she was still in high school:

... My dad is like a big education person. He didn't go to college but he's making sure that we... All three of us had to get at least a bachelor's. So, his biggest thing was education... it had to be a good school. So, he did all his research. So, I went and started different camps for soccer... So, I just got lucky and the coach here was the one that contacted me... and then my dad already knew this was a good educational school. He had done his homework. So, he was like 'yep, that's it. We want it'... It was pretty expensive. That was one thing we were scared about. But, A - my soccer scholarship helped a lot. I got some academic money. (Interview, Lexi, March 1, 2017) The previous Program Director took a very active role in recruiting students to come to KU and pursue Athletic Training. By taking the time to develop a rapport and connection with 
Abbey and Michael, she was able to convince them that KU and Athletic Training were the right choice:

She [Dr. Smith] took a lot of initiative to get me here. I mean she called me on a weekly basis making sure everything was taken care of... I called and talked with her. I met with her. I was still on the verge about it because the tuition is so expensive. I said, "I don't even know if I want to go into debt." She's like, "It'll be worth it." And she really, she really pushed me and helped me out a lot with it. (Interview, Abbey, March 1, 2017) ... I was in the position that I was going to transfer... to this campus... And so, I went and came here and visited Kennedy University with Dr. Smith. And she, kind of just, pretty much sold me on it from my very first meeting... And she talked about how the acceptance into grad school was $100 \%$ and the first time pass rate on the BOC was exceptional. And she just pretty much like sold the profession. She didn't really sell any point except that it's, it can be fun. (Interview, Michael, March 1, 2017)

As shown in the data above, the experiences of Cori, Abbey, and Michael were similar in that they emphasized proximity to home as a factor in their decision making process. All four students, Cori, Abbey, Michael and Lexi appreciated a quality education with personalized attention, with only two of the four students mentioning the Athletic Training program having a role in their decision to attend the university. All the various aspects of selection: proximity to home, financial aid packaging, recruitment by the institution (athletics/program), school/class size, and the reputation of the Kennedy University were affected by students' past experiences. Students assigned meaning to different aspects of those experiences to determine college and program choice. The aspects that students valued most had the greatest impact on college choice (Blumer, 1969). 
Initial impression of the athletic training environment. Each student at KU explained how their perception and initial impression of athletic training changed as they progressed through the program and continued to learn and experience more. Michael admitted falling prey to misconceptions around athletic training. He explained it in this way:

I just viewed it as all the misconceptions, all the wrong things. They're not just there to get the ice and water. Oh, and if there's an injury there, you know, you better to take care of it and they might know a lot. But they're probably, pretty much going to tell you, refer to someone else. And, I think, that was something that I, is misconstrued by society and that 'T' [trainer] word kind of gets in there and gives people the wrong impression. (Interview, Michael, March 1, 2017)

Cori and Abbey expressed similar impressions, such as, "I really just thought that an athletic trainer would work in a high school or college as an ankle taper or water bottle filler" (Interview, Cori, March 1, 2017), or “....as what everybody else sees it as. Somebody that stands on the sideline and is there for immediate medical assistance" (Interview, Abbey, March 1, 2017).

Students gained a greater appreciation and understanding of athletic training and the skill set required as they progressed through the program. Cori acknowledged, "I didn't understand they had a background in medicine and just everything, everything in athletic training” (Interview, March 1, 2017). Other students provided more detail as to what athletic training can involve, for example:

But I think now that I'm in it. It's, you know, a whole lot of things and you got to know more than just the brush of it because it can be more serious. And like heat illnesses you can see someone is having troubles in the heat but do you know the implications of what could happen if they continue? And so I guess, now you've got to be like a weather man. 
You have to be like a coach. You have to be like a psychologist. You kind of, all these different avenues thrown into one. And you're just a mix of everything... And also the rehabilitation process, I don't think a lot of people understand that athletic trainers are able to perform rehab and they know just as much as a PT. I would argue they know quite a few things just like a PT does. (Interview, Michael, March 1, 2017)

Abbey had some similar perceptions to Michael about how she grew in understanding of the professional aspects of the AT profession:

I knew they did rehab but once I started learning into it I've seen on the NATA website all the jobs that's opening, like, concussion stuff; you can work with the hockey teams doing that stuff. There's just so many opportunities with athletic training. And I now know that there is prevention...there's so many aspects that actually go into it. It's more of, it's a harder curriculum than what most people see it as. And a lot of people don't really understand how intense it gets. (laughter) It's intense. (Interview, Abbey, March 1, 2017)

While, overall, students admitted possessing self-confidence (5.5 to 6 - 5 Above average to 6 Very confident) in their own skill set in their final semester of academic work, one student admitted that confidence was an area in need of improvement. She rated her confidence as 4.5 (4 Confident to 5 Above average) due to the anxiety surrounding preparing for her BOC examination:

It is kind of, like where I am studying for boards right now... As a clinician whenever I'm working with athletes, I feel like my intelligence is so much higher (laughs). I can explain things and I know so much more than I realize that I know. But whenever I'm taking these practice tests, though, I feel so subpar (laughter). That's why I ranked it a 4.5. I 
have a basic understanding, like, entry-level athletic trainer. I got that. But as a professional and developing myself over the next few years, there's room for improvement. (Interview, Cori, March 1, 2017)

Abbey also expressed that BOC preparation anxiety had an impact on her confidence level to some degree, although she rated her confidence as a 6 Very Confident.

I feel prepared to be on my own. It's the BOC that's really (laughter). I feel prepared for the BOC because all the questions we're doing. But I still, that little nervous, nerveracking thing in here (points to head). I feel very prepared to be an athletic trainer. (Interview, March 1, 2017)

As one can see, the students positively gained a greater understanding of athletic training, what is specifically involved in being and becoming an athletic trainer through the program at KU. While students possess confidence in their own athletic training skill set, knowledge and decision making ability, this confidence is not entirely without some apprehensiveness in fulfilling all the requirements to become an athletic trainer by successfully obtaining the BOC credential.

Pros of the athletic training major. Interviewed students discussed numerous pros of the athletic training program. The positive aspects of the athletic training program ranged from exposure to a variety of clinical experiences/settings, meaningful relationships with peers/faculty/athletes, faculty/preceptor involvement attention, travel experience, hands on and balance of clinical requirements and life. Students appeared to be satisfied with their choice of academic major, the program and preparation for future pursuits.

While all students appreciated the variety of clinical experiences afforded to them in the clinical education component of KU's program, Michael and Cori expressed the greatest 
appreciation. Michael values this variety as the exposure to different settings allows him to be introduced to different areas of athletic training. This exposure helps him to determine which ones he may be better suited for or which settings he may wish to pursue in the future.

It's just a wide variety of opportunities that kind of I feel like I'm able to just seeOK, what options do I want; I'm not feeling this, OK, maybe something else. And just really explore and get kind of get that feeling before you have to job search. (Interview, Michael, March 1, 2017)

Cori has enjoyed the availability of the numerous off campus, healthcare resources in the greater Waterford metropolitan area to the students of Kennedy University as well as the traditional, athletic setting resources:

I've had rotations at hospitals, PT clinics, high schools, doctor's offices. In the hospitals, I've worked in the PT clinic and I've also observed surgeries. It's just a very well rounded, like, general medical introduction. So, that's what I most enjoyed. And I got to cover any and every kind of sport except for soccer. (Interview, Cori, March 1, 2017)

The opportunity to see and experience athletic training or realize the application of an athletic training skill set across various settings allows students to explore different matches of personality type and environment as described by Holland (1997). By witnessing through personal involvement or observation, students are afforded the opportunity to visual themselves in different work settings to determine which one they may be best suited.

Michael, who grew up in Ohio and Joy Ridge, West Virginia, enjoyed the reciprocal nature of empathy with his classmates and the close relationships developed through shared experiences: 
I'd say that everyone is kind of pretty close... They're the friends that you have here. They're with you and they struggle through the same things you struggle with. And so you can form relationships through that... (Interview, Michael, March 1, 2017)

The fostering of relationships and attention to the whole student by preceptors and faculty made Michael feel included and he even described it as a family experience:

And you don't ever feel like you're secluded whether it's in the morning clinics or whether your practice or during games. They [preceptors] make sure you have a job. Make sure that you feel important. And there's numerous times that the faculty will make sure that we're up with our grades, make sure that we're doing our homework, make sure that everything at home is all right, and any of the primary educators or any of the athletic trainers or anyone. If you have been struggling with something, something personal, you need someone to talk to, they make it clear that you can come and talk to us and it's an open door that they're always there. So, it's kind of like a family experience. (Interview, Michael, March 1, 2017)

Social personality types as described by Holland (1997) seek involvement in close relationships. The closeness of the relationships developed by those in the athletic training program of KU is apparent in the description of Michael's experience.

Active student engagement during clinical education noted during the researcher observation is also an important component to students. Students are thankful and enjoy the hands-on nature of the program where they are able to put content knowledge from the classroom into practice, or relate the two aspects together:

This year has been the most exciting for me because it's my senior year, my last year, and I'm able to do different things like the rotations... It's kind of more valuable to me now 
where I'm having rehab and stuff. Now, I'm able to actually do stuff on my own with little supervision. I can make my rehab plans. I can do everything and then $\mathrm{OK}$ it with everybody. (Interview, Abbey, March 1, 2017)

Lexi acknowledged that this enhances her learning, "I'd rather go for a 12-hour day of clinicals than a two-hour class. I learn better in that atmosphere" (Interview, March 1, 2017).

Kennedy University also appears to respect other demands, such as athletics, outside employment, etc., on a student's time outside of clinical and academic requirements. Students feel that they are able to find a balance of clinical requirements and life.

...the staff, program director, clinical coordinator, everybody is really accommodating. Like I said, I work. So, I am doing school and work. So, they help and they know that I work and understand I that I have to put work around school if that makes sense instead of school around work. (Interview, Abbey, March 1, 2017)

Travel experiences allow students to witness the entire process of athletic training event coverage, including home and away contests. Michael appreciated being about to see a broader view of athletic training, 'It kind of gives you all the ins and outs and see what life is really like. And it's fun" (Interview, March 1, 2017). Lexi took away another positive aspect to travel, "It was it was cool to see how different it was set up" (Interview, March 1, 2017).

Kennedy University's athletic training program appears to attempt to develop and support the whole individual. Athletic training education is the main focus of the program as Dallas Moore, institutional representative, explains his goal in education of athletic training students this way, "helping athletic training students become better athletic trainers than I was" (Interview, Dallas Moore, March 1, 2017). The program also sees its responsibility as being able to "expose students to a wide variety of opportunities. Meaning, you know, different preceptors, 
different locations, different philosophies" (Interview, Dallas Moore, March 1, 2017). The focus on more than a single context or view of athletic training also resonates through the perceptions and feelings of the students as illustrated in student excerpts. Even with a primary focus on athletic training education, a broader view of the individual as a person with responsibility and demands outside of that education is apparent in KU's program through the cited balance of academics and life. This balance can also link back to the focus on quality versus quantity of student clinical hours and making the most effective use of that time with the student.

Cons of the athletic training major. Soon-to-be graduates expressed one main con to the Athletic Training major. The students' concern revolved around their own time management skills, even though the balance of clinical requirements and life was cited as a pro. The time management challenges appear to be a greater challenge of the students electing to fast track through the program. An additional con was expressed pertaining to the broader context of the general education requirements of the institution.

Upon initial entrance into the program as a freshman, Michael saw time management as one of his greatest challenges.

I found that to be really difficult. Doing so many clinical hours a week and then going and trying to study and then trying to have a personal life. Starting out as a freshman, it, kind of, was difficult. (Interview, March 1, 2017)

Although as he became more comfortable with the requirements, his time management skills improved and he found it easier to balance, "But the more I progressed, the more I learned how to do it and the more I found out I was successful” (Interview, Michael, March 1, 2017).

Fast-tracking, or the opportunity to complete academic and clinical requirements within a shortened academic time frame from the traditional path, however, seems to again stress a 
student's time management skills. Michael, Lexi and Abbey were all completing the program requirements through the fast-track option. Each expressed the challenge of keeping up with the demands of selecting that option:

But I also found that in this last year was because I'm putting two into one, two years into one, kind of, this year. And so it's kind of a lot more of the time management you have to go to different, two clinical rotations at once and which is that in itself is awesome because you're able to see two different experiences and go to them and expand your network kind of quicker. But again, it is that time management that you really gotta hone in and make sure you get that taken care of. (Interview, Michael, March 1, 2017)

The largest challenge as alluded to above from Michael and reiterated by Abbey is completing two different clinical or practicum experiences simultaneously:

I'm doing two practicums right now so it's like I'm doing a PT clinic in the mornings and I'm doing sports in the evening. It's just, like, right now I'm really overwhelmed.

(Interview, Abbey, March 1, 2017)

Lexi stressed the importance of staying on task and following a schedule to manage the demands of fast-tracking and the workload:

The one part that is hard though with fast tracking this semester is there's just a lot of work. It's just. It's just so busy. I mean, I don't mind. You've got to get a schedule but that's one thing that I struggled with was, I guess, time, making time for homework and clinicals and work and class. (Interview, March 1, 2017)

Kennedy University also employs a general education curriculum based on liberal learning outcomes or LLOs. The general education components are strongly woven into each academic program of study. Students are required to repeatedly show competence in six different 
areas: citizenship, communication, creativity, critical thinking, ethical practice and inquiry. Abbey expressed the strongest opinion regarding LLOs and their impact of her educational experience as an athletic training student:

The LLOs. They are overbearing. (laughter) There's a lot to do with that. That's my least favorite part of all the coursework and everybody can say that. The LLOs are awful... We have to earn a LLO for each class. (Interview, Abbey, March 1, 2017)

The LLOs appear to add another perceived contextual requirement layer that students must fulfill and demonstrate competence in that are in in addition to the programmatic and CAATE educational requirements of the coursework. This student perception of an additional requirement versus a pairing or infusing of the two could detract a student's attention away from the primary course content or intent.

Even though the students expressed some cons of the athletic training program, which were mainly time management concerns for those electing the fast-track option; in general, it appears that KU has employed a support structure to help manage those cons. All four KU students reported a grade point average of 3.0 or higher. To be eligible for the fast-track option students must have and maintain a 3.5 or higher grade point average as this option is limited to high achieving students. Also, as noted in the pros of the athletic training program, students feel supported by the program faculty and preceptors in managing the requirements. Even the students themselves acknowledged that while it is challenging and at times overwhelming, they were able to figure out how to complete the necessary requirements.

Students' impressions of challenges of the field. As the KU senior athletic training students approached graduation, challenges facing the athletic training profession were not absent from their view. A lack of understanding by those outside of athletic training as to what 
the education or profession entails was a challenge. Soon-to-be graduates were also cognizant of an under-appreciation or lack of recognition for the work performed. Other challenges discussed by students included a lack of state regulation and low compensation as compared to other professions.

It's kind of another thing with the respect thing. I mean, people don't respect what we do so. They don't really see a higher demand for an increased pay because they think that maybe we just stand on the sideline. That's what we do. Other states like Texas, Virginia, Florida they see what an athletic trainer actually does. They, there's a higher demand for athletic trainers. Obviously higher pay because they know the worth of an athletic trainer. And it's just, like, it's new to West Virginia. There's ever so many schools that have athletic trainers. Those schools appreciate it. But, you know, it just has to be introduced. (Interview, Abbey, March 1, 2017)

By her comments above, one can see that Abbey connected a lack of understanding in what athletic trainers do or what the job responsibilities entail to a lack of respect for an athletic training skill set. States such as Texas, Virginia and Florida, as she mentions, do offer greater employment opportunities as well as higher compensation for athletic trainers as compared to West Virginia. Athletic training jobs in West Virginia are significantly limited at this time. The larger the number of employed athletic trainers correlates to a higher percentage of the public being exposed to an athletic trainer and thus the opportunity to understand what an athletic trainer's skill set is. Abbey sees public education in West Virginia as a way to correct this lack of understanding and respect, and a foundational basis for making improvements within West Virginia for athletic trainers. 
Lexi, too, is aware of a lack of public understanding regarding athletic training. She feels that passing licensure legislation in West Virginia for athletic training would be beneficial in making improvements, including compensation improvements, for athletic trainers.

I know that we don't have licensure here. We just went to the capitol to talk about it. We're still working on it... No licensure, that's a challenge. And then you go to California. They don't have anything. That's a challenge (laughs). Some states get paid higher than others... I know that. Right now, I have an intern or my clinical hours at Therapy House. The PTAs make more than the ATCs. That flusters me because I'm in a 4-year program they only did two. I was like, I could have done that at home but it's just, there's just little things that we're all still working on, I guess. (Interview, Lexi, March 1, 2017)

Kennedy University's campus is located within a reasonable travel distance to the state capitol. Kennedy University's athletic training program faculty, staff and students have historically been active participants with West Virginia Athletic Trainers' Association Hit the Hill Days. These days have focused on athletic training education to all elected officials, House and Senate, in West Virginia. Lexi's participation in this day allows her to see a broader and greater view of the challenges facing athletic training presently in WV.

Cori, in her own way and efforts, is trying to improve public education about the profession of athletic training by informing those around her that her background in athletic training is a track to medical school and other advanced healthcare degree programs:

I'm always really quick when people ask me what I'm doing or what I'm studying in college. I'm like, I'm an athletic trainer but I'm looking into medical programs, PT programs and residencies to follow my education because I want them to know that I 
have the knowledge to do that from my undergraduate qualifications. I don't want them to think that I am a personal trainer or an exercise scientist, that is not what my degree is in and it goes on so much further than that (pause). I don't know. I'm just quick to defend our education. (Interview, Cori, March 1, 2017)

Through the soon-to-be graduate's immersion into the profession of athletic training by KU's program, the students are not ignorant of multiple challenges facing athletic trainers at the present day. As Holland describes a pairing of personality and environment, it is apparent that these students have been empowered to take a proactive approach to attempt to lessen and eliminate those challenges as the pairing is better matched (Holland, 1997). Students are taking responsibility for educating others around them about the profession, becoming an advocate and active participants in education efforts. These students have also been involved in and educated on the legislative process and licensure regulation effort occurring in West Virginia. The soonto-be-graduates are aware of athletic training regulation across the United States and how that has impacted the profession in those states.

Of the four interviewed soon-to-be graduates, all four planned to persist initially in athletic training to some degree. Two students, Michael and Abbey, planned to pursue employment immediately in athletic training while also pursuing a master's degree through an online degree program. Michael intended to persist the longest in athletic training as he expressed a desire to work as a high school athletic trainer or possibly even pursue a position as an athletic trainer within a physician's office (Interview, Michael, March 1, 2017). Abbey, on the other hand, intended to pursue athletic training around her hometown of Rich Creek, West Virginia area. She had not totally eliminated the possibility of pursuing occupational therapy within the next five years (Interview, Abbey, March 1, 2017). One student, Lexi, was exploring 
graduate assistantships involving athletic training with a desire to study athletic administration at the master's level in order to eventually pursue a career in athletic administration, possibly even with the NCAA, at some point in her future (Interview, Lexi, March 1, 2017). The fourth soonto-be-graduate, Cori, had a three-track plan for the future that involved using athletic training as a stepping stone to medicine for biomedical engineering and orthotic/prosthetic school. Cori's long-term professional goal was to work with amputee athletes, building and creating prosthetics. While Cori did not see herself working as an athletic trainer at a high school or college longterm, she was willing to do that in the short term as she completed the remaining prerequisite requirements for application to graduate schools (Interview, Cori, March 1, 2017). From the career intentions of the four soon-to-be graduates, it appears the transition from Erikson stage five to stage six is still occurring (Erikson, 1968). Students are also continuing to seek a best match to their personality type and vocational environment (Holland, 1997). These young adults continue to further define their identities and explore various vocational options to find what best suits them.

Additional insights into the program and the challenges facing athletic training were obtained through the interview with the institutional representative of KU, Dallas Moore. Mr. Moore's tenure at KU was limited although he has been involved in athletic training education for 16 years. Due to the short time he had been at KU, he was not able to provide a long historical recount of career plans or intentions of program graduates as a basis of comparison to this graduating cohort but did speak to the regional employment opportunities available to athletic trainers. Even this larger metropolitan area of Waterford was not immune to limited employment offerings. The primary areas of employment of athletic trainers around Waterford were mainly in the traditional athletic training settings as outreach high school athletic trainers, 
high school athletic trainers employed within the school system, or collegiate athletic trainers. Some employment opportunity was also available through local physical therapy clinics. All areas offered limited job opportunity (Interview, Dallas Moore, March 1, 2017).

In discussing factors that influence new graduates career path decisions, Mr. Moore cited preceptor attitude toward their job and preceptor engagement level with the student. His experience is not necessarily specific to $\mathrm{KU}$, but to athletic training education in general. Specifically, Dallas explained it this way:

If you have a miserable preceptor who clearly expresses that they're burnt out and hate their job, I think that it's a very bad experience and you can't always control that. I mean everybody has a bad day and that's perfectly fine. But you can't walk around saying I hate my job and then expect the student to want the job. But I think that from a positive standpoint you have to engage the student. If the student understands what they're doing and can find passion in what they're doing then either way they're going to be successful. (Interview, March 1, 2017)

As an experienced athletic trainer and clinician, Mr. Moore acknowledged various challenges facing athletic training today. While the students expressed a number of similar challenges to Dallas, he was able to articulate additional challenges being faced. Dallas reiterated the students' perceived challenges of a lack of understanding by those outside of athletic training as to what the education or a poor societal perception and low compensation for the required skill and knowledge base. To better explain the lack of understanding that is present, he feels that, "We are continuing to add to the width of knowledge but not the depth of knowledge" which feeds the lack of understanding by those outside of athletic training. He continued to explain, "We are so 
busy running the gamut from one side to the other of how much our students have to know that we never get depth" (Interview, Dallas Moore, March 1 2017).

In terms of a poor societal perception, he explained that much of what an AT does is behind the scenes. The most visible part of athletic training is water and towels or what is mainly seen on TV. Dallas also spoke at length regarding the transition to the entry-level master's requirement for athletic training and how the two may impact each other. While he hopes the MSAT is more directed, its curriculums are more integrated versus linear and has an impact on compensation levels, he sees a great challenge of selling what we do compared to what is seen. He recounted an experience he had with a fan at a football game to explain:

We had some students working football and one of the moms or one of the fans comes down and was talking to two of our girls who were athletic training students and they were filling water, cups or something like that. And the mom goes 'Man, you guys look like you have so much fun. I wish I could have your job. Just fill up water and hand out towels.' And I'm thinking that's the perception. And here we are going to a master's degree and we're going to continue to fill up water and hand out towels. And yet I'm going to tell you that you need a master's degree to do that. That's sums it up for me. That is the perception. (Interview, Dallas Moore, March 1, 2017)

While the listed challenges may be present, Dallas offered ideas on how athletic trainers can create change. To begin, athletic trainers need to communicate effectively. ATs need to educate and, in essence, condition coaching staffs and administrators that working with a team or athletes does not come with automatic 24/7 access to the AT. ATs do not work for the coach. ATs are there for the health and safety of the athlete. An AT needs to be able to have work time and personal time. Secondly, ATs need to be better and more efficient with treatment plans 
utilizing the research that is available to them. By improving patient outcomes and treatment efficiency, Mr. Moore feels that, "If I'm good at my job, I shouldn't have to spend 15 hours a day doing it" (Interview, March 1, 2017).

As previously discussed through Erikson's theory individuals are influenced by others in their lives in various ways. Who we become is based on those influences and our experiences (Erikson, 1968). Mr. Moore is fully aware of potential challenges his students and graduates will face upon entry to the profession. Through mentoring his students, he is attempting to teach them how to be prepared for those challenges and to lessen those challenges. By decreasing the number of challenges faced within the profession, one may naturally theorize through application of Holland's vocational personality theory that finding a synergistic relationship of personality and environment would be easier to achieve (Holland, 1997). Not only is he attempting to teach students the required skill set, he is trying to equip the students with the proper tools and mindset to be in the athletic training environment.

\section{Carlin University}

Carlin University (CU) is mid-sized public institution with 13,000+ students enrolled. Carlin University (CU) is located in Bridgeville, WV, which is the second most populated city within the state. The greater metropolitan area spans seven counties and has a population of over 360,000. CU has sponsored an accredited athletic training education program since April 1997 (CAATE, 2016). Information from its athletic training program was collected in November of 2016.

Program space. The athletic training program of Carlin University is provided with a faculty office suite with an adjacent clinical athletic training classroom that can be utilized for small didactic classes. The program has a separate clinical classroom for laboratory classes 
located in a close but not adjacent area. The program faculty and students have access to an adjacent third space that can be utilized for faculty to faculty or faculty to student interactions. The program is housed within the College of Health Professions (Observation, November 15, 2016).

The researcher was granted access to one clinical education site on the campus of CU. The athletic training clinical facility is primarily used to provide athletic training services to the student athletes of $\mathrm{CU}$ and is located in their primary athletic building. The facility is a relatively large athletic training facility. This clinical site is equipped with three private office areas, one office/private examination area, a conference area with additional office work areas, a treatment area, a taping area, a storage area, a private, athletic training student locker area, and a wet room (Observation, November 15, 2016).

The athletic training facility was steady with patient treatments/evaluation while the researcher was present (Observation, November 15, 2016). Primarily, one clinical preceptor was available to a single senior athletic training student during the researcher's observation. Additional athletic training staff were present in the facility but mainly stayed in the conference room/work area that was not always visible by the researcher during observation of preceptorstudent interaction. A second athletic training student also stayed in this area working at the conference table while the researcher was present (Observation, November 15, 2016).

To learn more about the athletic training program offered at Carlin University, Dr. Harris Jones was interviewed the research. Dr. Jones explained that the athletic training program attempts to foster an environment that encourages strong ethical judgement by the athletic training students as well as showing the students how ATs can impact their local community outside of the traditional athletic training setting in areas such as obesity or tobacco use. The 
program strives to graduate students that pass their BOC exam on the first attempt and are prepared to enter the workforce in professional practice. As an athletic training educator with 36 years in higher education, Dr. Jones attempts to lead by example and show students that actions speak louder than words. Within the program, he encourages and attempts to foster peer mentoring and assessment (Interview, Dr. Harris Jones, November 15, 2016).

Three soon-to-be graduating senior athletic training students, one male and two female, participated in private, face-to-face interviews with the researcher. The emerging themes that arose from student interviews were attractors to athletic training, factors in selecting a college/university to attend, pros of an athletic training program, cons of an athletic training program, and students' perceived challenges present in the athletic training field.

Attractors. Participating students recounted personal past experience in athletics and involvement in sports as attractors to athletic training. The soon-to-be-graduates reflected on their exposure to an athletic trainer in high school. The desire to work within a team environment and care for others also showed to be reasons why students became interested in athletic training.

Chris, a local student from Bridgeville, explained how the meshing of his enjoyment of sports and being able to care for others attracted him to athletic training.

I chose it because, of course, I like, I like the being around the sports without actually like, being, playing sports myself. I like that aspect of it and then, also, being able to help someone from an injured state and get them, get them back and playing again. (Interview, November 15, 2016)

Michelle, another student from West Virginia, appreciated the athletic trainer that worked at her high school, the job that she did for the student-athletes and the mentorship she received from her: 
Like I said, the one athletic trainer that I had in high school she kind of made me want to do that. I liked how she got to travel with the teams... So, that one trainer kind of explained what athletic training was more to our team or whoever wanted to know about it. And, she helped me out a lot... So, I would say, definitely, her. She led me to want to be an athletic trainer. (Interview, November 15, 2016)

Lastly, the strongest affinity to sports and being around a sports environment was apparent in the third student:

So, like I said, sports are really important to me. I grew up doing them. I spent my summers and all my weekends in the fall and spring at softball tournaments. Umm, my family spends every Sunday together watching football and being in an atmosphere, being part of a sports family, especially in high school working with the football team. That always appealed to me. I found through that time that I loved taking care of people and the people I relate to the most are athletes. (Interview, Colleen, November 15, 2016) These students found a path to study Athletic Training through an initial interest in a healthcare field, i.e. athletic training or physical therapy. Erikson's and Holland's theories can both be applied in this context to offer an explanation. As we know upon entrance to college, traditionally aged individuals are in transition between Erikson's psychosocial theory of development stages of Identity versus Identity Confusion to Intimacy versus Isolation (Erikson, 1968). Athletic training is a social environment and attracts social personalities. In Holland's theory of personality type, the social personality characteristics include: friendliness, helpful, outgoing, cooperative, patient, empathetic and kind. Those in healthcare fields also value these characteristics. Social personalities like to work in groups and provide service to others (Western Reserve, 2011). The application of both Erikson and Holland theories in this case can help to 
understand the attraction of Athletic Training as a career choice. Athletic training allowed the students of CU to mesh aspects of their identity and personality with a career path.

Selection factors. Two soon-to-be graduates from West Virginia and one from Maryland agreed to participate in student interviews. Students' homes ranged from as close as five minutes from Carlin University to six hours distant. Factors that affected students' decisions about college choice included proximity to home, cost, a connection of someone to the school, and the demographics of the school were more important than the reputation of the program.

Even with Chris being from Bridgeville, he admitted he knew little of the athletic training program specifically, but had grown up a Carlin fan. The in-state cost of tuition also appealed to him in making his college choice:

Chris: I'm from Bridgeville, so (laughter) growing up a Carlin fan, I live five minutes from here, so, made a pretty easy choice.

Researcher: Being a local resident, was cost a factor?

Chris: Yes, that also helped with it too.

Researcher: What did you know about Carlin's athletic training program prior to coming here?

Chris: Nothing really (laughter) I knew that just my athletic trainer that was at my high school he went through their program. (Interview, Chris, November 15, 2016)

Michelle added another factor in regards to cost that was important to her in being a Promise Scholarship recipient and selecting a West Virginia school to attend with a rich, well-known history:

Yes, definitely, in-state (cost) was a big factor because, one of my scholarships was actually for in-state. I got the Promise Scholarship, so, I needed that money. So, I had to 
go in-state. (laughter). Carlin's history played a lot into it. ...I actually didn't know much about the athletic training program until I got here and I came to a couple meetings. And I think I came in a couple times and talked to Stephen. ... and just kind of got a feel for what the athletic training program actually was at Carlin. (Interview, Michelle, November $15,2016)$ ...I was told to just check [Carlin] out from a mutual, from a good friend, and I just looked online. I was, like, Division I. They have athletic training... six hours from home, Okay!... I could have potentially gone somewhere with maybe a more reputable program. Umm, but with Carlin being CAATE accredited and everything, I actually got lucky, I think, with Dr. Jones coming in the same time I did. But yeah, I had no idea about Carlin. None (laughter). Absolutely none, I just knew they have athletic training, "We're good!" (Interview, Colleen, November 15, 2016)

As previously noted with the University of Olympia and Kennedy University, the desire for West Virginia students to attend college close to home is present. Both students from West Virginia selected Carlin University due to the proximity to home. The impact of Appalachian culture on its youth and the strong sense of commitment to family and community is apparent (Russ, 2006; Ferry 2006). This is obvious in the students' decision about college choice, with a desire to stay somewhat close to home and family. Staying close to home or family, cost, connections and general demographics of the school also possessed meaning and value to the students of CU. The personal value placed on each was great enough to influence the students' decisions as explained through symbolic interactionism. Students' value of those factors informed the significant personal decision of selecting a college to attend (Blumer, 1969). 
Initial impression of the athletic training environment. The athletic training arena at Carlin University presents itself as initially laidback, fun and enjoyable but yet professional and serious. There are also occasions when the environment could be described as chaotic, "Umm, busy, very busy (laughter). Sometimes disorganized (laughter") (Interview, Michelle, November 15, 2016). Entering students often assumed the role of observer, "at first, I just kinda felt like a fly on the wall just watching everything happen" (Interview, Chris, November 15, 2016). Chris greatly enjoyed his time in the athletic training environment, but also understood the greater purpose of time spent there:

I would say that for the most part, it's really fun and laidback, but everyone knows when it's time to be serious and whenever things need to be accomplished and get done... (Interview, November 15, 2016)

While for Colleen, it was one of her favorite places to spend time and she even referred to it as her 'happy place':

The first word that comes to my mind is just, fun. Just 'cause I love it so it's fun for me. I think that if you really enjoy the environment it's, it's pleasant. Umm, I want to say most of the time it's relaxed. It's an enjoyable place to be. It's my happy place so I love being in the athletic training environment. (Interview, November 15, 2016)

Even though Chris started out as an initial observer and Michelle described the environment as 'busy' and 'disorganized' these three soon-to-be graduates gained confidence in their clinical skill sets, which ranged from a self-reported 4 (confident) to a 6 (very confident) as they matriculated through the program. This comfort level with the environment was made possible through strong faculty and preceptor instruction and community support. 
I think that at Carlin, our professors specifically, have given us the skills that we are going to need to be able to manage pretty much any situation thrown at us. My preceptor, one of her favorite things is to give me a scenario that she has experienced. Something off the wall that she thinks is weird that you're not going to probably have to deal with in your whole life. She will give me a scenario and she's like, “Okay, what's wrong with them?" And I'm going through an evaluation and I'm like, “I don't know what's wrong with them" (laughter). But it'll be really strange ones. Like, one of them was a swimmer. He had gotten on a plane to fly home for break and she's like, “Okay. He's whatever was wrong with him. Figure it out.” And I am, like, “I don't know” (laughter). It's really good to put us under pressure. Give us something that we are probably not going have to deal with, but you'd rather be over prepared than under prepared. (Interview, Michelle, November 15, 2016)

Chris appreciates the empathy that his classmates can share with each other and the support that brings, “Ah, I guess with fellow students it would just be 'we're all in the same boat', so we know what everyone's going through, so we're able to kinda help each other out" (Interview, November 15, 2016).

Pros of the athletic training major. Interviewed students discussed numerous pros of the athletic training program. The positive aspects of the athletic training program cited by students were variety of clinical experiences/setting, hands on or real life application, relationships with peers/preceptors/athletes, helpful faculty/preceptors, positive clinical experiences, travel experiences, and becoming prepared for work/life experiences. 
Exposure to a variety of experiences and hands on or real life application resonated through all three of the soon-to-be-graduates as a positive although this sums up the students' experience the best:

My favorite thing about our athletic training program is the different, the amount of hands on I get in my clinicals. And the different types of settings that I've been able to be exposed to. I have gotten to work with a multitude of sports and granted we don't have as many sports, maybe a big school like ABC State would've... You know, there are some days where I would be sitting there as a clinical student and my clinical director says, "If somebody gets hurt, it's you." I got so much hands on experience. (Interview, Colleen, November 15, 2016)

Developing and fostering strong relationships with peers, preceptors, athletes and helpful faculty and preceptors that led to positive clinical experiences was stressed by Chris: ...being with just a group, people, like our class, and like getting to know, like that, group of people really well. And having a group on campus that everyone, like, we all can relate to each other. (Umm) I really like that... We get to be with the different teams on campus and then whenever we get to travel with them (uhum) and (ah) getting to know the athletes better and stuff like that too. (Ah)... Um, with the faculty they've always been really good to, like, take their time and help us with things whenever we come to them with questions. And then, all the preceptors I've had I've enjoyed being with them. (Interview, November 15, 2016)

The nature of athletic training as a social environment and attracting social personalities is shown in the students' desire and appreciation in the fostering of meaningful relationships. Social personalities seek the development of close relationships with others (Holland, 1997). Michelle 
also appreciated her time with her clinical preceptors and the mentoring they provided, "I really enjoyed the fact the preceptors are really open to helping us. If we ever have any questions, need help on any assignment they are there to help" (Interview, November 15, 2106). While Colleen appreciated the numerous professional options that are in front of her with athletic training and being prepared for them:

I think that's my favorite part about athletic training in general, is that it's not, like. It's so specific, as far as curriculum, but it's so widespread compared to what you can do with your degree. So, being an athletic trainer, I can work in a hospital. I can work in a clinical setting with an orthopedic doctor, be a physician's extender. I can work at a high school, at a college, professional level. There's so many different things. (Interview, Colleen, November 15, 2016)

Cons of the athletic training major. Soon-to-be graduates balanced the pros of the athletic training program with a number of cons. Although travel experience was cited as a pro, it also arose as a con. Interviewed students also discussed poor communication/inconsistency within the program, scheduling of class and clinical overlap, time management, hours and burnout.

Michelle expressed disappointment with the lack of feasible travel opportunities for her to experience. While she admitted that opportunities had been offered to her, she was not in a position to accept these due to other demands of her time and schedule, and the duration of the time away from campus presented a challenge:

I know a lot of my classmates, especially, [for] football they travel. So, that would have been a nice experience (laughter). I don't think I've travelled at all not even while I was at a high school. The opportunity has been there... Because soccer is gone sometimes 
from Thursday to Tuesday. That's a whole week almost, that's just not. For some people it might be reasonable for them but not me. (Interview, November 15, 2016)

Michelle also wished for a greater coordination in scheduling of classes and clinicals. Michelle feels as if she is giving up or losing out on one experience due to the other:

...today, I have class in the evening so that kind of interferes with practice times... I know my preceptor doesn't like that either. She's always like tell them to changeWhy do they have class during a practice time? Because even if you're at a high school that's the time when they will be practicing. So, you are missing out on all that experience. (Interview, November 15, 2016)

Time management and experiencing burnout or a sense of being overwhelmed was a con for Chris. It seems that at times throughout the semester, a number of things can hit at once that can be daunting to manage:

Whenever you start having a bunch of exams at one time and you have to be at practice, games and just whenever there's just a lot going on at one time... It'd just be hard, you know, ah, being up doing homework really late, then turning around, and having to be up at 5:30-6:00 o'clock in the morning to get to a practice or something like that. (Interview, November 15, 2016)

Michelle was also not without time management concerns:

This semester was a little bit more difficult because I have worked this semester. So, I have had to figure out, "Ok, I can go to work this time. Then go to clinicals. Then, go to class" (laughter) so it's been tough... (Interview, November 15, 2016) 
A lack of effective and consistent communication was also an apparent con present at Carlin University. Improved communication pathways could be instituted among faculty and in preceptor to student communication.

...sometimes there's a lack of communication between Stephen and Dr. Jones....We get confused a lot what protocol were using or, you know, what range of motion is a norm. You know, it's a range of whatever degrees on one test and then the next test we put that down and it's marked wrong. So, it's a lot of inconsistency and it's very apparent lack of communication... and sometimes with the preceptors, they don't fully know exactly what they can allow us to do or what not... I did have a preceptor that, again, awful with communication. I guess, I did something that wasn't, in his mind, wasn't appropriate and I was never pulled aside and told what, what I was doing. I wasn't given a head's up. I was given a cold shoulder and awkward tension that I had no idea what was going on. And then all of a sudden I wasn't allowed back at that site. (Interview, Colleen, November 15, 2016)

Students' impressions of challenges of the field. As participating CU senior athletic training students approached a nearing graduation date, challenges facing athletic training presently were not absent from their view. This small group of three students was able to articulate a number of perceived challenges in athletic training. Those challenges included a lack of recognition for the work performed, a lack of understanding/knowledge of those outside of AT to what it entails, misconceptions of the athletic trainer and personal trainer roles, lack of regulation, heavy hour load, low compensation, difficult work-life balance, and physical therapy is a more attractive profession with a higher salary scale and better schedule. 
Colleen thoroughly and thoughtfully expressed her perception that multiple facets of the challenges facing athletic training should be included:

People just don't understand what we do. They don't understand how long the hours are. They don't understand how much goes into being an athletic trainer. We have to know, we have to have so many different skills, like, a jack-of-all-trades... So, then the general public says... "Are you a personal trainer?" "Can you do what a physical therapist can do?" You know, they understand what a physical therapist is and a personal trainer is. I'm like, "Yes, I can come up with a workout for you. Yes, I can develop a rehabilitation program." I can do both, but I am neither (laughter). So, I think the most, the most difficult thing is just people genuinely just don't understand what exactly we do. And then, on top of how much we do. Umm, and I think that's what's so special about being an athletic trainer is that you are such a well-rounded individual. But, people, even though, you sometimes are underappreciated. The people that do understand what you do, your athletes and the people you work with every day, and really do appreciate you and really at the end of the day know that you worked really hard to be there for them. (Interview, November 15, 2016)

Michelle connected a lack of state regulations to a lack of understanding around the profession and feels that licensure could help eliminate some of the confusion for the public: Specifically, in West Virginia, I know licensure is a big issue. They're fighting for licensure. That would probably be the biggest thing. So, umm, I know a lot of people don't know what an athletic trainer is. They're, “Oh you're in athletic training? Oh, like, you can give me a workout" (laughter). No, I mean, I can. Don't get me wrong but that's not what I do. So, getting athletic training out there, what it specifically is. It's not 
personal training, which is a misconception, big misconception, I think, a lot of people have. So, I think, definitely getting licensure; more rules, stricter rules in states, because in West Virginia right now you can do whatever you want. Yeah, you want to do that, "Go right ahead" (laughter). And getting the word out there to what athletic training is because most people don't know. (Interview, Michelle, November 15, 2016)

All three students, Chris, Michelle, and Colleen expressed concerns over compensation levels, high hour load and work-life balance challenges. Chris even related an AT's salary to that of PTs, "I think entry level for a PT is twice, if not more than twice, than what entry ATs make" (Interview, November 15, 2016) while Michelle and Colleen focused more on workload in relation to compensation and work life:

It's definitely a con compared to pay... The athletic trainers are overworked. Maybe that's due to the fact they need more athletic trainers. But, my preceptor specifically, will come in at 8 o'clock maybe and then soccer practice. Soccer season is over now, but she might not get out of there 'til 8 o'clock. That's a long day (laughter). That's a really long day. So, definitely workload is a big issue... I know at Carlin they are making, like, $\$ 25,000$, which is insane. That's below minimum wage if you, like, do the math, if you calculate it hourly. (Interview, Michelle, November 15, 2016) It depends on who you are. If you enjoy just working all the time and you don't have a family, it's fine. But, you know, you have your family and you have your friends... So, I think that the workload is, is a challenge for sure. I think that's a huge reason why there are not a million athletic trainers in the world. You know, there are a lot of us. But, there's not an abundance of us. I think it's purely because of the amount of hours that athletic trainers are required to put in... I'm just really not getting paid enough for what I 
do. And that's why being an athletic trainer, you have to love it. If you don't love it, at the end of the day it's really not gonna be worth it for you if you don't love what you do every day. (Interview, Colleen, November 15, 2016)

Two of the three students from Carlin University had intentions of attending physical therapy school while the third student, Colleen, had planned to pursue a master's degree in athletic training or a related field and to stay in the profession of athletic training (Interview, Colleen, November 15, 2016). Chris had applied to physical therapy school and was waiting on decisions about his applications. While he did not intend to stay directly in the profession of athletic training, he did feel that his background in AT would be beneficial to him as he had already been able to get experience with patient communication, professional communication and the hands-on practice with evaluation, treatment and rehabilitation that would carry over (Interview, Chris, November, 15, 2016). Michelle had plans to attend physical therapy school as well. Michelle shared that she had an interest in physical therapy for some time. She was drawn more to the rehabilitation side of athletic training and physical therapy while she also wishes to work as a PT with a sports team one day (Interview, Michelle, November 15, 2016). Michelle felt similar to that of Chris in that a background in AT would be beneficial to her in PT school and the future.

In the interview with Dr. Harris Jones, he reiterated some of the perceived challenges discussed by the three soon-to-be-graduates, such as workload challenge, society's perception/misconceptions, and compensation, especially when compared to other related professions. Dr. Jones noted that although he has seen the perception change and improvement during his professional career, a great deal still needs to be accomplished to make further improvements, especially in West Virginia. Dr. Jones is a strong advocate of representing the 
profession correctly with the proper terminology and avoidance of just using the term "trainer".

He has thought and contemplated as a name change for the profession has been considered more than once what positive or negative impact that may have. He also feels it is very important for ATs to work on improving the perception of athletic training:

I want the people on the outside, the lay people, to understand what we do, more than tape and throw out the water and ice. That's always been my mission or my goal. Still is unfortunately (laughs) in West Virginia, in some cases. (Interview, Dr. Harris Jones, November 15, 2016)

Although not entirely convinced one way or another about the name change debate, Dr. Jones was also an advocate of the medical model of athletic training, and of creating distance from athletics. By transitioning to a medical model, he felt that athletic training would make positive impacts in regards to work load, burnout rates and attrition rates, especially with those in the collegiate setting. Using the medical model in athletic training, according to Dr. Jones, should improve daily work schedules, decrease burnout and work load hours, and improve work-life balance (Interview, Dr. Harris Jones, November 15, 2016).

As someone who makes their livelihood in higher education, Dr. Jones articulated a number of concerns surrounding the transition of athletic training education to the entry-level master's degree. Those concerns revolved around faculty expertise in areas of the degree, state licensure and scope of practice conflicts with the degree change including the impact on programs and schools, the resources needed, and program numbers and sustainability (Interview, Dr. Harris Jones, November 15, 2016). 


\section{University of Rawlins}

The University of Rawlins (UR) is the largest Athletic Training program examined in this study. The University of Rawlins is a large, public land grant research institution. Located in Riverside, West Virginia, UR is within easy traveling distance to four metropolitan areas. An accredited Athletic Training Program has been offered at the University of Rawlins since September 1995, and the information included in this dissertation was collected in March of 2017.

Program space. The University of Rawlins' (UR's) athletic training program has dedicated, didactic and clinical classroom space. The faculty office location provided ample workspace for the program's three faculty members with private faculty offices. Students and faculty also had available access to an adjacent, shared (with the graduate athletic training program) research laboratory area. Down the hall just a short distance, an inviting third space was available for one-on-one interaction, small group interaction or casual daily interaction (Observation, March 24, 2017).

The researcher observed athletic training student clinical activity in one clinical education site. This athletic training facility is used to provide athletic training services to UR's student athletes of specified sports. The facility is a smaller, traditional athletic training facility. This clinical site is equipped with two private office areas, one shared office area, a treatment area, a rehabilitation area, a taping and first aid area and a wet room (Observation, March 24, 2017).

A great deal of activity was occurring while the researcher was present. Numerous student athletes were present, working with their respective athletic training staff members for treatment or rehabilitation, which allowed athletic training students to witness real-life application of athletic training skills and techniques. With five undergraduate athletic training 
students present, the preceptor to student ratio was 1:1.25. Although multiple clinical preceptors were available to numerous athletic training students of all levels, not all students present were assigned to a specified preceptor (Observation, March 24, 2017).

Two female and one male soon to be graduating senior athletic training students participated in private, face-to-face interviews with the researcher. The emerging themes that arose from student interviews were attractors to athletic training, factors in selecting a college/university to attend, pros of an athletic training program, cons of an athletic training program, initial impression of an athletic training environment, and challenges present in the athletic training field.

Attractors. As students recounted their initial attraction to athletic training, they shared common experiences from the past. Those experiences involved high school sports participation, exposure to an athletic trainer while in high school, and an interest in a healthcare profession and exposure to physical therapy while in high school. Students shared the following:

Personal, past experience with injury that led students to seek physical therapy or the evaluation by an athletic trainer introduced students in greater detail to athletic training. Students had a first-hand account or interaction with the profession that grew from there.

I had a lot of experience with PTs because I had a lot of chronic shoulder pain... And when I was exploring the majors, I found athletic training and kind of related it back to her and that's kind of, where I built off of that. (Interview, Chloe, March 24, 2017) In high school, I was involved in sports. I played soccer, tennis and I ran track... during my junior year, an injury occurred and we had an athletic trainer. I went to her to have the injury assessed. Upon her evaluation and spending the time with her, I gained interest in 
what she was doing and I had the opportunity to shadow her. After doing so, I declared that I would pursue athletic training for college. (Interview, Krista, March 24, 2017)

Chloe and Krista both recounted meaningful past experiences that led them to be introduced to athletic training. That introduction further lead to the desire to learn and experience more of athletic training and ultimately had a strong enough influence on their career pursuits. This is understood by the three basic principles described in symbolic interactionism by Blumer (1969). Colin had a slightly different high school experience. Colin attended a technical school for nursing beginning in his junior year of high school. While enrolled in his first semester, he completed an assignment that required research on three professions of interest. Colin recalled: I wrote my paper on occupational therapy, physical therapy, and athletic training. The more that I researched athletic training, the more that I became interested in athletic training. (Interview, March 24, 2017)

As seen in the reasons students choose to pursue athletic training in college, connections can be made back to Erikson's theory (1968). All three students detail past experiences or influences in their lives that helped lay a path to pursue AT. Students connected athletic training to a lived personal experience and interest.

Selection factors. West Virginia, Maryland and Pennsylvania represented the home states of participating students. Hometown locations from the University of Rawlins ranged from 30 minutes driving distance to just under four hours away. The following factors influenced students' decisions in selecting a college/university to attend: proximity to home and the reputation of the Athletic Training program. Krista explained why she chose UR this way: The University of Rawlins stood out the most as it was more welcoming and I was able to meet one of the clinical coordinators during my visit. They sold the program during my 
visit. They shared that there was more alumni in the NFL that graduated from the University of Rawlins. I thought that was neat. These factors drew me in. (Interview, March 24, 2017)

While Krista used alumni success in her decision making process, Colin wanted to be close to home after initially planning to attend a school in Florida:

At the last second, I chose to go to UR because I didn't think that I was ready to go that far away from home. I am from southern West Virginia, so UR is only about 3 hours away... A big reason that I chose UR was because I am from West Virginia. (Interview, March 24, 2017)

Although Colin considered attending college far away, the hold of the influence of Appalachian culture on his college choice won out. Staying connected to his West Virginia roots remained powerful and caused a change in his decision as supported by the research of Ferry (2006) and Russ (2006).

Initial impression of the athletic training environment. Soon-to-be graduates described their initial impressions of the Athletic Training environment and what skills would be required for their success in the program. Students quickly understood that completing the athletic training program at UR was going to be demanding, time intensive, and would require time management skills.

Time management is an early challenge of students upon official entry to the program. Students have to quickly transition and keep up with increased clinical education demands on their time all while keeping up with a normal course load of classroom requirements:

Once you get into the program, that first semester is a big transition. You go from being in the athletic training room 2-4 hours per week to 20 hours per week. You go to classes 
in the morning, and then go straight to your clinical hours. Some rotations you may even have hours before your classes begin. You also have anatomy and a cadaver lab that first semester which are hard classes, so you really have to manage your time well that first semester. It does get easier after because you know what to expect. (Interview, Colin, March 24, 2017)

Krista realized early that the program would require dedication and devotion to be successful, "You definitely have to be devoted because again it's very time consuming and the demands of the profession is time consuming as well" (Interview, March 24, 2017). Both Colin and Krista realized as they were being introduced to a new vocational environment, the necessary time management skills and characteristics needed to be successful in the program. Through this recognition, students were able to improve their own personal skills and traits to fit the demands of the environment.

Pros of the athletic training major. Interviewed students named many pros of the athletic training program. Positive aspects of the athletic training program ranged from exposure to a variety of clinical experiences/settings, meaningful relationships with peers/faculty/athletes, mentoring, networking, travel experience, and a rewarding experience. In general, students appeared to be satisfied with their choice of academic major, the athletic training program, and UR.

Colin expressed his satisfaction with the variety of clinical experiences available to students:

I like that, at UR, they allow you to rotate with various sports to give more opportunities to see where you would want to work after graduating... and I think traveling is a lot of fun. (Interview, March 24, 2017) 
Colin also described developing relationships as part of his positive athletic training experience, "You experience so many personalities, and I really enjoy that and getting to know all of my athletes" (Interview, March 24, 2017).

Meaningful preceptor-student relationships and mentoring were described by students in greater detail:

We [preceptor/student] have a really good relationship. I still talk to her almost like every day. She's great. And I know I can count her with anything. Ask her any questions. Really to have that to fall back on whether I am a staff member somewhere else or whatever I can always ask her about something. Jessie, the clinical coordinator, has helped us so, so much whether it's just talking about life and what we want to do or if it's something specific. (Interview, Chloe, March 24, 2017)

The students of UR exhibit strong social personality characteristics through their comments of the importance and enjoyment of relationship development while matriculating through the program. This directly matches with Holland's definition of social personality characteristics in the desire to have meaningful relationships (1997).

It appears that as the soon-to-be graduates approach graduation and prepare to leave the UR for their future pursuits, the ability to stay connected to mentors from the UR is important to them. The nature of the preceptor/student relationship allows students at UR to feel comfortable in obtaining advice beyond just professional athletic training advice. This is present in Chloe's comments above as well as Colin's below, as students are confident they always have someone to turn to:

Even after I finish a rotation, I can still talk with them. I am able to even help out with those sports following my rotation with them. If I ever need anything, they are always 
there when I need them. I believe that all of the preceptors give you the opportunity to grow and want you to succeed. (Interview, Colin, March 24, 2017)

One unique aspect of UR that was discussed by the students of UR was the opportunity for network that the program has provided:

I think the networking aspect of it has been pretty cool. We have been able to meet many people who have taken different paths in athletic training. So, it's neat to see athletic trainers emerging in different settings. From meeting people and then witnessing how the program offers opportunities from helping with research opportunities, doing internships - NFL, etc. In fact, I worked with Cirque du Soleil during the summer of 2014. The program has allowed us to have opportunities, which eventually helped me determine where I would like to go with my career and so forth. (Interview, Krista, March 24, 2017) Even as a student, Chloe has experienced gratifying aspects of athletic training. She acknowledged that while it may be difficult for others to understand the dynamics of an athletic trainer-athlete relationship without experiencing it, being an athletic training student has been extremely positive:

It's been one of the most rewarding aspects of my life... But just the people you meet and these athletes do really have like a dependency on you. They care about you. And they, they do respect you whether they always show it or not. And it is just like rewarding personally just because you see the progress that you're making with these athletes. And it's rewarding to see them back in the game or see them progress and just be able to help them in any way. (Interview, Chloe, March 24, 2017)

In connecting the soon-to-be graduates experiences with the conceptual framework, Krista's positive experience of networking which improved her ability to learn of various 
settings in AT and determine a career path for her future supports Holland's (1997) theory. Chloe and Colin's accounts though are better explained using Erikson (1968). Chloe and Colin are driven by aspects of identity development focusing on their impact or relationship with others. Krista, on the other hand, appears to be more career focused in her path and employing her intrapersonal intelligence to meet her goals in determining her best suited vocational environment.

Cons of the athletic training major. The UR athletic training program did not present without any cons. Two main cons were present. Those were time management and work-life balance struggles. In regards to time management, Chloe expressed her collegiate career as not being a 'normal student' and potential sacrifice as compared to her peers in other academic programs:

As far as bad things, it is a lot of time. I feel like nobody, like none of my friends outside the program understand what it is to be in this position. I always you know call home and say I have this, this and this and do. And it's because I'm not a normal student. You know, they're out sunbathing in the sun and I'm in a football field or something like that. So, it is. It was just something that you had to realize this. You're not a normal student. It's part of your job and you kind of have to accept it. (Interview, Chloe, March 24, 2017)

The second con that students are challenged to deal with and resolve is work-life balance and managing when the two intersect, as this representative student expressed:

Maintaining an appropriate relationship with the student athletes was also required. This was crucial as the patients were close in age. There's still that line which is very funny when you'll see them out at restaurants or out and about. (Interview, Krista, March 24, 2017) 
As Chloe and Krista matriculated through the program and neared graduation, their connection or identification with a real professional in athletic training is visible. In the comments above, these two soon-to-be graduates are no longer as strongly identified as merely a student. They are beginning the transition in identifying as a full professional through behavior and actions. This coincides with the growth of their individual identity development.

Students' impressions of challenges of the field. As the University of Rawlins' senior athletic training students approached graduation, they were not ignorant of perceived challenges currently facing athletic training. This group of soon-to-be graduates referenced a lack of understanding and public awareness as to what the job entails. Other notable challenges recounted were misconceptions around athletic training, the lack of regulation or licensure of athletic training in West Virginia, and work-life balance challenges.

Colin explained the public's lack of understanding and public awareness around this issue:

A lot of people I talk to don't know what athletic training is. They assume we're just personal trainers or that we're going to coach or something, so they're still learning what it is. (Interview, March 24, 2017)

Chloe was frustrated by this misconception of athletic training: It really, really bothers me when people say, "Oh you' re glorified water girls" or whatever. That really, really bothers me because I want to be like, "You don't understand what we go through". Yeah, we spend our lives on a field. But, it's because we have to. Because the minute somebody goes down, who are you going to look to? Us. So, it really bothers me that that's the perception of it. (Interview, March 24, 2017) 
The lack of regulation or licensure of the practice of athletic training does not apply to all states; however, it is something that is a concern in West Virginia:

Depending on what state you're in, licensure can be a big thing (laughs) hindering the athletic training profession. Just in terms of what you are allowed to do as an athletic trainer. (Interview, Colin, March 24, 2017)

Lastly, work-life balance challenges are summed up best by these statements, “...the demands of the profession make it difficult to maintain a work-life balance. The seasons are getting longer. In fact, there is hardly an off-season in many sports" (Interview, Krista, March 24, 2017) and "I feel like most people don't think that they have enough time for themselves or families" (Interview, Colin, March 24, 2017).

All three students from UR planned to persist initially in the profession of athletic training. Krista had secured a graduate assistant position and intended to pursue a master's degree in Sport, Fitness, Recreation and Leadership. She had not fully ruled out the possibly of attending Physical Therapy school in the future after working in athletic training for 5 years (Interview, Krista, March 24, 2017). Colin and Chloe had not yet finalized their post graduation plans. Colin hoped to obtain a graduate assistant position working with soccer, preferably men's soccer, while pursuing a master's degree in Athletic Training or a related field. His plan B was to seek a one-year internship position if he was not selected for a graduate assistantship. Colin's long-term career aspirations were to work in the area of professional soccer (Interview, Colin, March 24, 2017). Chloe had been offered a graduate assistant position at a small liberal arts school but was unsure if she was going to accept it or not at the time of her interview. Her original plan prior to the offer was to begin working, expand her professional experience and then apply to PA school within a year or two (Interview, Chloe, March 24, 2017). 
Dr. Jonathan Riley participated in an interview as the institutional representative from the University of Rawlins. Just like the three students interviewed, he discussed a number of challenges facing athletic training presently. Like other institutional representatives, Dr. Riley had concerns over the transition to the entry-level master's degree for the profession. His concerns were rooted in the impact the transition might have on colleges and universities as well as a disconnect between AT and other professions that could result. Dr. Riley explained the disconnect:

I think it's going to greatly create more of a disconnect between athletic training and other health professions perhaps. Because, you know, a lot of our athletic trainers now, what do they do? They get a bachelor's degree and maybe a master's degree as a GA and then they might go to PT school, PA school, med school. Well, I don't foresee that these kids are going to do that now. And so you had great representation in these professions. We had good representation just, you know, there were more and more going into those areas. And now that's pretty much going to stop. I feel it's going to stop. (Interview, March 24, 2017)

Dr. Riley's other noted challenges for athletic training centered around the lack of licensure for athletic training in West Virginia and the state's job market. Obtaining licensure, Dr. Riley feels would have a positive impact on athletic training and the state's employment outlook in the field. He unfortunately has witnessed that a number of program graduates from West Virginia and other states have to leave WV in the search of gainful employment. As the state's largest land grant institution, Dr. Riley understands UR's role in educating residents, educating the workforce of West Virginia, and attracting others from outside the state to West 
Virginia. Dr. Riley elaborated on the impact of a student's financial situation upon graduation to the challenges faced:

We said probably half to two thirds of our kids were from out of state. Well, they're paying out of state tuition and sometimes our kids leave here and they're in six digits with loans, on an athletic training salary. Sometimes they don't have any choice but to move back home and maybe I gotta to move in with mom and dad and I gotta get a job close to home because I can't afford to pay my loans off and rent and utilities and everything else. So, kids in state maybe not as much of an issue. They have less of a job, job opportunities here within state. They leave the state. And probably, and kids have said, "I want to stay in West Virginia and if I have to leave I'll leave. But I eventually will migrate back." So, in their situation, they're leaving and they don't have a great amount of debt as, as opposed to what some of these out of state kids do. So, I think finances. Financing certainly is a big factor. You know, particularly the fact that they realize, "OK I'm not going to make a huge amount of money working as an athletic trainer”. So, I think that in that regard affects it both ways. (Dr. Jonathan Riley, Interview, March 24, 2017)

Although challenges are present in athletic training and in West Virginia, Dr. Jonathan Riley expressed that he desired that the program have good students that can pass the BOC and become credentialed athletic trainers that have opportunities available to them upon graduation. Many involved with the athletic training program lead by example. The program emphasizes the 'big picture' of athletic training by exhibiting past student successes and engaging students with program alumni:

We really try to incorporate and talk about the successes of previous students and what they're doing and how they got there and what it took for them to get there. So, if we, if 
we always make that present and known to our current students, I really think that helps them to envision and see the big picture and they then buy into the concept. (Interview, March 24, 2017)

The program also sets high expectations of students, stresses professionalism and effective communication in preparing graduates for the future (Interview, Dr. Jonathan Riley, March 24, 2017).

\section{Cross Case Analysis}

In the cross-case analysis, commonalities and differences of the four college/university cases will be presented. The most obvious commonality of all four cases is that all programs are CAATE accredited athletic training programs as this was also a factor of inclusion and selection for the research. Although each program is held to the same CAATE standards and requirements, each program is afforded the benefit of institutional, or programmatic autonomy, on implementation of those standards by CAATE. Many of the commonalities appear to be inherent in athletic training education or the profession of athletic training although each institution or program, in its own right, has a uniqueness to it, as described above. Differences of each tended to lie within the make-up or experience of faculty/staff/preceptors, student experience/background, broader institutional characteristics, and how the major themes were interpreted and experienced.

As students enter a "psychosocial moratorium" as defined by Erikson (1968), the influences of family, culture, environment, and personal, lived experiences all influence one's identity that further impacts decisions about college and major choices. During this moratorium, students were charged with selecting a field of study with the intention of that choice leading to a career as well as selecting the institution at which to study. In selecting both of these, students 
are consciously and sub-consciously aligning college choice and major with their individual identity and personality, as described by Holland (1997), in search of the best fit. CAATE accreditation acted an equalizer to all four programs in terms of athletic training education. The differences in influence of program faculty/staff expertise and institutional organization or resources present in each case allowed for students to obtain that best fit.

As previously reported, the broader themes that emerged from each case were the same or similar among the four institutions. This may be due to the nature of the questions that soonto-be-graduating students were asked during the face-to-face interviews. However, the specific codes from each individual or individual case varied and the same experiences or perceptions were not present across all four cases. In the cross-case analysis, the commonalities and differences across each case will be presented within each emerging theme. The six tables used to help structure this section illustrate a case-by-case comparison of themes and sub-themes. These themes and sub-themes are analyzed in the text that follows. The following key can be used to interpret each of the six tables showing students' data that are presented in this section. Color Key for the following Tables.

\begin{tabular}{|c|c|c|c|}
\hline Present in & Present in & Present in & Present in \\
all 4 cases & 3 cases & 2 cases & only 1 case \\
\hline
\end{tabular}

This analysis of four colleges and universities in the state of West Virginia shows some key similarities among the four sites; there were several core factors that drew students to these campuses to study AT (Table 7). 
Table 7

Attractors to Athletic Training

\begin{tabular}{|c|c|c|c|}
\hline $\begin{array}{c}\text { University of } \\
\text { Olympia }\end{array}$ & Kennedy University & Carlin University & $\begin{array}{c}\text { University of } \\
\text { Rawlins }\end{array}$ \\
\hline High school athlete & High school athlete & High school athlete & High school athlete \\
\hline $\begin{array}{c}\text { Exposure to AT in } \\
\text { high school }\end{array}$ & $\begin{array}{c}\text { Exposure to AT in } \\
\text { high school }\end{array}$ & $\begin{array}{c}\text { Exposure to AT in } \\
\text { high school }\end{array}$ & $\begin{array}{c}\text { Exposure to AT in } \\
\text { high school }\end{array}$ \\
\hline Sports/Athletes & $\begin{array}{c}\text { Sports/team } \\
\text { environment }\end{array}$ & Sports/Athletes & Healthcare profession \\
\hline $\begin{array}{c}\text { Caring for } \\
\text { others/helping }\end{array}$ & Healthcare profession & $\begin{array}{c}\text { Team environment } \\
\text { Caring for } \\
\text { others/helping }\end{array}$ & $\begin{array}{c}\text { Exposure to PT while } \\
\text { in HS }\end{array}$ \\
\hline Healthcare profession & & & \\
\hline
\end{tabular}

As shown in Table 7, personal history was a crucial factor, with students' high schools playing a key role. In all cases and in all university and college programs, being a high school athlete and being exposed to AT early, in high school, paved the way for interest in an AT major and career; this was not an interest that was cultivated once students entered college specifically at Carlin University and the University of Rawlins. At the University of Olympia and Kennedy University, five of the seven students interviewed continued to participate in athletics at the collegiate level to some degree upon entrance to college while none of the six students interviewed at the other schools pursued athletics at the collegiate level. This can be explained by the athletic affiliation of the University of Olympia and Kennedy University as compared to that of Carlin University and the University of Rawlins and the inherent demands that accompany the athletic affiliation. University of Olympia and Kennedy University are NCAA Division II schools as opposed to Carlin University and the University of Rawlins being NCAA Division I institutions. Further combining those differences with the individual interest of the students (school size, financial aid packaging/cost, etc.) and students' self-efficacy levels when evaluating which university to attend, offers plausible explanations for why not all students pursued 
participation in collegiate athletics. This finding resonates with Erikson's theory of psychosocial development. Athletic training as a major choice allowed all thirteen students to remain connected to their athletic past by being involved in an athletic arena and atmosphere while pursuing a college degree. Students pursued an area of interest and an environment that was comfortable, familiar to them and was part of their identity at that time.

Class, race and gender of the interviewed students did not appear to present with a vast number of notable differences or patterns. Of the thirteen participating students, see Table 6, seven students had estimated household income levels at or below $\$ 70,000 /$ year (only one below $\$ 40,000 /$ year), five provided an estimation of $\$ 71,000$ to $\$ 100,000 /$ year and only one student selected $\$ 100,000 /$ year plus. The thirteen students were comprised of five males with four from West Virginia and eight females with three from West Virginia. Race was not specifically asked by participants. One participating student did discuss being an African American in athletic training during her interview. The researcher feels that a safe assumption is that the other twelve soon-to-be graduates were Caucasian. Taking into consideration the racial demographics of West Virginia and the racial/ethnic and gender demographics of athletic trainers as reported by NATA, the make-up of participating soon-to-be-graduates is not surprisingly different. Fifty-five percent of NATA members are female and $3.94 \%$ of NATA members represent the African American community (NATA, 2018a; NATA, 2018b).

There were more complicated patterns of attraction. I surmise that in these cases, the context of the university or college mattered in students' attraction because some but not all students were included in these courses. At the University of Olympia, Kennedy University, and Carlin University, the three schools with small to mid-sized institutional enrollments, the connection students could have to the universities' sports and athletic teams cemented most 
students' interest in AT as a career. This was not an important attractor at the University of Rawlins because of its larger institutional size. Carlin University, in contrast to the University of Olympia, Kennedy University, and the University of Rawlins, attracted students to AT that reported having a strong desire to attend PT school prior to entering college. These students found AT to be a closely related gateway to that field or had an interest in sports but learned more about AT once admitted to the program. The University of Olympia and Kennedy University also each had students with an initial interest in PT late in high school or even initially in college but throughout their formal introduction to AT and learning more about the profession decided to not pursue PT and pursue AT as a career choice. The possibilities of working in a health-related field was a draw for students who saw AT as a natural way to combine their interests and experience in athletics with their interest and experience in health care. It is likely that this was not a salient attractor for students at Carlin University because both students continued to pursue their physical therapy school interests with no intention of working within the field of athletic training. These interests were also informed by theory because it is possible that these two students at Carlin University possessed a greater sense of identity. The connection of athletic training to athletics was less important for these two students while the overlap of athletic training to physical therapy was of greater importance and AT was used as a stepping stone to PT. Students were not intimidated by the athletic arena as they each had participated in athletics in the past, however, athletics did not play as great a role in their individual identity as other factors.

Interestingly, in this "helping" profession, only three (two female and one male) students in two of the schools, University of Olympia and Carlin University, mentioned altruistic values as a reason for desiring to be an athletic trainer. This can be explained by Holland's Theory of 
Vocational Personalities. Holland's theory offers that while individuals have a dominant personality type, a sub- or tertiary type may be present as well. Holland states that the dominant personality type is that which will determine the primary direction of one's occupational choice (Holland, 1997). While all thirteen students exhibit a dominant social personality type, the three students mentioning altruistic values may possess a stronger social personality type over the subor tertiary types present, which influences their caring nature.

In sum, wanting to major in AT started early, when students were in high school. The desire was undergirded by being exposed to AT regularly while they were in high school, a point in time during which psychosocial development in the individual is working through how to belong to a society and 'fit in' all while looking to their future (career, relationships, families, etc.). The influences, personal interests and level of development of the Identity stage can have a significant impact on the students' academic and occupational decisions as they continue to define the boundaries of who they are and what they wish to become (Erikson, 1968). Desiring a career in healthcare was also an important factor for students across the four campuses, indicating the importance of positioning AT as a healthcare career as well as an athletic-oriented career. It does not appear that the AT major was as strongly connected to helping and caring dispositions. Choosing AT was more about the career orientation of the position than the day-today labor in the minds of students who selected this major.

Table 8 illustrates the factors that students used in determining which college or university they might attend. 
Table 8

Factors in Selecting College/University to Attend

\begin{tabular}{|c|c|c|c|}
\hline University of Olympia & Kennedy University & Carlin University & $\begin{array}{c}\text { University of } \\
\text { Rawlins } \\
\end{array}$ \\
\hline Proximity to home & Proximity to home & Proximity to home & Proximity to home \\
\hline Cost & Size of school/classes & Cost & $\begin{array}{l}\text { Reputation of } \\
\text { program }\end{array}$ \\
\hline Size & Recruited for athletics & $\begin{array}{c}\text { Connection of someone } \\
\text { to school }\end{array}$ & \\
\hline $\begin{array}{c}\text { Demographics of } \\
\text { school more important } \\
\text { than reputation of } \\
\text { program }\end{array}$ & Financial aid package & $\begin{array}{c}\text { Demographics of } \\
\text { school more important } \\
\text { than reputation of } \\
\text { program }\end{array}$ & \\
\hline Community/welcoming & $\begin{array}{l}\text { Reputation of program } \\
\text { thru PD/alums - others } \\
\text { school }\end{array}$ & & \\
\hline
\end{tabular}

Note: Orange $=$ present in all 4 cases; Blue = present in 3 cases; Green = present in 2 cases; Yellow= present in 1 case

Given the importance of high school experience to students' desire to become ATs, it is not surprising that choosing a college or university close to home was the most consistent and important to AT students in West Virginia. As shown in Table 8, it is surprising that more factors were not present at the University of Rawlins. The University of Rawlins had a stronger public face as the largest land grant institution of West Virginia. At the University of Rawlins, cost factors may have been less important because of the notoriety of attending a large, well-known state university. Program reputation was very important at Kennedy University and the University of Rawlins, likely because of the involvement of local program alumni in recruiting and alumni placement in the field. This was less important at the University of Olympia and Carlin University, because of the welcoming nature of the schools or having a connection to someone who had an established connection to the school. Even though West Virginia is known for its close, familial culture, it was not an overwhelming factor in students' choice of college or university. Factors like a welcoming environment, going to school with people they know, the 
smaller size of the institution and small class sizes were mentioned infrequently, suggesting that students drew a strong line between their own families and the community and "family" they envisioned creating in the new college or university environment. It was more important to be in close proximity to home than to have the imagined opportunity to create a new family at school.

These student comments were confirmed during my discussions and observations during my campus visits. Numerous students expressed the desire to have the ability to 'experience' college while maintaining a closeness to home. Students wanted to create a level of independence and time to continue to grow and mature away from their family without entirely sacrificing the ability to be with their family or 'home' when desired. As mentioned earlier, Appalachian culture creates strong ties to family and a desire to remain close (Ferry, 2006, Russ, 2006). Tying this cultural aspect with Erikson's theory when students are attending college, these students clearly wanted an opportunity to remain close to home while greater defining their own identity independently and who they are individually (Erikson, 1968). 
Table 9 below shows students' thinking about the most positive elements of their AT

program.

Table 9

Pros of an AT Program

\begin{tabular}{|c|c|c|c|}
\hline University of Olympia & Kennedy University & Carlin University & University of Rawlins \\
\hline $\begin{array}{c}\text { Variety of } \\
\text { experiences/settings }\end{array}$ & $\begin{array}{c}\text { Variety of } \\
\text { experiences/exposure }\end{array}$ & $\begin{array}{c}\text { Variety of } \\
\text { experiences/settings }\end{array}$ & $\begin{array}{c}\text { Variety of experiences/ } \\
\text { exposure }\end{array}$ \\
\hline $\begin{array}{c}\text { Relationships with } \\
\text { peers/preceptors/ } \\
\text { athletes }\end{array}$ & Travel experience & $\begin{array}{l}\text { Hands on/Real life } \\
\text { application }\end{array}$ & Travel experience \\
\hline $\begin{array}{c}\text { Helpful } \\
\text { faculty/preceptors }\end{array}$ & Hands on & $\begin{array}{c}\text { Relationships with } \\
\text { peers/preceptors/ } \\
\text { athletes }\end{array}$ & $\begin{array}{c}\text { Relationships with } \\
\text { peers/preceptors/ } \\
\text { athletes }\end{array}$ \\
\hline $\begin{array}{l}\text { Positive clinical } \\
\text { experiences }\end{array}$ & $\begin{array}{l}\text { Relationships with } \\
\text { peers/preceptors/ } \\
\text { athletes }\end{array}$ & $\begin{array}{l}\text { Helpful } \\
\text { faculty/preceptors }\end{array}$ & Mentoring \\
\hline Travel experiences & $\begin{array}{c}\text { Faculty } \\
\text { involvement/attention }\end{array}$ & $\begin{array}{c}\text { Positive clinical } \\
\text { experiences }\end{array}$ & Networking \\
\hline $\begin{array}{c}\text { Strong } \\
\text { teaching/Challenging }\end{array}$ & $\begin{array}{l}\text { Balance of clinical } \\
\text { (hours) and life }\end{array}$ & Travel experiences & Rewarding \\
\hline Fair & & $\begin{array}{c}\text { Prepared for life/work } \\
\text { experiences }\end{array}$ & \\
\hline \multicolumn{4}{|l|}{$\begin{array}{l}\text { Gains skills for all of } \\
\text { life }\end{array}$} \\
\hline Positive environment & & & \\
\hline
\end{tabular}

Note : Orange $=$ present in all 4 cases; Blue $=$ present in 3 cases; Green $=$ present in 2 cases; Yellow= present in 1 case

There were three strongly consistent and overarching themes that all of the students across all colleges and universities mentioned as positive, influential aspects of their work. These were: (1) experiencing a variety of clinical settings; (2) forming relationships with peers, preceptors, and athletes; and (3) traveling to various places as part of the program. It is very interesting that the students, who consistently connected their personal narratives to home (being close to home, being motivated by home, etc.) saw opportunities to branch out and experience 
new and different opportunities as positive and impactful. An explanation of this could be as these students are continuing personal growth and identity a new interest in exploration is sparked. By the variety of clinical settings and forming deeper, meaningful relationships with new influences in their lives, students are curious to learn and experience more than what they have known to date. These new experiences have an impact on the students' identity development as well as allows them to find their own vocational niche as explained by Erikson (1968) and Holland (1997). These might be elements to expand and deepen in the future.

It is also important to note that there were many other positive elements that were important to some students and not others, and that appeared to be very context-dependent. For example, multiple faculty comments and challenging coursework was mentioned as a strength for the University of Olympia, but less so for Kennedy University and Carlin University, and the support was framed more generally as mentorship rather than faculty or teaching support at the University of Rawlins. From my campus visits, observations, and interviews with program staff, it became apparent that this was because students at the University of Olympia respected, but yet felt intimidated at times by the knowledge of program faculty/staff. The clinical preceptors at Kennedy University and Carlin University engaged with students more during clinical education. While in clinical education experiences, students were able to obtain more hands on practice and reinforcement of didactic and laboratory classroom instruction that translates to improved understanding of athletic training concepts and thus the student may not perceive the coursework as challenging in nature. The mentorship noted at the University of Rawlins by students arises out of the make-up of the faculty and preceptor relationships. While the students of the University of Rawlins did not express the program as hands on in nature, students did speak of the meaningful experiences of classroom and clinical education. This is most likely due to the 
nature of competitive NCAA Division I athletics and the pressure present in that environment on ATs and coaching staffs. The faculty and preceptors of the University of Rawlins found alternate ways to engage the students through mentorship when direct hands on experience was not ideal.

Another interesting finding that distinguished Kennedy University from the other institutions was that all Kennedy University students highlighted the importance of balancing clinical engagement and their personal lives, yet this was not mentioned by a single student at the other institutions. This might be because three of the students at Kennedy University were completing the program through the fast track option. Kennedy University also stressed the importance of quality versus quantity during the clinical education components. These are important elements to consider because both of those factors individually and together express to the student that their time, academic and personal, is valuable and respected by the program. These elements also model for students a greater sense of work-life balance.

Another important aspect, as we consider preparedness and success in the AT workforce, is that at least a couple students at both Carlin University and the University of Rawlins mentioned that their institutions were preparing them for success in their field, for example through networking experiences. It might be important to consider in more depth how these two universities organize to prepare students. For example, at the University of Rawlins, program faculty allowed for frequent connections and worked to highlight various program alumni. This allows student engagement within the profession by other ATs without limits or borders by broadening their professional network. The program is not handicapped by utilizing only the resources that are available within close proximity. This also allows students to expand their knowledge base of professional opportunities beyond what they are able to experience directly within the program and requirements. 
These comments, experiences, and contexts were confirmed by my observations and discussions during the campus visits. Students from the University of Rawlins described the opportunity for internships with program alumni and the connections available to them especially within professional sports. This was reinforced by interviews with program faculty as well as observed on the program's institutional website.

Table 10 below shows, in contrast to the positive program elements just mentioned, the negative aspects or "cons" that the students saw as impactful of their experiences.

Table 10

Cons of an AT Program

\begin{tabular}{|c|c|c|c|}
\hline University of Olympia & Kennedy University & Carlin University & University of Rawlins \\
\hline No travel & Time management & No travel & Time management \\
\hline Hours & $\begin{array}{c}\text { Gen ed requirements of } \\
\text { institution }\end{array}$ & $\begin{array}{c}\text { Scheduling of } \\
\text { class/clinicals overlap }\end{array}$ & Work-life balance \\
\hline Burnout potential & & Burnout & \\
\hline Time management & & Hours & \\
\hline Gen Ed Requirements & & Time management & \\
\hline & & $\begin{array}{c}\text { Busy work } \\
\text { inconsistency }\end{array}$ & \\
\hline
\end{tabular}

Note: Orange $=$ present in all 4 cases; Blue $=$ present in 3 cases; Green $=$ present in 2 cases; Yellow= present in 1 case

Significantly, only one negative element was highly consistent across all programs and students, and that was the aspect of time management. There was, in the opinion of students, too much to do in too little time. In light of program accreditation requirements and standards, programs need be cognizant of how clinical education is structured to allow students to manage their time well without compromising a student's clinical experience or providing a false sense of professional socialization to AT. Consistent with the positive findings about Kennedy 
University instilling a positive work-life balance, there were not specific negatives listed for this institution regarding elements that would negate that. On the other hand, the remaining institutions and especially the University of Olympia and Carlin University had many negative examples of how organizational elements impacted students directly. However, these negative elements were not experienced by all students and in many cases by only one. These elements included aspects such as scheduling of class/clinical conflicts, too many general education requirements, busy work, poor communication, and a high potential for student burnout during the program. These elements were observed and/or communicated by institutional representatives during my campus visits.

Table 11 below depicts students' initial impressions of their AT environments at their respective universities.

Table 11

Initial Impressions of the AT Environment

\begin{tabular}{|c|c|c|c|}
\hline University of Olympia & Kennedy University & Carlin University & University of Rawlins \\
\hline Initial observer & $\begin{array}{l}\text { Initially water bottle } \\
\text { fillers \& ankle tapers }\end{array}$ & Initial observer & demanding \\
\hline Fun/Enjoyable & $\begin{array}{l}\text { Challenging/intense/ke } \\
\text { eps you on your toes }\end{array}$ & Fun/Enjoyable & time intense \\
\hline Intimidating initially & $\begin{array}{c}\text { gateway to other } \\
\text { professions }\end{array}$ & Laidback & $\begin{array}{c}\text { time management } \\
\text { necessary }\end{array}$ \\
\hline $\begin{array}{c}\text { Professional and } \\
\text { serious }\end{array}$ & $\begin{array}{c}\text { Much more than } \\
\text { perceptions }\end{array}$ & $\begin{array}{c}\text { Professional and } \\
\text { serious }\end{array}$ & \\
\hline Chaotic/fast paced & & Chaotic & \\
\hline
\end{tabular}

Note $:$ Orange $=$ present in all 4 cases; Blue $=$ present in 3 cases; Green $=$ present in 2 cases; Yellow= present in 1 case

The students' initial impressions confirm that institutional context is important to take into account when considering their experiences with AT more broadly. In this study, three of the programs, University of Olympia, Kennedy University, and Carlin University, were 
interpreted in complex ways by the students, for example at once intimidating, serious and professional on one hand while lighthearted, chaotic, fun-loving and enjoyable on the other. Only the University of Rawlins presented as very intensive at the outset, although this characterization was based on only one student's comments.

Based on my visits to and observations of each of the programs, the atmosphere of the clinical education environment greatly influences a student's impression. Students that were actively engaged with clinical preceptors from the onset developed a comfort level much more rapidly than students who were not as engaged and viewed more as student observers. The observers gained comfort and confidence as they matriculated through the program but this occurred over a greater period of time. As discussed previously regarding the students' desire to be part of a community, especially the students from Appalachian states, and the positivity of the development of meaningful relationships, these students aspired to assimilate into their new environment or fit in quickly. As students felt more included into the environment, their focus could turn more to specific AT skills and application leading to improvement in self-confidence levels. This allowed students to gain a greater understanding of their identity within the environment. Active, consistent engagement also allows students to improve their understanding of what athletic training entails, true characteristics of athletic training and self-efficacy while in that environment.

Table 12 informs understandings of the challenges with the four AT programs. These insights are particularly important as they represent not simply initial impressions, but insights gleaned over several years of experience with the programs. 
Table 12

Students' Impressions of Challenges in AT

\begin{tabular}{|c|c|c|c|}
\hline University of Olympia & Kennedy University & Carlin University & University of Rawlins \\
\hline $\begin{array}{l}\text { Lack of recognition for } \\
\text { work performed }\end{array}$ & $\begin{array}{l}\text { Lack of recognition } \\
\text { for work performed }\end{array}$ & $\begin{array}{l}\text { Lack of recognition } \\
\text { for work performed }\end{array}$ & $\begin{array}{l}\text { public education on } \\
\text { profession }\end{array}$ \\
\hline $\begin{array}{c}\text { Lack of } \\
\text { understanding/knowled } \\
\text { ge of those outside of } \\
\text { AT to what it entails }\end{array}$ & $\begin{array}{l}\text { Lack of } \\
\text { understanding/knowle } \\
\text { dge of those outside of } \\
\text { AT to what it entails }\end{array}$ & $\begin{array}{c}\text { Lack of } \\
\text { understanding/knowl } \\
\text { edge of those outside } \\
\text { of AT to what it } \\
\text { entails }\end{array}$ & Lack of understanding \\
\hline $\begin{array}{l}\text { Misconceptions - } \\
\text { Trainer? Personal } \\
\text { Trainer? }\end{array}$ & $\begin{array}{l}\text { Misconceptions - } \\
\text { Trainer? Personal } \\
\text { Trainer? }\end{array}$ & $\begin{array}{l}\text { Misconceptions - } \\
\text { Trainer? Personal } \\
\text { Trainer? }\end{array}$ & Misconceptions \\
\hline $\begin{array}{l}\text { High hour load/difficult } \\
\text { schedule }\end{array}$ & Lack of regulation & Lack of regulation & $\begin{array}{c}\text { Lack of regulation - } \\
\text { licensure }\end{array}$ \\
\hline Low compensation & Underappreciated & High hour load & work life balance \\
\hline \multirow[t]{3}{*}{$\begin{array}{l}\text { Difficult work/life } \\
\text { balance }\end{array}$} & $\begin{array}{c}\text { Low compensation } \\
\text { compared to other } \\
\text { professions }\end{array}$ & Low compensation & \\
\hline & & $\begin{array}{l}\text { Difficult work/life } \\
\text { balance }\end{array}$ & \\
\hline & & $\begin{array}{l}\text { PT more attractive } \\
\text { with higher } \\
\text { salary/schedule }\end{array}$ & \\
\hline
\end{tabular}

Note: Orange $=$ present in all 4 cases; Blue = present in 3 cases; Green = present in 2 cases; Yellow= present in 1 case

Students had strong and consistent opinions about the challenges of AT as it would affect them as professionals in practice. They all saw and believed that the two major challenges were first, how outsiders to the AT profession perceived it and, more specifically, how ATs were conflated with personal trainers in everyday discourse. These two misperceptions were problematic, in students' opinions, because students are acutely aware of the knowledge base and skill set they have gained and acquired. AT students are held to programmatic requirements, standards and rigor throughout the program. Students are conflicted by other related professions being clearly understood and identified while AT remains in a confused misperception. Students' 
largest frustration lies with the fact that AT requires a minimum of a bachelor's degree and it is often confused with non-degree requiring professional designations.

Several students at all institutions, except the University of Rawlins, saw compensation and recognition as challenges for the AT field. It is interesting to consider why students did not perceive salary and recognition as problematic when they attended the University of Rawlins when they did at the other institutions. Perhaps that was a function of the kinds of programs they observed and the particular mentors and networks they became a part of as well as how the profession was discussed in the program. This is an important issue in a profession in which the details of the profession and salaries do range significantly by region and the specifics of the profession.

Additional areas that were significant concerns for most students at most schools were attention to regulation and licensure and work-life balance. Students are obviously aware that presently in the US, only seven states (WV, SC, NY, OR, HI, CO and CA) do not have licensure for ATs. Of those seven remaining states, only one, California, has no form of state regulation at all. West Virginia, Hawaii, Oregon, and Colorado are registration states while South Carolina and New York are certification states (BOCATC, 2018). Students understand that in healthcare professions, state regulation and state licensure govern those areas. Licensing requirements are put into place to secure a minimum standard, protect the public and establish a scope of practice for that profession. The lack of this licensing requirement and state regulation in West Virginia specifically de-emphasizes the value of the knowledge and skills needed to be a competent, qualified athletic training professional.

Students preparing for graduation and looking to their future career and adult lives picture a number of different things for themselves. Even while completing the program, some 
students found it challenging to balance and manage the time demands of athletic training. As students prepare and plan for a future that includes a spouse or significant other and eventually a family, students have observed and experienced the demands of a job in athletic training. Soonto-be-graduates even upon entry to the profession have already contemplated how long they may be able to continue in AT beyond graduation. Many reflected on the fact that, at present, they were young and able to travel with no commitments and the hours did not 'bother them for now'. These students were able to see potential work-life conflict arise though as their adult lives continue to transition into possible marriage, children and a family. Recognition that individual priorities can alter at that point was present.

An additional smaller conflict also arose within the Appalachian cultural context as three students from West Virginia and one from Maryland expressed a desire to return home to their high schools and provide athletic training coverage to those student athletes. These students had awareness of a need within their local communities and expressed wanting to return to give back to their community in that fashion. The conflict arises in the job availability in that area and their communal needs.

A student's ability to look beyond college and into what their future may include is the greatest application of Erikson's theory of stage transition (Erikson, 1968). These students are contemplating what their future may include or what they desire it to include at some point. Students are beginning to envision themselves in Stage Six. The exact timeline for this is what causes a small degree of uncertainty for them. As the students continue to transition into adulthood and further their psychosocial development, this may challenge Holland's theory slightly (1997). While students may possess matched personality traits that fit an athletic training environment that may not coincide with other factors or priorities that the student also desires to 
have in their life. The student will have to determine how to best include and manage those priorities and they realize that could involve a vocational change if they are unable to manage all simultaneously.

In sum, the six themes discussed in the cross case and corroborated through observation and discussions with college and university personnel suggest that athletic training possesses a unique set of positive attributes and challenges, specifically in West Virginia. Recognition of both positives and challenges may be ever important as educational programs transition from the bachelor's degree to the entry-level master's degree. These issues will be taken up and elaborated in Chapter Five, which presents the Implications and Conclusions for this project. 


\section{Chapter Five: Implications and Conclusions}

Chapter five of this dissertation summarizes the key findings of this dissertation related to the research questions of:

1. What are the factors, experiences, and/or circumstances that contribute to senior athletic training students approaching graduation planning to persist and pursue the athletic training profession?

2. What are the factors, experiences, and circumstances that contribute to senior athletic training students approaching graduation leading to displacement and not planning to seek employment in the athletic training profession?

The aim of this research study was to determine factors that influence athletic training soon-to-be graduates' decisions to persist in or displace from the athletic training profession. Athletic training has shown continual growth in the number of professionally certified individuals since 1950. For this growth to continue and meet the need of the projected employment growth of up to $21 \%$ from 2104 to 2024, displacement of graduates from ATPs must continually be examined (BLS, 2015, para. 1).

In Chapter Four, the evidence presented supports the six themes that emerged from the data. Through the examination of four different athletic training programs in West Virginia, this study identified attractors that draw students to pursue athletic training as field of study and the factors that influence a student's decision on college choice. Additionally, a student's initial impression of the athletic training environment, pros of an athletic training program and cons of an athletic training program were determined. Lastly, this research defined students' impressions of challenges of the field. 
This chapter extends the answers to the research questions. Conceptual, methodological and most importantly practice and policy considerations that emerge from this study are explored. Suggestions for future research in athletic training education and the larger context of the profession as a whole are also discussed.

\section{Conceptual Implications}

Two main theories guided this research inquiry, Erikson's Psychosocial Theory of Development and Holland's Theory of Vocational Personalities. Erikson's theory provides an understanding of where the student may be in terms of psychosocial development upon entry to college and the influences that affect that. Holland's theory, in contrast, provides a framework for existing personality traits and how those align with an individual's vocational choice.

Erikson's Psychosocial Theory of Development was applicable for the thirteen participating students. Application of Erikson's theory to the soon-to-be-graduates involves understanding the transition of one stage to another. While Erikson provides age ranges for transition and length of each stage of this developmental theory, the ages do not necessarily need be concrete and finite. Traditional aged college students are undergoing a transition from stage five to stage six. During this transition or psychosocial moratorium as described by Erikson, the young adult, or college-aged student, is permitted to explore and examine career possibilities, values, and societal roles. This often occurs free from the expectation of commitments and longterm responsibilities. As the individual moves through stage five and begins to cement an understanding of their personal identity, they seek how to mesh the roles and skills planted earlier with the ideals of the day. Identity confusion can occur in stage five that may delay or cause a longer transition from stage five to six. Identity confusion may lead one to experiment with different work or educational activities (Erikson, 1968). 
A negative consequence to identity confusion is vocational or educational experimentation that could result in a financial strain for the individual especially as the cost of education, specifically higher education continues to rise. Experimentation can lead to additional time to degree completion or skill acquisition that has financial implications. Students may feel pressure to graduate on time even though they are studying a field that is not best suited for them. These students may have earned a degree that they later feel is useless to them as they no longer have a desire to pursue that area as a career choice. Or students may elect to pursue additional schooling after graduation that could have been their original path and a more direct route by having a greater sense of identity upon entrance to their chosen field.

The soon-to-be-graduates clearly articulated their observations and interpretations of the subtleties of the athletic training profession, including the craft and culture. Students also were aware of some of the inner workings of the programs even though the program focus was on academic objectives and accreditation standards. Students are constantly learning from their surroundings and environment. All of this is occurring while the individual is determining what exactly their chosen career or vocational path will be.

As presented in Chapter Four, a history of athletics participation and a strong affinity for athletics was an attractor for all soon-to-be graduates to choose athletic training as a field of study. Even though this attraction was present, students regularly admitted that their knowledge of what athletic training involves was significantly limited upon entry to the program. Students gained a greater understanding of athletic training as they progressed to graduation. Students absorbed classroom, didactic and laboratory knowledge and skills, as well as out of the classroom knowledge and skills surrounding athletic training. Students' love of the athletic 
environment and their strong connection to an identity with athletics or sport connects them to the athletic training world as they are searching to shape their future of mature adulthood.

As students pursue their college education, a shaping continues of how the future looks for them as an individual, who they are and what they need. Students engaged in this study can be categorized into one of three categories: (1) used AT as a gateway to another predetermined profession from the onset, (2) fell in love with athletic training as their knowledge base increased and they anticipated a long-term career in AT, or (3) enjoyed AT a great deal and have immediate plans to pursue a short-term career in the field but as they look further into their future the length of that career is unknown at this time due to characteristics of the field. Students are still in the process of determining their own individual needs and desires. Many realize that those may continue to change over time. As these changes (i.e., marriage, children, family, etc.) occur, they realize vocational pursuits may change as well to better match their needs or wants. Application of Holland's Theory of Vocational Personalities in the context of this research study presented greater challenges. The overarching premise of Holland's theory is a matching of one of six personality types to one of six environment types. Athletic training is a social environment. Holland's social environment values social personality types who are helpful, friendly and trustworthy. Individuals in this environment typically excel at teaching, counseling, nursing, and medicine, providing information and solving social problems. Social personality characteristics are friendly, helpful, outgoing, cooperative, patient, empathetic and kind. Social personalities also like to work in groups, help with problems, provide service to others, or plan and supervise activities (Western Reserve, 2011).

While it is clear that athletic training is a social environment and the interviewed students possess dominant social personality characteristics, the secondary or tertiary personality 
characteristics of individuals were not as easy to identify in this case. Social personality characteristics of the soon-to-be graduates clearly rose to the forefront as the students recounted and described the positives of their relationship development with peers, faculty, preceptors, and athletes. Students also expressed interest in areas of healthcare professions and helping athletes, which match the social environment characteristics. Many soon-to-be-graduates expressed a desire to be within a team or collaborative environment.

Through Holland's theory, there are 120 possible personality variations that include the social personality as the dominant personality type. Personality type order of all six personalities was not identified in this particular study. Secondary, tertiary and other subsequent personality type order will vary from individual to individual. Greater understanding of this order in each individual may have shown to be beneficial to better match personality type and environmental models to vocational choice.

On other aspect that should be considered regarding Holland's theory is the possibility of a more sociological approach to personality psychology or vocational psychology is warranted in future studies. A pairing of merely personality traits and environment may help provide initial direction or focus interest but it may not result entirely in personal satisfaction on behalf of the individual as social contexts shift and change for the individual. Vocational choice, satisfaction and fulfillment can be impacted by a multitude of other factors, such as familial obligations, financial obligations, or work environment.

While not the main theoretical focus of this study and more of an underlying subcomponent, a sociological aspect considered is symbolic interactionism as termed by Blumer (1969). Application of the three basic principles of symbolic interactionism through interpretivism to the findings of this study can be explained as follows. The first principle states 
that human beings act towards things on the basis of the meanings that things have for them. The characteristics of an athletic training environment traditionally involve the nature of sport, athletics, or a team. Students derived meaning from their individual past experience within or around athletics. The attraction to athletic training arose from this meaning. This leads students to choose careers path that they relate to, connect to, or value.

The second principle of symbolic interactionism asserts that the meaning of such things is derived from, or arises out of, the social interaction that one has with one's fellows. Life decisions are impacted by interaction or influences of our family, environment, and culture, our lived life experiences. Students frequently referred to the importance of relationships, family and past, personal experiences within the context of their athletic training experience and future intentions. The third and final principle proclaims the meanings are handled in, and modified through, an interpretative process used by the person in dealing with things that he encounters (Blumer, 1969). We derive meaning from our lived life experiences and interactions that then influence and affect our future decisions and life path. Students are continuously processing and evaluating personal and professional experiences that inform new decisions. Employing the third principle must involve learning from one's past, living in the present and combining the experiences of those two to guide the future.

\section{Methodological Implications}

A pilot study utilizing students at my own institution was employed for this study prior to formal data collection. Through conducting this pilot, I gained practice in interviewing and probing techniques. It also helped to improve my listening and note taking skills during conducting the interviews. Execution of this pilot study also allowed for a greater understanding or comprehension by participants of the questions asked. The question testing allowed for the 
assurance that students would not be confused by wording or language contained within the questions. For others with limited qualitative interviewing experience, I would recommend employing pilot studies in their research to enhance the quality of the data collected.

The cross case analysis selected for this research identified that more similarities exist in the four cases examined than originally anticipated. The similarities of the cases may be a result of programmatic accreditation factors, institutions all within WV and the same higher education market, and/or the similar nature of athletic training student backgrounds. Also, interestingly the differences across the four cases appeared more inherently due to institutional context (e.g., institution size, general education curriculum requirements, athletic conference affiliation) than specific program delivery. By being an athletic training educator for the past twenty-two years at a single institution of higher education in West Virginia, I sought to determine if other ATPs around the state experienced similar or different paths of their program graduates as I had witnessed throughout my career at my own institution.

Prior to conducting this study, I assumed that the selected cases would have greater diversity within cases among the home states of athletic training students given the size and location of the cases. Greater diversity within cases would have also resulted in greater diversity across cases. The pool of thirteen volunteer students did not present as such with only one student from outside of WV or a bordering state. Recognizably, this may have been solely in the students who volunteered to be interviewed. Sampling or recruitment of students could have been more directed and purposeful in working with Program Directors in securing participants of greater diversity. Clearer criterion regarding gender, race, home state as an initial guideline for Program Directors may have resulted in greater participant diversity given the fact that programs did have overall enrollments that included greater variation to some or all of those factors but not 
necessarily all within the soon-to-be-graduating cohort. From a larger programmatic standpoint and as reported by the institutional representatives, overall student home state make-up was consistent with the initial assumptions. Comfort was found in the fact that the four programs appeared to be challenged by similar factors in terms of student recruitment, maintenance of CAATE compliance, and graduate placement.

The qualitative nature of this research provided greater detail and depth into beginning to find answers to the research questions than a quantitative study might have. Survey or quantitative methods would not have allowed the participants to tell their individual stories of how they were initially attracted to athletic training, what was gained by going through program, and more discretely their intentions following graduation. Face-to-face interviews and the opportunity to observe students in their own environment helped provide a contextual reference to the responses students provided to the interview questions. While qualitative methods have been utilized more and more in athletic training education research, qualitative methods need to continue to be utilized across all athletic training research and athletic trainers should be encouraged to engage in qualitative questioning. Qualitative research that examines more deeply into the challenges around public knowledge and understanding of athletic training may show of benefit to formulating effective solutions and strategies for improvement.

While qualitative research may be able to provide greater detail or depth to questions posed across athletic training, researchers should also consider the inherent demands of executing qualitative research. Qualitative research is a time extensive and may be of great challenge for the average practicing athletic trainer or educator managing full-time employment, familial commitments, or other interests. Seeking others within the profession across the country with common research interests leading to the creation of research teams could show beneficial 
in project execution and completion. Many athletic trainers are accustomed to working within a team or collaborative arena. Exploring research questions should be included in that.

For this research specifically, I was both an insider having worked in athletic training and athletic training in WV for over 21 years and at the same time an outsider as I am not involved directly with any of the specific cases studied. From these two perspectives, I was afforded advantages and disadvantages. Possessing the knowledge of CAATE accreditation standards, living a shared or similar experience with many of the students or institutional representatives, understanding the present climate of athletic training in WV, gaining access to cases for examination, and having the initial career information for 21 years of graduating cohorts each were advantages to conducting this study. Disadvantages experienced presented as attempting to gather enough information on each case to gain an intimate understanding of the program in its own individual context and lacking a more established relationship with students to filter through true responses versus responding in a manner that they thought they should or stating what they thought I wanted to hear.

Researchers embarking on a qualitative research project should consider the following advice and challenges. As mentioned thus far, qualitative research is a time intensive research process. The researcher should first outline an overall conservative timeline that guides the research process, especially a timeline for data collection, fieldwork, organization of data, analysis of data and reporting the data. Set a number of short terms goals for each part of the process. This will allow you to see accomplishment and maintain focus on the larger goal. Secondly, maintain good notes or journaling (written or audio) of your thoughts along the way as you work through each step and process the data. Replaying audio tapes while reviewing interview transcripts proved to be of tremendous benefit as I began coding each one. The 
auditory and visual reminders of personal notes took me back, in a sense, to the actual interview. As you begin to compile these notes, create a system of organization that makes sense to you. The amount of data you collect can become overwhelming if you do not have a sound organizational structure to maintain it. This will also help in preventing any key components from getting lost or hidden along the way. Continuously refresh your memory of the conceptual framework so these concepts remain in the forefront of your analysis and subsequent conclusions. Lastly, finding a trusted colleague, friend, or advisor for support, occasional debriefing or data dumping allows the researcher to process and talk through the larger practice implications of the findings in the data.

\section{Practice and Policy Implications}

As illustrated in Chapter Four through the data from the interviews with institutional representatives, employment availability in a student's familiar geographic location, and as suggested by Stilger and colleagues (1999), athletic training employment issues appear to be a potential factor of athletic training graduate attrition. Seven of the thirteen participating soon-tobe graduates were from West Virginia while the remaining six students were from Maryland (3), Ohio (1), Pennsylvania (1) and Delaware (1). A review of current available job opportunities listed on the NATA Career Center as of October 11, 2018 shows the following number of available full-time employment positions (out of a total of 149 full-time positions) in each of the respective home states, NATA District III (West Virginia, Maryland, Virginia, North Carolina, South Carolina and DC) and other states mentioned by the participants:

$\begin{array}{llllll}\text { West Virginia } & 2 & \text { North Carolina } & 8 & \text { Texas } & 10 \\ \text { Ohio } & 1 & \text { South Carolina } & 4 & \text { Florida } & 8 \\ \text { Pennsylvania } & 5 & \text { District of Columbia } & 0 & & \\ \text { Maryland } & 9 & \text { Virginia } & 6 & & \\ \text { Delaware } & 7 & & & \end{array}$


A further breakdown of those vacant positions results the following job requirements.

Table 13

NATA Job Posting Qualifications (NATA, 2018c)

\begin{tabular}{|c|c|c|c|c|c|c|}
\hline & $\begin{array}{c}\text { BS } \\
\text { Required }\end{array}$ & $\begin{array}{c}\text { MS } \\
\text { Preferred }\end{array}$ & $\begin{array}{c}\text { MS } \\
\text { Required }\end{array}$ & $\begin{array}{c}\text { Earned } \\
\text { Doctorate }\end{array}$ & $\begin{array}{c}\text { Experience } \\
\text { Required } 5 \\
\text { years }+\end{array}$ & $\begin{array}{c}\text { Additional } \\
\text { Professional } \\
\text { Credentials } \\
\text { Required }\end{array}$ \\
\hline WV & 2 & & & & & \\
\hline $\mathrm{OH}$ & & & & 1 & & \\
\hline $\mathrm{PA}$ & 1 & 1 & 1 & 2 & & \\
\hline $\mathrm{MD}$ & 8 & & & & 1 & \\
\hline $\mathrm{DE}$ & 4 & 3 & & & & \\
\hline $\mathrm{NC}$ & 4 & 3 & & 1 & & \\
\hline $\mathrm{SC}$ & 4 & & & & & \\
\hline $\mathrm{DC}$ & 0 & & & & & \\
\hline VA & 3 & 1 & & 2 & & \\
\hline $\mathrm{TX}$ & 1 & 3 & 2 & 2 & 1 & 1 (PT) \\
\hline FL & 6 & 1 & & & & 1 (CSCS) \\
\hline
\end{tabular}

The limits of job availability in a student's home state are clear and apparent, as one must also consider the competition for job placement from other AT program graduates not included in this study from the four West Virginian institutions represented as well as other CAATE accredited ATPs across the US.

Of the 45 example positions shown that entry-level graduates could consider applying for, master's preferred positions included, in Table 13, fifty-seven (57.8) percent of those are within the five states represented outside of the students' five home states, which supports the limited employment possibilities for athletic training graduates within and around West Virginia. Job availability does appear to vary across the United States and employment opportunities are available. Athletic training educators in West Virginia need to be aware and cognizant of the impact that Appalachian culture has on its youth and the role the culture plays in their professional development and aspirations. These young adults possess strong ties and 
commitment to their family culture, their communities and their states, especially those from West Virginia. West Virginian students, specifically, expressed desires of returning to their high schools to be an AT and give back to their community in that fashion. Students desire the ability to remain close with friends and family as they begin starting their own adult lives.

Program educators, faculty and institutions involved in athletic training education should implement practices to foster students' knowledge of employment possibilities within West Virginia, as well as out of West Virginia. Career counseling and career mentoring should begin early in a student's academic career and continue throughout the program (Mazerolle et al., 2016). Instructing students on job search preparation, developing a resume, interview preparation, methods of locating employment opportunities, the discussion of career options, and career service centers is also supported by the previous research of Stilger et al. (1999). Understanding a student's short-term and long-term career goals upon entrance to the program and following those throughout completion of the academic program will allow educators to more effectively advise and mentor students on career pathways and employment opportunities. Programs should also consider recruiting diverse faculty/preceptors with differing professional backgrounds and connections to be involved with the program to broaden the professional network available to program students and graduates. Strong alumni connections, encouraging or even requiring students to complete various outside internship opportunities, travel opportunities to meet other athletic trainers or observe additional athletic training venues or inviting perspective employers to campuses to speak with students are all ways to improve a student's understanding and knowledge base of what employment opportunities are available to them upon graduation. Bowman and Dodge (20111) also suggest students having the opportunity to visualize themselves practicing a career in AT. By expanding the number of positions a student 
is exposed, the program can assist the student in that visualization process. In today's technological age, programs could consider utilizing video conferencing as a means to enhance a student's professional network.

With a limited job market in West Virginia, programs and career counselors will need to mentor all students, but especially West Virginian students, on how to be strategic in their employment search. A student should be encouraged to look at their career as fluid and flexible over time. Any single job or location does not need to be viewed as forever. Educating students on the fact that temporarily leaving the state or their home could prove beneficial. Being able to have experiences outside of what is familiar and comfortable to them will allow the student to grow personally and professionally. Programs and graduates should embrace that bringing outside perspectives and experiences, both positive and negative, back to West Virginia will aid in making improvements in athletic training across the state. Students should be encouraged to maintain their connections to their West Virginian alma maters and homes, and constantly be aware of new or open employment opportunities for them to return home. Programs can encourage graduates to remain actively involved through serving as potential internship sites, sharing lived professional experiences with current students, guest speakers, journal clubs or even creating mentorship connections between graduates and current students. Programs can use Alumni Highlights in newsletters, websites or social media as well to facilitate those connections. Additional ideas are having students make connections to other ATs at home or locally to the program. Students could complete interviews with that AT and then share their experience with classmates or even connect this to an AT promotion or NATA Month. All of these activities will allow students to build a professional network of their own as well as improve a student's professional socialization into the profession. Educators need to be reminded 
that professional socialization also includes an organizational socialization aspect in which individuals enter the work force (Mensch et al., 2005; Pitney, 2002, 2006; Pitney et al., 2002).

Cultural context was an important component to this study. Athletic training and athletic training education in WV presents its own set of unique Appalachian cultural challenges. Recognition of those cultural challenges and strong ties to WV will allow educators in the state to better serve all students, but especially those from West Virginia who desire to remain close or connected to home. Athletic training advocacy outside of the profession also continues to be a challenge present in West Virginia with the lack of understanding of what AT entails encountered by participants. Nurturing and developing advocacy networks outside of athletic training around the state will improve the overall status of the profession. Career mentoring and strategy development need to sensitive to learning about cultural contexts and multiculturalism inside and outside of West Virginia when supporting students in making connections and building networks. Programs need to be exploring ways to address gender discrimination in Athletic Training that lingers through opportunities and support as well as educating students about the socio-political context as it affects recruitment and hiring.

Personally and professionally, completion of this project has given me greater insight into the importance of career mentorship and advisement. Program educators, myself included, can often lose focus on educational competencies, skill acquisition, exam pass rates, and accreditation standards. Through conducting this research, I have gained a greater understanding of the role programs should take in assisting students and graduates in finding suitable and wellmatched job placements. Educators need to avoid falling into the trap of sending graduates out into the world of job searching entirely on their own. This can and should be something that is 
discussed early and continually throughout the program and there are ways to implement this without significant challenge to the program.

As one example, more specifically, in my own program, implementation can be accomplished through extending our mentoring program that we presently have in place for first year students to continue throughout the program. This would allow athletic training students to carry one mentor through the program, in addition to, the mentorship received by various clinical preceptors. Directed mentorship needs to understand a student's long-term career aspirations and then advise the student on how to best achieve their goals. Faculty and staff training and guidance will need to be incorporated into this implementation as well. Expansion of an athletic training student's personal and professional network and knowledge will better allow the student to fully realize the opportunities available to them and how to best be successful at pursuing those.

Producing marketable, employable graduates in various athletic training settings will impact both individual and institutional identities. Characteristics of individual identity are tied to vocational choice as seen by applying Erikson's theory. Through mentorship, networking and career placement counseling, programs can assist students in improving the match of their personal identity to job placement within athletic training. Appropriate mentorship can aid in development of the student's professional identity (Mazerolle et al., 2016). Increasing the employability of program graduates will then in turn have a positive impact on institutional identity through expansion of the program network and further marketability due to its cyclical nature.

Societal perceptions of athletic training is another area found in this study that needs to continually be evaluated and assessed by professionals in the field. In earlier research by Benes 
and Mazerolle (2014), the presence of public misconceptions about the profession and a lack of respect for the profession were present. Building from those findings, similar perceptions were clear and consistent across all cases examined in this research that athletic training students and educators regularly encounter a lack of understanding regarding athletic training or public misconceptions about athletic training. Athletic trainers need to continue public education efforts within local communities as well as at the state, district and national levels. Ongoing, regular consistent efforts with a clear and consistent message needs to be shared across all practitioners, educators and students. NATA Month campaigns filtering to local communities need to continue. Other examples may include inviting others (administration, faculty, staff, other healthcare professionals, etc.) within your community to an AT Open House or a Meet an AT Day. Program students can assist with these efforts as a volunteer or course requirement. Encourage visitation of high school students to your facility for career shadowing or participate in career days. Programs may even decide to co-host an event in a neutral location. Continue to use the local media and social media in these efforts. These are just a few ideas of how correct information regarding athletic training can be shared in attempt to improve public education

Athletic training is inherently a job that often occurs behind the scenes and in an isolated manner. Mensch and colleagues (2005) concluded that even varsity basketball coaches working with athletic trainers possessed a limited knowledge and understanding of athletic trainer's qualifications, professional preparation and experiences. With strong roots remaining in the traditional athletic training settings of high school, collegiate or professional sports, a large percent of athletic trainers work in areas with athletes and other athletic trainers. Athletes or athletic trainers are not as commonly found in the populations that need education on what athletic training is or what athletic trainers do. Visible components of athletic training are: 
providing ice, water, taping, sideline activity, or being the one running onto the athletic field when an athlete is injured. Participants at each case site admitted having their own initial lack of understanding and misconceptions or encountering others with the existing public misperceptions. Recall the comments from KU students, "I really just thought that an athletic trainer would work in a high school or college as an ankle taper or water bottle filler" (Interview, Cori, March 1, 2017), or “...as what everybody else sees it as. Somebody that stands on the sideline and is there for immediate medical assistance" (Interview, Abbey, March 1, 2017). Or Chloe from UR as she expressed her frustration, "It really, really bothers me when people say, "Oh you' re glorified water girls" or whatever" (Interview, Chloe, March 24, 2017). Athletic trainers need to continually bring the behind the scenes skill set to the forefront for the public to see and appreciate. Those behind the scenes skills are expertise in injury/illness prevention and wellness promotion, examination, assessment and diagnosis of injuries/illness, therapeutic intervention, immediate and emergency care skills and healthcare administration. Athletic trainers are leaders and experts in concussion evaluation and management. A sample of an athletic trainer's daily work responsibilities can be found in Appendix F: Sample AT Position Descriptions.

As a start, athletic trainers should be encouraged to improve education among coaches and coaching staffs to better the understanding and perceptions relayed to others regarding the profession and the required skill set. Starting on the frontlines and enhancing education of those that ATs work most closely with day in and day out can lead to greater advocacy from others outside of AT. Fostering relationships with coaches and coaching staffs then can enable athletic trainers to employ coaches in high profile and influential positions (i.e., those at large, wellknown NCAA Division I institutions) to assist in their own AT education and advocacy efforts. 
The same or similar efforts can be used with high profile athletes as well. For example, the NATA advocacy group has utilized Kobe Bryant of the Los Angeles Lakers to increase education and awareness.

Athletic trainers also need to be thoughtful in the message sent to others regarding the profession and skill set. The misconceptions need not be reinforced and actions to help eliminate them should be taken. For example, when athletic trainers or athletic training educators are developing educational or promotional pieces, careful consideration as to what is included in the publication is important. Athletic trainers should be utilizing consistent and recommended language by the NATA, BOC and CAATE in media and in practice. Examples of language variances are trainer versus athletic trainer or training room versus athletic training facility/clinic. If photographs or illustrations are used, select images that represent the full skill set of an athletic trainer and highlight the behind the scenes skills that are less acknowledged or understood. Avoid images that represent athletic trainers in a stereotypical light. Athletic training program administrators and athletic training staffs will need to educate others around them of the same. Patience, consistency and unified efforts are necessary in public education advancement.

Program educators, including clinical preceptors, need to assist and educate athletic training students on answering the question, "What is an Athletic Trainer?" Athletic trainers and athletic training students feed the lack of understanding of the profession and fall victim by answering that question at times with a response of, "Have you ever watched sports on TV and seen the people that run onto the field when an injury occurs? That's me. That's what athletic trainers do." Using this or a similar response fuels the confusion around the skill set and knowledge required to be an athletic trainer. Athletic training students and athletic trainers should avoid the convenient, 30-second, canned answer. When the appropriate behavior and 
language is modeled for students through the educational component of becoming and AT, the students will continue to emulate that upon entry to the profession. These concepts relate to the process of professional socialization (Mensch et al., 2005; Pitney, 2002, 2006; Pitney et al., 2002). Athletic training can also benefit by involving multiple generations, older to young, of athletic trainers involved in these efforts as this could allow various perspectives on relaying the message to the public.

Educators need also be reminded that students are influenced by their experiences and others around them. The second principle of Blumer's symbolic interactionism illustrates these influences (1969). Positive preceptor engagement and interaction with all student levels in the program should occur early and often, otherwise, students may perceive themselves as outsiders and feel uncomfortable in the environment. Successful mentoring and professional socialization in athletic training may further influence a student's identity formation as the student gains a greater understanding of who they are and what that means as explained by Erikson (1968). Athletic training advocacy influences may become a part of that identity as the student progresses to professional entry to the profession. In the context of Holland's theory (1997), modeling and mimicking athletic training advocacy, may support an improved pairing of personality type and vocational environment.

Lastly, the concepts of burnout (Capel, 1986; Campbell et al., 1985; Clapper \& Harris, 2006; Giacobbi, 2009; Hendrix et al., 2000; Kania et al., 2006) and how that is related to professional socialization continue to present challenges for the profession of athletic training. Athletic training students seem more aware of the demands and subtleties of the profession than many may realize. While athletic training educators and preceptors are focused on instructing athletic training students in the necessary skill sets, meeting skill competency levels, maintaining 
accreditation standards and BOC examination preparedness, athletic training students are absorbing more than the technical skills, required educational competencies and abilities of the profession. Athletic training students recognize the impact of irregular, inconsistent or last minute changing athletic training schedules, the number of hours worked each day/week, the stress and strain that can be placed on an athletic trainer with a family, the perceived lack of respect from others ATs, and/or low compensation scales. One or all of the listed factors can be potential sources of burnout for an athletic trainer or lead to poor job satisfaction, but as educators, we need to possess a self-awareness of how we handle each particular instance or situation and what message that sends to athletic training students about the profession.

Each day presents with conflict or stress to some degree and the workplace is not immune to this. Athletic training program leaders and faculty need to equip those involved with the program with the necessary tools and tactics to be able to deal with professional realities of various athletic training settings. The recommendation is not to create a false sense of professional utopia for athletic training students but to better prepare them to handle workplace stress or conflict. Entering athletic trainers need be prepared for the organizational socialization phase that enables individuals to adjust to the demands of the profession (Mensch et al., 2005; Pitney, 2002, 2006; Pitney et al., 2002).

As concluded by Klossner (2008) clinical education experiences and clinical educator interaction of knowledge application allow for the definition of role expectations within a profession. All educators, didactic and clinical, should strive to create learning experiences for all aspects of the field, not just skill acquisition, that provide students with a sense of affirmation and feelings of legitimation. This will facilitate socialization in developing athletic trainers. Consider the following example. An athletic trainer serving as a clinical preceptor for a 
sophomore level athletic training student receives notice that an athletic practice for that day has just been rescheduled for three hours later than originally scheduled. This rescheduling of practice could potentially change the entire outlook of that athletic trainer's workday. The preceptor needs to be encouraged to be equipped with an administrative policy to follow that affords the preceptor and athletic training student protection to some degree. Should this policy not be in place for protection, the program and the preceptor need to be conscious of how to respond to this situation. Empowering the practicing athletic trainer in the preceptor role teaches the athletic training student the subtleties of the profession in a real life context. Seeing a negative reaction by the preceptor with only complaining about what has just transpired is what the program should strive to avoid. Taking advantage of the workplace conflict that has presented, discussing potential ways of handling the conflict and finding appropriate, and finding professional resolution to the problem should be presented to the student. Professional socialization needs to be evaluated on a continual basis by programs.

Preparing students to better manage workplace conflict or stress and enhancing their socialization to the profession may lead to greater job satisfaction and lower burnout rates. In considering workplace conflict and burnout, I am reminded of Eric's comment cited previously: And then the hours (pause). The hours are kind of, hmm, not really coordinated because one-time practice might be at six in the morning and then the next one. So, you can't really make plans. I can see why athletic training kind of has, like, a burnout because of hours especially with the pay. (Interview, Eric, February 9, 2017)

Students need to be encouraged, empowered and understand how to resolve situations that may result in stress as he describes. Students' self-efficacy in facing the conflict when it arises after entry to the profession will be improved if students are given a knowledge base and strategy pool 
to draw from during their educational experience. Programs should include mentorship and education on effective workplace communication and professionalism that is consistent throughout the educational experience. Enabling students in creating solutions to workplace conflict for athletic trainers can lead to an overall improvement in the profession, a decrease in the perceived challenges, as well as lower burnout as presented by Capel (1986), Kania and colleagues (2009), and Clapper and Harris (2006).

\section{Limitations of the Study}

One significant limitation of this study is its generalizability to other athletic training programs and senior athletic training students approaching graduation. Only participants from four West Virginian entry-level undergraduate ATPs were studied. The determined results are not entirely applicable to students approaching graduation of entry-level master's programs or states other than West Virginia. It is also necessary to recognize that some senior students' decisions had not been finalized when engaged with the researcher. The researcher recognizes that the intentions of the soon-to-be graduates may have changed after data collection due to a number of factors including, but not necessarily limited to, graduate school acceptance/denial, employment opportunities or offers, or decisions that were based on family obligations.

The absence of prolonged engagement is another limitation. Each participant only completed one interview session. Multiple interview sessions may have provided more insight into decisions to persist in, or leave athletic training. Additional follow-up with soon-to-be graduates following graduation at a 3- to 6-month period may have provided the researcher with more concrete plans on the students' selected career paths. This would have allowed the researcher to compare students' intentions to students' lived realities. 
In conducting a qualitative study, research bias must be recognized and at times can be considered a limitation. As described in Researcher Positionality previously, I have been involved in the athletic training field for the past 27 years in some capacity or another. This is the primary reason why I chose to study the influences on students that result in them persisting or not persisting in the field of athletic training. The majority of my 27 years have been spent in the traditional collegiate athletic training setting. For the past 21 years specifically, I have been working with athletic training students and athletes at a small, private liberal arts institution located in north central, rural West Virginia. For the past 10 1/2 years, I have served as a Program Director for an ATP. Throughout my professional career, I witnessed many students successfully complete the academic and clinical requirements of the ATP and then essentially choose one of three career paths: continue in the profession of athletic training, pursue a career in a different healthcare field, or choose a completely different career path. My own professional pursuits, experience and interests guided the basis of this inquiry. Due to the nature of this study being a doctoral dissertation, investigator, or multiple analyst triangulation, was not feasible, permissible or realistic. Multiple researchers examining and analyzing collected data may have checked any bias present.

\section{Ideas for Future Research}

Possessing a greater understanding of the complexities of the profession of athletic training, which involve the dynamics of individual attraction, career guidance, professional placement opportunities and challenges that need addressed for overall improvement in the field is important for all athletic training educators and leaders. All of these areas need to be researched more intently and purposefully. While all the findings of this and past research may not be completely applicable to the current transition to an entry-level master's degree, some 
components and context will be transferrable. It is unknown at this time what impact the transition will have on the profession in regards to recruitment, retention, job availability, compensation or societal perception.

Attractors to athletic training determined in this study vary greatly for individuals pursuing an entry-level master's program. In future research, exploring and utilization of various vocational assessment tools in athletic training could show benefits of improving retention in educational programs and the profession. Athletic training offers numerous employment settings. Finding that an individual is matched for athletic training is step one. Step two involves matching that individual to the appropriate setting within AT. A more in-depth understanding of factors of persistence should also be incorporated into this matching of individual and setting. Suggested career mentoring will be more directed with the appropriate set of vocational assessment resources. Additionally, if continual solutions are not found to improve the perceived challenges that exist, they will remain regardless of the degree level for entry into the profession.

One additional aspect to be explored in the future and, especially as AT education transitions to the entry-level master's degree requirement, is to determine if any differences exist in a student's perception of pros and cons relative to where the AT program is organizationally housed academically (e.g., in health sciences or in physical education/sport science). Societal perception should also be included in this examination. Research findings will help to inform athletic training educators, higher education administrators and CAATE on the best practice standard for athletic training education programs.

Future studies also need to examine the impact of societal perception or a lack of understanding of AT and the relationship to employee burnout. Research should examine the result of societal perception throughout different AT settings and the impact on ATs in those 
respective settings to identify similarities or differences. Additional research should include the exploration of professional socialization, how students are prepared for entry and the role it plays in burnout after entry to the profession. Lastly, future research in athletic training needs to examine AT education and the profession as a whole from a greater sociological perspective examining the components and impact of race, gender, class and sexuality. Identifying deficiencies of sociological diversity will assist in developing ideas and strategies for improvement.

\section{Conclusions}

Through completing this research study, I have gained a greater awareness and recognition of athletic training education, deficiencies in that education in mentorship of students, and a broadened understanding of the challenges facing AT in West Virginia. Findings in this study will better inform my ability to be an effective athletic training educator as I continue to evaluate the practices and outcomes of my own program. While AT educators are firmly committed to passing on the craft of AT to students and developing competent, qualified practitioners and professionals, there are aspects that are in need of additional attention. In the four cases studied, educators should feel a sense of pride in their soon-to-be-graduates as each of the students felt adequately prepared to leave the safe boundaries of their college and university setting and enter the employment market with the needed skills and qualifications to perform the job. However, the same cannot be said of the students' confidence level in securing a desired athletic training employment position in their immediate future. As an educator, personally, I want my graduates to find employment opportunities with ease and, in an ideal world, to produce program graduates that are sought after by potential employers in West Virginia and beyond. 
The attractors of athletic training require additional research and greater understanding especially as the transition to the entry-level master's degree takes place. Programs and institutions need to understand how to recruit and retain students with an affinity for athletic training. This affinity may change though from what educators have been accustomed to as the majority of students entering athletic training programs in the future will be 21-22 years of age or older. These individuals will have a different level of psychosocial development, possess a different level of maturity and may or may not have the same identity characteristics of students of the past. These differences in student demographics may help alleviate a challenge faced in athletic training education, in terms of, athletic training student attrition. This change might also bring a more focused curricular delivery but may create new and different challenges for student recruitment.

Athletic training educators need to continue to utilize each other and their respective institutions as valuable resource networks for each other, especially in a small state like West Virginia. While they each have their own programmatic goals and identity, athletic training advocacy can be a joint effort throughout the state and beyond. More effective communication about employment opportunities and job markets around the state should be shared within this network to improve graduate placement.

In this time of degree transition, educators need to have a strong pulse on the positives and negatives of athletic training education and the challenges present in the profession. Possessing an intimate knowledge of these, even at the bachelor's level, should not be overlooked or undervalued. Creative implementation of the positive aspects of athletic training education need to occur with the goal of enhancing those positives. On the other hand, fully understanding the negatives of athletic training is also useful so that the same do not present 
themselves during or after the degree transition. To conclude, continual evaluation of the challenges in athletic training, perceived or real, must occur and all involved with AT should work together in developing effective solutions to overcoming the challenges for the betterment of the profession. 


\section{Appendix A: Student Participant Questionnaire}

Name:

Gender:

Age:

Place of permanent residence:

Hometown:

Undergraduate CGPA:

email:

$$
\begin{aligned}
& 4.0-3.5 \\
& 3.49-3.0 \\
& 2.99-2.5 \\
& 2.5-2.0
\end{aligned}
$$

Please rate your confidence level in your athletic training skills on the following scale. Please circle.

$\begin{array}{ccccccc}1 & 2 & 3 & 4 & 5 & 6 & 7 \\ \begin{array}{c}\text { Little to no } \\ \text { confidence }\end{array} & \begin{array}{c}\text { Somewhat } \\ \text { confident }\end{array} & \begin{array}{c}\text { Below average } \\ \text { confidence }\end{array} & \text { Confident } & \begin{array}{c}\text { Above average } \\ \text { confidence }\end{array} & \begin{array}{c}\text { Very } \\ \text { confident }\end{array} & \begin{array}{c}\text { Extremely } \\ \text { confident }\end{array}\end{array}$

How was your education financed? Check all that apply.

Scholarships

Grants

Loans

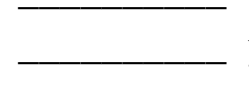

yours parents

other

Parents

Other

Estimated family/household Income

25,000-40,000:

41,000-55,000:

56,000-70,000:

71,000-85,000:

86,000-100,000:

$100,000+$ :

Professional certifications:

Currently hold:

CPR/AED

Healthcare Provider:

CSCS:

C-PT:

EMT-B:

Other: (please provide 
Plan to pursue:

CSCS:

C-PT:

EMT-B:

Paramedic:

PA:

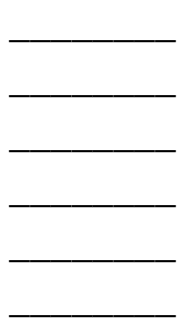

PT:

$\mathrm{RN}$ :

$\mathrm{MD} / \mathrm{DO}$ :

DC:

ATC:

Other:

BOC Exam Anticipated Date:

Desired entry level salary upon entering the workforce full-time: 


\section{Appendix B: Approaching Graduation Student Interview Protocol}

Good morning/good afternoon/good evening, thank you for participating in this research study. The purpose of the study is to examine the career intentions of soon to be athletic training graduates. This study is being conducted in partial fulfillment of the doctoral degree requirements I am pursuing at West Virginia University. I would like to audiotape this interview in order to accurately represent what you say; may I have your permission to tape this interview? Before we begin, I want to make sure you understand the following:

- Your responses will be kept anonymous or confidential; at no time will your name be revealed during reporting.

- Your name will not be attached to either the tape or notes from this interview, or to transcribed data.

- Your participation is entirely voluntary, you can choose to stop the interview at any time and you do not have to answer every question.

- Your class standing, grades, or job status will not be affected by your refusal to participate or to withdraw from the study.

1. Can you begin by sharing your experience with Athletic Training prior to coming to $?$

- Personal experience as an athlete?

- High school experience with AT?

- Family experience with AT?

- Other experience with AT?

2. Describe how and why you chose AT as an undergraduate academic major.

- Was AT your first major choice?

○ What other majors did you consider? Please elaborate why you considered that/those.

○ What aspects of ___ helped you chose that university/college to attend?

- Geographic location?

- Cost? (refer to financing of education)

- Reputation of school/program?

3. What aspects of being an undergraduate athletic training student have you enjoyed?

Disliked?

○ Relationships with faculty? Preceptors? Athletes? Peers?

- Classroom experiences?

- Clinical experiences?

- Hours? Schedule?

- Requirements of program?

- Travel?

- Workload?

- Describe the characteristics of an AT environment.

○ How do you see yourself fitting into an AT environment? Why do you fit? Not fit? 
4. On the questionnaire you ranked your confidence level in your AT skills as a , would you please explain that response in more detail now?

- Preparation for entering the workforce?

5. What are the challenges that you feel the AT profession is facing presently?

- Society's perception of AT?

- Workload demands?

- Work-life balance?

- Have you heard or read anything regarding salary for ATs? How do you think that compares to (if other professions of interest)?

○ How do you feel other professions impact AT? Ex: Physical Therapy?

6. What are your professional plans upon graduation? (If AT, proceed to number 8. If not AT, proceed to number $7 \mathrm{a} / \mathrm{b}$.)

○ Employment? Where? Desired location?

- Graduate School? What degree are you seeking?

- Intentions after obtaining that degree?

o Other?

7a. If not pursuing AT or further education in AT:

Do you expect to use the skills acquired as an undergraduate ATS (athletic training student) in the future as you (insert response from \#6)? If so, please share how you anticipate using those skills?

7b. Describe the factors causing you not to pursue a career in athletic training.

- Was salary a factor?

- Was the availability of a position a factor?

- Was job status a factor?

- Demands of workload-hours, etc.

- Something else?

8. Where do you see yourself in 5 years?

a. Professionally?

i. Work Setting?

b. Personally?

i. Married? Single? Family? Living in

c. Describe a picture of what your life may look like.

9. Is there anything I haven't asked about that you think I should know for this study? 


\section{Appendix C: Institutional Representative Pre-Interview Transcript}

Thank you for participating in this research study. The purpose of the study is to examine the career intentions of athletic training students approaching graduation. This study is being conducted in partial fulfillment of the doctoral degree requirements I am pursuing at West Virginia University. This questionnaire is being provided to you in advance so that you can familiarize yourself with the information that I wish to obtain during a follow-up face to face interview and realizing some inquiries may require additional time for you to determine. Please feel free to use this sheet or additional sheets to make notes or provide responses.

1. Please describe your background as an Athletic Training Educator.

2. Describe your role as an Athletic Training Educator.

- What are your desired learning outcomes for your students?

- What are the programmatic learning outcomes set by your institution?

- What strategies have you found to be most effective? In what context do these occur? 
- What is important for students to know that can best be taught outside the college classroom?

- What other elements of your role have I not asked about that you believe are important?

3. What career or educational plans have your current senior students shared with you?

- How many graduating seniors are currently enrolled in your program?

- How many plan to enroll in graduate school? Of these, what areas do they plan to study?

- How many hope to enter the work-force? Which positions will they target? 
4. In tracking your program's graduates, what are their backgrounds and where are they now?

- Where are your students from originally? What percentage are from WV? What percentage are from other states?

- Of those graduates who have chosen AT careers, in which settings and locations are they now working? Of those graduates who have chosen to go on to physical therapy training, in which settings and locations are they now attending school?

- Of those graduates who have chosen to attend physician's assistant training or medical school, in which settings and locations are they now attending school? Other?

- Have you noticed any particular trends regarding students' career choices?

5. What professional settings are your students exposed to through the curriculum (for example, as field trips, practicum settings, internship placements, guest speakers, etc.)? 
6. What are the challenges that you feel the AT profession is facing presently?

7. What are the local and regional employment placement rates of ATs?

8. Please describe the factors that influence new graduates' career paths in AT, both positively and negatively.

9. Is there anything I haven't asked about that you think I should know for this study? 


\section{Appendix D: Institutional Representative Interview Protocol}

Thank you for participating in this research study. The purpose of the study is to examine the career intentions of athletic training students approaching graduation. This study is being conducted in partial fulfillment of the doctoral degree requirements I am pursuing at West Virginia University. I would like to audiotape this interview in order to accurately represent what you say; may I have your permission to tape this interview? Before we begin, I want to make sure you understand the following:

- Your responses will be kept anonymous or confidential; at no time will your name be revealed during reporting.

- Your name will not be attached to either the tape or notes from this interview, or to transcribed data.

- Your participation is entirely voluntary, you can choose to stop the interview at any time and you do not have to answer every question.

1. Please describe your background as an Athletic Training Educator.

- How many years have you worked as a preceptor?

- How many years have you worked as a PD?

- How long have you worked in your present position?

- What is your experience working at other institutions?

- What is your experience working with AT students outside of your present institution?

2. Describe your role as an Athletic Training Educator.

- What are your desired learning outcomes for your students?

- What are the programmatic learning outcomes set by your institution?

- How do you mentor students?

- What strategies have you found to be most effective? In what context do these occur?

- What is important for students to know that can best be taught outside the college classroom?

- How is work-life balance taught to students throughout the program?

- What other elements of your role have I not asked about that you believe are important?

3. What career or educational plans have your current senior students shared with you?

- How many graduating seniors are currently enrolled in your program?

- How many plan to enroll in graduate school? Of these, what areas do they plan to study?

- How many hope to enter the work-force? Which positions will they target?

4. In tracking your program's graduates, what are their backgrounds and where are they now? 
- Where are your students from originally? What percentage are from WV? What percentage are from other states?

- Of those graduates who have chosen AT careers, in which settings and locations are they now working? Of those graduates who have chosen to go on to physical therapy training, in which settings and locations are they now attending school?

- Of those graduates who have chosen to attend physician's assistant training or medical school, in which settings and locations are they now attending school? Other?

- Have you noticed any particular trends regarding students' career choices?

5. What professional settings are your students exposed to through the curriculum (for example, as field trips, practicum settings, internship placements, guest speakers, etc.)?

- Traditional - collegiate/high school/professional sports

- Military

- Hospital/clinic

- Outreach AT

- Industrial

- Physician's offices/physician extender

- Other

6. What are the challenges that you feel the AT profession is facing presently?

- Is society's perception of AT a challenge? Why/why not?

- Are workload demands challenging? Why/why not?

- Is work-life balance challenging? Why/why not?

- Is compensation an issue? Why/why not?

- Does competition with other professions (e.g., physical therapy) present a challenge? Why/why not?

- What other challenges do you see?

7. What are the local and regional employment placement rates of ATs?

8. Please describe the factors that influence new graduates' career paths in AT, both positively and negatively.

- Lack of employment opportunity

- Hour demands of positions

- Work-life balance

- Entry-level salary

- Relationships with preceptors/mentors

- Relationships with patients

- Others?

9. Is there anything I haven't asked about that you think I should know for this study? 
Appendix E: Coding Sample

\begin{tabular}{|c|c|c|c|}
\hline Site 4-1 & Site 4-2 & Site 4-3 & THEMES \\
\hline EXPERIENCE WITH AT & EXPERIENCE WITH AT & EXPERIENCE WITH AT & $\begin{array}{c}\text { Attractors to Athletic } \\
\text { Training }\end{array}$ \\
\hline relationship with HS AT & No exposure to an AT & HS AT (basic AT things) & HS Athlete \\
\hline shadowed HS AT & $\begin{array}{c}\text { Researched AT for a HS } \\
\text { project (OT, AT, PT) }\end{array}$ & HS Athlete & $\begin{array}{l}\text { Exposure to AT in high } \\
\text { school }\end{array}$ \\
\hline HS athlete & Did nursing in HS & $\begin{array}{l}\text { Experience with PT due to } \\
\text { injury }\end{array}$ & Healthcare profession \\
\hline sustained an injury in HS & $\begin{array}{c}\text { No family experience with } \\
\text { AT }\end{array}$ & $\mathrm{AT}$ related to $\mathrm{PT}$ & Exposure to PT while in HS \\
\hline HS AT & $\begin{array}{c}\text { Cousins had an AT at HS in } \\
\text { VA }\end{array}$ & no family experience & \\
\hline \multicolumn{4}{|l|}{$\begin{array}{c}\text { helped start an AT program } \\
\text { at HS }\end{array}$} \\
\hline \multicolumn{4}{|l|}{ no family experience } \\
\hline & & & $\begin{array}{l}\text { Factors in selecting } \\
\text { college/university to attend }\end{array}$ \\
\hline CHOOSING AT & CHOOSING AT & CHOOSING AT & Proximity to home \\
\hline $\begin{array}{c}\text { Stepping stone to PT } \\
\text { (eventually) }\end{array}$ & $\begin{array}{c}\text { HS nursing program steered } \\
\text { to AT }\end{array}$ & $\begin{array}{c}\text { Chemistry first, but changed } \\
\text { before classes began }\end{array}$ & Reputation of program \\
\hline \multirow[t]{6}{*}{ AT first major choice } & $\begin{array}{l}\text { First year in program is } \\
\text { intimidating }\end{array}$ & wanted DI & \\
\hline & Lots of attrition in first year & $\begin{array}{l}\text { was introduced to AT and } \\
\text { switched }\end{array}$ & \\
\hline & & & Pros of AT Program \\
\hline & & & $\begin{array}{c}\text { Variety of experiences/ } \\
\text { exposure }\end{array}$ \\
\hline & & & Travel experience \\
\hline & & & $\begin{array}{c}\text { Relationships with } \\
\text { peers/preceptors/athletes }\end{array}$ \\
\hline
\end{tabular}




\begin{tabular}{|c|c|c|c|}
\hline Site 4-1 & Site 4-2 & Site 4-3 & THEMES \\
\hline $\begin{array}{c}\text { CHOOSING } \\
\text { SCHOOL/PROGRAM }\end{array}$ & $\begin{array}{c}\text { CHOOSING } \\
\text { SCHOOL/PROGRAM }\end{array}$ & $\begin{array}{c}\text { CHOOSING } \\
\text { SCHOOL/PROGRAM }\end{array}$ & Pros of AT Program cont. \\
\hline welcoming CEC & $\begin{array}{c}\text { Originally choose school in } \\
\text { FL - changed }\end{array}$ & all expensive & Mentoring \\
\hline school and NFL connection & from WV & school cheaper option & Networking \\
\hline Program reputation & close to home & Dad worked at UR & Rewarding \\
\hline Close to home & $\begin{array}{l}\text { once at school - reputation of } \\
\text { program }\end{array}$ & close to home & \\
\hline \multirow[t]{2}{*}{$\begin{array}{l}\text { Cost factor but reputation } \\
\text { won }\end{array}$} & aid package better in FL & good program & \\
\hline & $\begin{array}{l}\text { proximity to home won over } \\
\text { aid }\end{array}$ & $\begin{array}{l}\text { Duquesne/Pitt -- did not like } \\
\text { programs }\end{array}$ & \\
\hline ASPECTS + or - & ASPECTS + or - & ASPECTS + or - & Cons of AT Program \\
\hline networking & helping people & athletes reliance on AT & Time management \\
\hline internships & medical field & athletes care about AT & Work-life balance \\
\hline NFL & sports environment & athletes respect AT & \\
\hline Cirque du Soleil & variety of rotations & observe progress with athlete & \\
\hline Alum network & different providers & help athlete & \\
\hline $\begin{array}{c}\text { Different ATs in different } \\
\text { settings }\end{array}$ & exposure to different settings & good preceptor relationships & $\begin{array}{c}\text { Initial impression of AT } \\
\text { environment }\end{array}$ \\
\hline Understanding faculty/staff & teamwork skills & rewarding as an AT & demanding \\
\hline team atmosphere & mentoring from preceptors & relationships with athletes & time intense \\
\hline fun & independence & learned a great deal & time management necessary \\
\hline
\end{tabular}




\begin{tabular}{|c|c|c|c|}
\hline Site 4-1 & Site 4-2 & Site 4-3 & THEMES \\
\hline ASPECTS + or - cont. & ASPECTS + or - cont. & ASPECTS + or - cont. & \\
\hline helpful staff & $\begin{array}{l}\text { learning from other's } \\
\text { experiences }\end{array}$ & DI opened doors & \\
\hline grown as a clinician & enjoys being busy & $\begin{array}{l}\text { more than a job for } \\
\text { staff/preceptors }\end{array}$ & Challenges Present in AT \\
\hline initially challenging & long hours are enjoyable & mentors & $\begin{array}{l}\text { public education on } \\
\text { profession }\end{array}$ \\
\hline time management & wants to be in ATF & connections & Lack of understanding \\
\hline had to find the way & $\begin{array}{c}\text { program has balance with } \\
\text { clinicals }\end{array}$ & time commitment & Misconceptions \\
\hline takes a while to adjust & work-life balance & not a normal student & Lack of regulation - licensure \\
\hline learn role & lots of travel opportunity & cadaver a plus & work life balance \\
\hline travel & travel + & visual learner & \\
\hline demanding schedule & busy but manageable & some tasks can be demeaning & \\
\hline missed classes & good use of time & other tasks are rewarding & \\
\hline GPA & & oral practicals a neg & \\
\hline ethics & & travel + & \\
\hline professionalism & & great experience & \\
\hline \multirow[t]{6}{*}{$\begin{array}{c}\text { balance of peer \& ATS with } \\
\text { athletes }\end{array}$} & & $\begin{array}{l}\text { travel can be overwhelming } \\
\text { at first }\end{array}$ & \\
\hline & & adjusted quickly to demands & \\
\hline & & prioritize \& time mgmt & \\
\hline & & workload is a lot but doable & \\
\hline & & $\begin{array}{c}\text { program helps you mature, } \\
\text { be more adult }\end{array}$ & \\
\hline & & $\begin{array}{l}\text { puts you out there, personal } \\
\text { growth }\end{array}$ & \\
\hline
\end{tabular}




\begin{tabular}{|c|c|c|c|}
\hline Site 4-1 & Site 4-2 & Site 4-3 & \\
\hline $\begin{array}{c}\text { CHARACTERISTICS OF } \\
\text { AT ENVIRO } \\
\end{array}$ & $\begin{array}{c}\text { CHARACTERISTICS OF } \\
\text { AT ENVIRO } \\
\end{array}$ & $\begin{array}{c}\text { CHARACTERISTICS OF } \\
\text { AT ENVIRO }\end{array}$ & \\
\hline devoted & time management important & $\begin{array}{l}\text { amazed at the need of } \\
\text { athletes }\end{array}$ & \\
\hline demanding & learn to balance work-life & hands on & \\
\hline time consuming & support available to adjust & scared and anxious as a PAT & \\
\hline hard work & & $\begin{array}{l}\text { sees need to educate others } \\
\text { on AT }\end{array}$ & \\
\hline \multicolumn{4}{|l|}{ enthused/interested } \\
\hline \multicolumn{4}{|l|}{ caring person } \\
\hline \multicolumn{4}{|l|}{ supportive } \\
\hline \multicolumn{4}{|l|}{ empathy not sympathy } \\
\hline FIT TO AT & FIT TO AT & FIT TO AT & \\
\hline fit well & good fit & good fit & \\
\hline gratifying experience & enjoys team environment & long term in AT questionable & \\
\hline loves helping others & peer learning/teaching & & \\
\hline \multicolumn{4}{|l|}{ worked hard } \\
\hline \multicolumn{4}{|l|}{ effort } \\
\hline \multicolumn{4}{|l|}{ minority, female } \\
\hline \multicolumn{4}{|l|}{ trusted and respected ATS } \\
\hline $\begin{array}{l}\text { CONFIDENCE LEVEL -- } \\
4\end{array}$ & $\begin{array}{l}\text { CONFIDENCE LEVEL -- } \\
6\end{array}$ & $\begin{array}{l}\text { CONFIDENCE LEVEL -- } \\
5\end{array}$ & \\
\hline high expectations & autonomy & more independent & \\
\hline anxious about GA position & admin lacking & ready & \\
\hline prepared & $\begin{array}{l}\text { preceptors gave more } \\
\text { independence }\end{array}$ & confidence is growing & \\
\hline responsible, mature & prepared & BOC anxiety & \\
\hline
\end{tabular}




\begin{tabular}{|c|c|c|c|}
\hline Site 4-1 & Site 4-2 & Site 4-3 & \\
\hline $\begin{array}{l}\text { CONFIDENCE LEVEL -- } \\
4 \text { cont. }\end{array}$ & $\begin{array}{c}\text { CONFIDENCE LEVEL -- } \\
6 \text { cont. }\end{array}$ & $\begin{array}{l}\text { CONFIDENCE LEVEL -- } \\
5 \text { cont. }\end{array}$ & \\
\hline \multirow[t]{2}{*}{ understands it is entry-level } & & autonomy & \\
\hline & & independent & \\
\hline POST GRAD PLANS & POST GRAD PLANS & POST GRAD PLANS & \\
\hline MS program & $\begin{array}{c}\text { Seeking GA with soccer, } \\
\text { MLS }\end{array}$ & $\begin{array}{l}\text { GA in MS program - Sports } \\
\text { Admin online }\end{array}$ & \\
\hline GA & $\begin{array}{l}\text { Michigan State \#1 choice of } \\
\text { grad program }\end{array}$ & HS AT possibly & \\
\hline $\begin{array}{c}\text { Sport, Fitness, Recreation } \\
\text { Leadership }\end{array}$ & $\begin{array}{l}\text { or intern position and re- } \\
\text { apply to MSU }\end{array}$ & $\begin{array}{c}\text { GA experience and free } \\
\text { degree }\end{array}$ & \\
\hline DePaul University & & PA possibly in future & \\
\hline $\begin{array}{l}\text { CHALLENGES OF } \\
\text { PROFESSION }\end{array}$ & $\begin{array}{l}\text { CHALLENGES OF } \\
\text { PROFESSION }\end{array}$ & $\begin{array}{l}\text { CHALLENGES OF } \\
\text { PROFESSION }\end{array}$ & \\
\hline work-life & licensure in WV & glorified water girls & \\
\hline public education improving & job availability & name change & \\
\hline misconceptions & year round seasons & lack of understanding & \\
\hline lack of education & work-life & lack of education & \\
\hline $\begin{array}{l}\text { AT need to promote } \\
\text { themselves }\end{array}$ & growing field/profession & misconceptions & \\
\hline \multirow[t]{5}{*}{ lack of respect for AT } & time & demanding schedule & \\
\hline & lack of education & work-life balance & \\
\hline & personal trainer & & \\
\hline & $\begin{array}{l}\text { access to AT helps educate } \& \\
\text { profession }\end{array}$ & & \\
\hline & $\begin{array}{l}\text { AT at HS helps educate } \\
\text { public }\end{array}$ & & \\
\hline
\end{tabular}




\begin{tabular}{|c|c|c|c|}
\hline Site 4-1 & Site 4-2 & Site 4-3 & \\
\hline $\begin{array}{c}\text { IMPACT OF } \\
\text { WORKLOAD ON AT }\end{array}$ & $\begin{array}{c}\text { IMPACT OF } \\
\text { WORKLOAD ON AT }\end{array}$ & $\begin{array}{c}\text { IMPACT OF } \\
\text { WORKLOAD ON AT }\end{array}$ & \\
\hline longer athletic seasons & year round seasons & demanding schedule & \\
\hline burnout & work-life & on call $24 / 7$ & \\
\hline work hours & time biggest concern & work-life conflict & \\
\hline \multicolumn{4}{|l|}{ dropout rate } \\
\hline \multicolumn{4}{|l|}{ difficult work-life balance } \\
\hline \multicolumn{4}{|l|}{ demands fluctuate } \\
\hline \multicolumn{4}{|l|}{ enjoy what you do } \\
\hline \multicolumn{4}{|l|}{ family balance is modeled } \\
\hline \multicolumn{4}{|l|}{ work hard, play hard } \\
\hline ENTRY-LEVEL SALARY & ENTRY-LEVEL SALARY & ENTRY-LEVEL SALARY & \\
\hline AT low salary & $\begin{array}{l}\text { has not researched much } \\
\text { since HS }\end{array}$ & salary not too bad & \\
\hline $\begin{array}{l}\text { insurance reimbursement }+ \\
\text { for PT }\end{array}$ & $55-60000$ & site salaries low & \\
\hline $\begin{array}{l}\text { more involved in AT than PT } \\
\text { with patient }\end{array}$ & & $\begin{array}{c}\text { was aware of proposed labor } \\
\text { law impact }\end{array}$ & \\
\hline IMPACT OF AT \& PT & $\begin{array}{c}\text { IMPACT OF AT \& other } \\
\text { professions }\end{array}$ & IMPACT OF AT \& PT & \\
\hline $\begin{array}{l}\text { AT \& PT beneficial } \\
\text { relationship }\end{array}$ & $\begin{array}{c}\text { WV - licensure -- PT neg } \\
\text { impact }\end{array}$ & positive -- MD, PA, PT, RN & \\
\hline HealthWorks & $\begin{array}{l}\text { HS AT -- large impact } \\
\text { rapport with others }\end{array}$ & has had positive interactions & \\
\hline \multirow[t]{2}{*}{ collaboration is a +} & Professional relationships + & $\begin{array}{l}\text { dual credentialed help build } \\
\text { bridges }\end{array}$ & \\
\hline & $\begin{array}{l}\text { Positive professional } \\
\text { relationships help AT }\end{array}$ & & \\
\hline
\end{tabular}




\begin{tabular}{|c|c|c|c|}
\hline Site 4-1 & Site 4-2 & Site 4-3 & \\
\hline $\begin{array}{c}\text { DESIRED WORK } \\
\text { LOCATION/SETTING }\end{array}$ & $\begin{array}{c}\text { DESIRED WORK } \\
\text { LOCATION/SETTING }\end{array}$ & $\begin{array}{c}\text { DESIRED WORK } \\
\text { LOCATION/SETTING }\end{array}$ & \\
\hline \multirow[t]{3}{*}{$\begin{array}{c}\text { Clinical AT then PT, } 5 \text { years } \\
\text { as AT }\end{array}$} & Professional soccer -- MLS & AT clinic position & \\
\hline & & stable & \\
\hline & & considering PA, unsure & \\
\hline \multicolumn{4}{|l|}{$\begin{array}{l}\text { SKILL OVERLAP -- AT to } \\
\text { PT }\end{array}$} \\
\hline \multicolumn{4}{|l|}{$\begin{array}{l}\text { Using education to be a } \\
\text { better clinician }\end{array}$} \\
\hline \multicolumn{4}{|l|}{$\begin{array}{l}\text { Real world, real life } \\
\text { experience (over bio) }\end{array}$} \\
\hline WHY ? & & WHY consider PA? & \\
\hline \multirow[t]{5}{*}{ PT better schedule, hours } & & PA good long-term career & \\
\hline & & $\begin{array}{l}\text { unsure about AT for the } \\
\text { long-term }\end{array}$ & \\
\hline & & enjoying AT at present & \\
\hline & & on call $24 / 7$ with AT & \\
\hline & & AT work-life conflict, family & \\
\hline 5 years & 5 years & 5 years & \\
\hline Professionally & Professionally & Professionally & \\
\hline $\begin{array}{c}\text { PT in NYC/Chicago -- } \\
\text { eventually }\end{array}$ & MLS & employed full-time & \\
\hline AT Working & & happy with job & \\
\hline Personally & Personally & Personally & \\
\hline \multirow[t]{3}{*}{ Living in metropolitan area } & Dating possibly & close to family & \\
\hline & $\mathrm{CO}, \mathrm{WA}, \mathrm{OR}$ & $\begin{array}{l}\text { KY -- Lexington or near } \\
\text { Columbus }\end{array}$ & \\
\hline & & possibly further south & \\
\hline
\end{tabular}




\section{Appendix F: Sample AT Position Descriptions}

Sample Job Description: College/University - Director of Sports Medicine

\section{SUMMARY OF COMPANY}

Enter a brief description of who is hiring the AT.

POSITION TITLE: Director of Sports Medicine

REPORTS TO:

Medical Supervision:

Health Care Administrative Supervision:

\section{QUALIFICATIONS:}

Required

YEARS OF EXPERIENCE: Enter preferred years of experience here

EDUCATION: Master's Degree

CERTIFICATION/LICENSES: Must be BOC certified and possess state athletic training licensure, certification or registration. NPI Number Required.

\section{SPECIFIC DUTIES \& RESPONSIBLITIES:}

- Administers and oversees the care, prevention, evaluation, treatment and rehabilitation of injuries to all student-athletes.

- Provides specific clinical care as assigned by the Medical Director.

- With Medical Director, manages and supervises sports medicine staff.

- Organizes and maintains all medical records in accordance with federal and state regulations.

- Develops and maintains emergency action plans for all permanent and temporary practice and competition venues in accordance with university risk management guidelines and state regulations.

- Develops and maintains all department guidelines, policy and procedure in accordance with national/international best practices and consensus statements.

- With Medical Director, develops and maintains all service contract with medical consultants.

- Prepares clear and accurate reports regarding travel authorities, expenditure reconciliations, visa reconciliations, inventory lists and requested accounting.

- Maintains student-athlete insurance information.

- Maintains good communication with the insurance providers and manages all paperwork required for claims.

- Develops and manages the Athletic Training Facility, budgets and policies to maintain optimal health, safety and welfare of all constituents.

- Coordinates the purchasing and use of all equipment and supplies needed for the operation of the athletic training facility, in accordance with State and University policies.

- With Medical Director, Plans and coordinates physical examinations and screenings.

- Communicate with physicians and coaching staff regarding the injury status of athletes.

- Makes appropriate physician's referrals and appointments. 
- Organizes and administers drug testing per department policy.

- Assists the institution in hosting athletic events.

- Assists the Athletic Director and coaching staff in determining whether the athletic facility is in optimal and safe condition.

- Helps monitor weather conditions and dangerous environments (humidity/lightning).

- Adheres to Conference guidelines, including visiting team accommodations and services.

- Ensures the Athletic Department staff maintains First-Aid, CPR and AED certification.

- Responsible for implementation and rehearsal of health and safety best practices.

- With Medical Director assigns Athletic Health Care Administrator per NCAA guidelines.

- Knowledge of rules and regulations set forth by the NCAA and conference should be maintained, reviewed and practiced to ensure compliance relative to those applicable duties.

NUMBER/DESCRIPTION OF PATIENTS RESPONSIBLE FOR: Provide number of patients and patient population the AT is responsible for.

TRAVEL REQUIREMENTS: List any travel requirements here.

\section{PHYSICAL REQUIREMENTS}

Work is medium demand. Lifting 100 pounds maximum with frequent lifting and/or carrying of objects. Medium strength is required to position patients for examination. May assist patients as needed, helping them on and off the exam table. Ability to work a flexible schedule, including evenings, weekends, and holidays.

SUPERVISORY RESPONSIBILITIES: This statement should accurately reflect all individuals this position is directly supervising including sports nutrition, sports psychologist, strength and conditioning coaches, etc.

\section{ADDITIONAL QUALIFYING FACTORS}

- Is there a pre-employment drug test that must be passed?

- Is there a background screening check that must be passed?

- Is transportation to/from work a necessity?

- Is holding a valid driver's license a necessity?

- This is also where Shareholder Preference, Equal Opportunity Employments, and any other legal disclaimers would be placed within the job description.

WEBSITE OF HIRING ORGANIZATION LINK HERE

(NATA, 2018d) 


\section{NodA The Market \\ Careers in College Athletics}

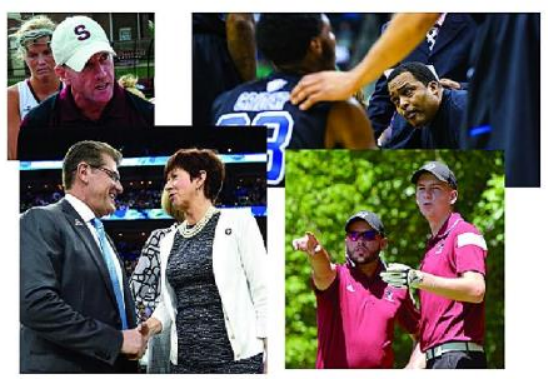

Employers? Post Jobs and More

Home Jobs Your Profile Resources
Q Search $\odot$ Browse $P$ Explore $\triangle$ Your Job Alerts $\$$ Your Saved Jobs

W Back to Search

< Previous Job Next Job >

\section{Assistant Athletic Trainer}

SAVE

\section{Indian Hills Community College}

Minimum Job Requirements:

-Bachelor's Degree required and Master's Degree preferred.

\section{Application}

-Current certification by the National Athletic Trainers' Association Board of Certification.

- Licensed as an Athletic Trainer in the State of lowa, or eligible for licensure.

-Must relate well to people and display a high degree of competency within the discipline.

-Effective communication skills with diverse personalities in both personal and group settings.

First Name

Last Name

Job Summary:

This position will assist the Head Athletic Trainer with the development, coordination, and administration of a comprehensive sports medical program for all Indian Hills athletic programs on the Ottumwa and Centerville campuses, assuring availability of acute injury treatment at college athletic functions. Some evening and weekend hours will be required. Flexible summer scheduling may also be required.

Work Performed: 
$11 / 30 / 2018$

-Assist the Head Athletic Trainer with coordination and administration of a comprehensive sports medical program for the College, including: injury prevention programs, injury evaluations, injury management, and injury treatment.

- Oversight of athletic training software Sports Ware including continued data entry of student athlete demographic information, injury reports, student athlete primary insurance information and injury history.

-Manage pre-participation information on a daily basis to ensure files up to date and communicate with coaches daily about status of studentathletes.

-Travel to Centerville campus for care of baseball and sport shooting student-athletes minimum 2-3 days per week.

-Responsible for all "off-season" sports including treatments, rehabilitation plans, practice coverage, and other duties related to student-athlete care.

-Provide athletic training services for the College's athletic department, including attendance at home competitions, coordinating coverage for scheduled practices, with the potential for some travel to away events.

-Work with Head Athletic Trainer to administer programs regarding health care for the student athletes (ex. Medical clearances reports, physical exams, physician referrals, insurance and consent forms, safety equipment) and with student athletes.

- Have an understanding of each of the colleges insurances policies, including athletic and international student and work with those companies to ensure proper filing of athletic injury claims.

-Monitor and evaluate students during practicum experiences. Maintain documentation of injuries and student experience hours.

-Represent the College in the most positive manner with prospective, former and current students, clients, suppliers and the community.

-Schedule clinic hours for student consultation.

-Maintain cooperative relationships with professional personnel, local organizations, public officials and other interested people.

-Meet all assigned office commitments as scheduled.

-Submit to Student Services reports on all students who may be in need of counsel.

-Serve actively on any committee to which appointed.

-Keep accurate inventories of equipment and supplies and submit requisitions for needed materials.

-Promptly report repairs needed for equipment.

-Stay up to date with trends in the field and equipment as appropriate

-Maintain regular and consistent attendance at work.
Please include your resume and up to two additional documents.

\section{Add File}

\section{APPLY NOW}

By using this feature you agree to our Terms and Conditions and Privacy Policy.

\section{Details}

Posted:

November 5, 2018

Location:

Ottumwa, lowa

Salary:

$\$ 28,798-\$ 34,780$

Type:

Full-time - Experienced

Sector:

Jr. Collegiate Sports

Categories:

Sports Medicine, Sports Medicine Athletic Training

\section{Required Education:}

4 Year Degree 
$11 / 30 / 2018$

Assistant Athletic Trainer, Employment | NCAA

-Other duties as may be assigned.

Responsible To: Head Athletic Trainer; Director, Athletics/Student

Services

Position Level: Para I - Non-Exempt - Traditional Funding - at will

employment on a letter of employment

Yearly Employment Length: 3 1/2 Term (167 days), Full Time

Schedule: As scheduled

Starting Salary Range: $\$ 28,798-\$ 34,780$

$\checkmark$ Create a Job Alert for Similar Jobs

\section{About Indian Hills Community College}

Indian Hills Community College is a comprehensive two-year community college in Southeast lowa with campuses in Ottumwa and Centerville.

The college offers an arts and sciences curriculum, instruction in over 40 technical programs, and an extensive customized learning program.

Powered By NAYLOR

\section{ASSOCLATION SOLUTIOAS}

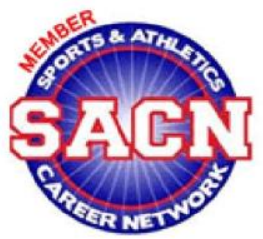

(NCAA, 2018) 


\section{Nod4 The Market Careers in College Athletics}

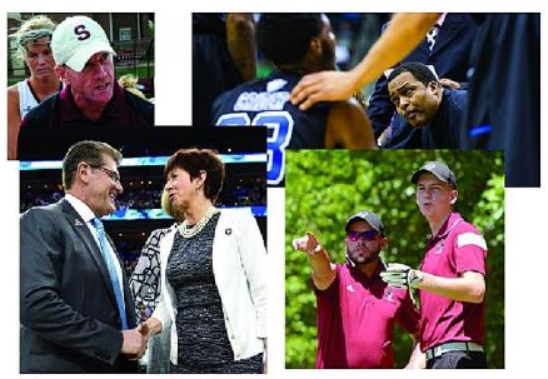

Employers? Post Jobs and More

Home Jobs Your Profile Resources
Q Search $\odot$ Browse $P$ Explore $\triangle$ Your Job Alerts $\$$ Your Saved Jobs

W Back to Search

< Previous Job Next Job >

\section{Assistant Athletic Trainer}

SAVE

\section{UGA Athletic Association}

\section{**To apply for this posting send cover letter and resume to hrdept@sports.uga.edu**}

\begin{abstract}
Supervise and coordinate athletic training services for student-athletes participating in intercollegiate athletic programs for the University of Georgia Athletic Association, working under the medical direction of team physicians and in conjunction with referring physicians, other ancillary medical professionals, and UGAAA staff (athletic training, athletic administration, athletic coaching, strength and conditioning, sports nutrition, counseling/sports psychology, academics).
\end{abstract}

Prevention of Athletic Injuries: $10 \%$ of overall duties 1.pre-participation physical examinations a.assist in coordinating pre-participation physical examinations for student-athletes b.coordinate and schedule required follow-up appts from physicals 2 .movement assessments 3 . preventative maintenance rehabilitation programs 4 .mobility, flexibility, strength, and conditioning programs 5 .fitting of protective equipment, including fabrication of tape, braces, and special pads

Emergency Care and First Aid: $5 \%$ of overall duties 1.emergency plan development 2.emergency care coordination with ATC, EMS and MD 3.emergency equipment management 4.emergency medicine inservicing a.maintenance of CPR / AED certification b.yearly review of emergency protocols
Q Job Seeker Sign In Your Account $\nabla$

\section{Application}

First Name

Last Name

Email

Message To Employer... 
$11 / 30 / 2018$

Recognition, Evaluation and Management of Athletic Injuries: $30 \%$ of overall duties 1.serve as assistant athletic trainer for track \& field/cross country a.includes S\&C, practice, and competition coverage and travel responsibilities 2.coordinate coverage and supervise medical care for track \& field/cross country as well as other student-athletes, sports, events as assigned by director of sports medicine 3 .initial assessment and treatment of athletic injuries 4. physician referral as appropriate a.daily communication with team clinicians b.regular communication with specialty clinicians as appropriate 5.utilize casting, splinting, immobilization, and ambulatory assistive devices 6 .wound care 7.diagnostic testing appointments 8.use of therapeutic modalities and exercise

Rehabilitation of Athletic Injuries: $30 \%$ of overall duties 1 implementation of rehabilitation programs under MD supervision a.participate in rehabilitation progress update meetings b.maintain appropriate communication with supervising clinicians 2.development of rehabilitation protocols a.coordinate rehabilitation with director sports medicine and/or director of rehabilitation 3.use of therapeutic modalities and exercise 4 .athletic rehabilitation progress reports 5 .isokinetic testing 6.aquatic rehabilitation

Athlete Education and Counseling: $10 \%$ of overall duties 1.athletic injury education 2.injury / illness prevention education 3.fitness / strength and conditioning education in collaboration with S\&C coach 4.nutritional counseling and referral to registered dietician as appropriate 5.general counseling and referral to mental health clinician as appropriate 6.athletic training and sports medicine presentations 7.regular attendance of continuing education activities

Organization and Administration: $15 \%$ of overall duties 1 .supervision of athletic training interns and student athletic trainers 2.documentation in electronic medical records 3.collection of pertinent medical documents (i.e. hospital records, surgery reports, etc...) 4.collection of injury / incident data for research purposes as assigned 5.participate in collaborative learning efforts for athletic training staff 6.organization and administration of athletic training room (main and satellite facilities) 7.supply and equipment inventory 8.completion of athletic insurance forms working with insurance coordinator 9 .Ensures compliance with NCAA, SEC and institutional rules and regulations as related to the area of Sports Medicine

\section{Minimum Education and Experience Requirements:}

Bachelor's degree required. Master's degree preferred. NATA certification required. Must have or be eligible for Georgia athletic training licensure. Must have at least two years of related experience in sports medicine. Knowledge of NCAA and SEC regulations desired.

Supervisory Responsibilities: Supervise intern athletic trainers and undergraduate athletic training students.

NOTES:

Employer will assist with relocation costs.
(1) Attachments:

Please include your resume and up to two additional documents.

$$
\text { Add File }
$$

\section{APPLY NOW}

By using this feature you agree to our Terms and Conditions and Privacy Policy.

\section{Details}

Posted:

November 30, 2018

Location:

Athens, Georgia

Salary:

Commensurate with experience

Type:

Full-time - Experienced

Sector:

Collegiate Sports

\section{Categories:}

Sports Medicine, Sports Medicine Athletic Training

\section{Preferred Education: Masters}

(NCAA, 2018) 


\section{References}

Albaugh, J.A. (2003). Keeping Nurses in Nursing: The Profession's Challenge for today. Urol Nurs, 23(3):193-9.

America's Health Rankings. (2016). America’s Health Rankings State Data: West Virginia. Retrieved from http://www.americashealthrankings.org/WV

Barrett, J. J., Gillentine, A., Lamberth, J., \& Daughtrey, C. L. (2002). Job satisfaction of NATABOC certified athletic trainers at division one national collegiate athletic association institutions in the southeastern conference. International Sports Journal, Summer, 1-13.

Bell, A.T. (1989). Analysis of job satisfaction determinants in NATA-certified athletic trainers employed in different settings (Doctoral dissertation). ProQuest Dissertations Publishing. (9012906)

Benes, S.S. \& Mazerolle, S.M. (2014). Factors Influencing Athletic Training Students' Perceptions of the Athletic Training Profession and Career Choice. Athletic Training Education Journal, 9(3), 104-112.

Bowman, T.G. \& Thomas M. Dodge, T.M. (2011). Factors of Persistence Among Graduates of Athletic Training Education Programs. Journal of Athletic Training, 46(6), 665-671.

BLS. (2015). Bureau of Labor Statistics Occupational Outlook Handbook. Retrieved from http://www.bls.gov/ooh/healthcare/athletic-trainers.htm\#tab-6

BLS. (2016a). Bureau of Labor Statistics Local Area Unemployment Statistics Map. Retrieved from http://data.bls.gov/map/MapToolServlet?survey=la\&map=county\&seasonal=u

BLS. (2016b). Bureau of Labor Statistics Occupational Employment Statistics Query System. http://data.bls.gov/oes/search.jsp?data_tool=OES 
BLS. (2016c). Bureau of Labor Statistics Occupational Employment Statistics. Retrieved from http://www.bls.gov/oes/current/oes299091.htm\#st

Blumer, H. (1969). Symbolic Interactionism Perspective and Method. Englewood Cliffs, New Jersey: Prentice Hall.

BOCATC. (2016a). What is an Athletic Trainer. Retrieved from http://www.bocatc.org/public/what-is-an-athletic-trainer

BOCATC. (2016b). Public. What is an Athletic Trainer? Retrieved from http://www.bocatc.org/public

BOCATC. (2018). State Regulation. Retrieved from http://www.bocatc.org/state-regulation CAATE. (2006). CAATE Newsletter Fall 5(2), 1-6.

CAATE. (2015). Changes in Standards and Updates. September 28.

CAATE. (2016). Search Accredited Programs. Retrieved from http://caate.net/search-foraccredited-program/

Campbell D., Miller, M.H., \& Robinson, W.W. (1985). The Prevalence of Burnout Among Athletic Trainers. Athletic Training, Summer, 110-13; 148.

Capel, S. A. (1986). Psychological and organizational factors related to burnout in athletic trainers. Athletic Training, 21, 322-327.

Capel, S. A. (1990). Attrition of athletic trainers. Athletic Training, 25, 34-39.

Carnegie. (2015). Institution Lookup. Retrieved from http://carnegieclassifications.iu.edu/lookup/lookup.php

Clapper, D., \& Harris, L. (2006). Determining professional burnout of certified athletic trainers employed in the big ten athletic conference (abstract). Journal of Athletic Training, 41(2), S-72-S-73. 
Careerpatri. (2016). Holland Theory of Vocational Personalities. Retrieved from http://careerpatri.com/holland_theory.aspx

Crotty, M. (2015). The Foundations of Social Research Meaning and Perspective in the Research Process. Los Angeles, CA: SAGE Publications. (Original work published 1998)

Delforge, G.D. \& Behnke, R.S. (1999). The History and Evolution of Athletic Training Education in the United States. Journal of Athletic Training, 34(1), 53-61.

Deskins, J., Ruseski, J., Lego, B., Bowen, E., Christiadi, Meszaros, J., \& Pokharel, S.B. (2015). 2016 West Virginia Economic Outlook. Morgantown, WV: Bureau of Business \& Economic Research.

Erikson, E.H. (1968). Identity Youth and Crisis. New York, NY: W.W. Norton.

Ferry, N.M. (2006). Factors Influencing Career Choices of Adolescents and Young Adults in Rural Pennsylvania (Research in Brief 3RIB7). Journal of Extension, 44(3). Retrieved from http://www.joe.org/joe/2006june/rb7.php

Fouad, N.A. \& Byars-Winston, A.M. (2005). Cultural Context of Career Choice: MetaAnalysis of Race/Ethnicity Differences. The Career Development Quarterly, 53, 223233.

Giacobbi, P.R. (2009). Low Burnout and High Engagement Levels in Athletic Trainers: Results of a Nationwide Random Sample. Journal of Athletic Training, 44(4), 370-77.

Goodman, A. (2007). Retention and Attrition Factors of Female Certified Athletic Trainers in the National Collegiate Athletic Association Division-I Football Bowl Subdivision Setting (Doctoral Dissertation). ProQuest Dissertations Publishing. (3296658) 
Gupta, G. (1991). Student attrition: A challenge for allied health education programs. Journal of the American Medical Association, 266, 963-967.

Hancock, D.R. \& Algozzine, B. (2011). Doing Case Study Research A Practical Guide for Beginning Researchers. ( $2^{\text {nd }}$ Ed.) New York, NY: Teacher's College Press.

Hendrix, A. E., Acevedo, E. O., \& Hebert, E. (2000). An examination of stress and burnout in certified athletic trainers at Division I-A universities. Journal of Athletic Training, 35, 139-144.

Hermanowicz, J. (Ed.). (2011). The American Academic Profession: Transformation in Contemporary Higher Education. Baltimore: The Johns Hopkins Press.

Holland, J.L. (1997). Making Vocational Choices A Theory of Vocational Personalities and Work Environments. ( ${ }^{\text {rd }}$ Ed.). Odessa, FL: PAR.

HRSA. (2014). Health professional shortage areas. Retrieved from http://www.hrsa.gov/shortage/

HRSA Data Warehouse. (2016). HPSA Find. Retrieved from http://datawarehouse.hrsa.gov/tools/analyzers/HpsaFind.aspx

Judd, M. R., \& Perkins, S. A. (2004). Athletic training program directors' perceptions on job selection, satisfaction, and attrition. Journal of Athletic Training, 39, 185-192.

Kania, M., Meyer, B., \& Ebersole, K. (2006). Burnout among ATCs at NCAA institutions is related to stress and pressure from coaches (abstract). Journal of Athletic Training, 41(2), S-72.

Kania, M., Meyer, B., \& Ebersole, K. (2009). Personal and Environmental Characteristics Predicting Burnout Among Certified Athletic Trainers at National Collegiate Athletic Association Institutions. Journal of Athletic Training, 44(1), 58-66. 
Klossner, J. (2008). The role of legitimation in the professional socialization of second-year undergraduate Athletic Training students. Journal of Athletic Training, 43(4), $379-385$.

Koehneke, P. (2003). Educating the Future of the Profession. Athletic Therapy Today, 8, 5, 1. Lincoln, YS. \& Guba, EG. (1985). Naturalistic Inquiry. Newbury Park, CA: SAGE Publications.

Mazerolle, S. M., Bruening, J. E., Casa, D. J., Burton, L., \& Van Heest, J. (2006). The impact of work-family conflict on job satisfaction and life satisfaction in division I-A athletic trainers (abstract). Journal of Athletic Training, 41(2), S-73.

Mazerolle, S. M., Bowman, T. G., \& Dodge, T. M. (2014). The professional socialization of the Athletic Trainer serving as a preceptor. Journal of Athletic Training, 49(1), 7582.

Mazerolle, S. M., Eason, C. M., Nottingham S., Barrett J. L. (2016). Athletic training students' perceptions of mentorship in clinical education. Athl Train Educ J, 11(2), 72-81.

McLeod, S. (2013). Erik Erikson. Retrieved from http://www.simplypsychology.org/ErikErikson.html

Medical dictionary. (2016). Burnout definition. Retrieved from http://medicaldictionary.thefreedictionary.com/burnout

Mensch, J., Crews, C., \& Mitchell, M. (2005). Competing perspectives during organizational socialization on the role of certified athletic trainers in high school settings. Journal of Athletic Training, 40, 333-340. 
Milazzo, S. A., Miller, T. W., Bruening, J. E., \& Faghri, P. D. (2006). A survey of division I-A athletic trainers on bidirectional work-family conflict and its relation to job satisfaction (abstract). Journal of Athletic Training, 41(2), S-73.

NATA. (2015a). History. Retrieved from: http://www.nata.org/history

NATA. (2015b). NATA Membership Statistics. Retrieved from http://members.nata.org/members1/documents/membstats/2014EOY-stats.htm

NATA. (2015c). Athletic Training. Retrieved from https://www.nata.org/about/athletic-training NATA. (2018a). Quick Facts. Retrieved from https://www.nata.org/nata-quick-facts

NATA. (2018b). Ethnicity Report. Retrieved from https://www.nata.org/sites/default/files/ethnicity-report.pdf

NATA. (2018c). Career Center. Retrieved from https://jobs.nata.org/

NATA. (2018d). Career \& Education. Retrieved from https://www.nata.org/careereducation/career-center/post-a-job/sample-job-descriptions

NCAA. (2018). The Market Careers in College Athletics. Retrieved from https://ncaamarket.ncaa.org/jobseekers/

Neibert, P., Huot, C. \& Sexton, P. (2010). Career Decisions of Senior Athletic Training Students and Recent Graduates of Accredited Athletic Training Education Programs. Athletic Training Education Journal, 5(3), 101-108.

Patton, M.Q. (2002). Qualitative Research and Evaluative Methods. ( $\left.3^{\mathrm{rd}} \mathrm{Ed}\right)$. Thousand Oaks, CA: SAGE Publications.

Perrin, D.H. (2007). Athletic Training: From Physical Education to Allied Health. Quest, 59, $111-123$. 
Pitney, W. A. (2002). The professional socialization of certified athletic trainers in high school settings: A grounded theory investigation. Journal of Athletic Training, 37, 286-292.

Pitney, W. A. (2006). Organizational influences and quality-of-life issues during the professional socialization of certified athletic trainers working in the National Collegiate Athletic Association Division I setting. Journal of Athletic Training, 41, 189-195.

Pitney, W. A., Ilsley, P., \& Rintala, J. (2002). The professional socialization of certified athletic trainers in the National Collegiate Athletic Association Division I context. Journal of Athletic Training, 37, 63-70.

Russ, K.A. (2006). Effects of Appalachian Culture on Career Choice. (Doctoral dissertation). ProQuest Dissertations Publishing. (3218078)

Saldana, J. (2013). The Coding Manual for Qualitative Researchers. (2 ${ }^{\text {nd }}$ Ed.) Los Angeles, CA: SAGE Publications. (Original work published 2009)

Seidman, I. (2013). Interviewing as Qualitative Research A Guide for Researchers in Education $\&$ the Social Sciences. ( ${ }^{\text {th }}$ Ed.) New York, NY: Teachers College.

Stake, R.E. (2006). Multiple Case Study Analysis. New York, NY: The Guilford Press.

Stilger, V.G., Meador, R., Tsuchiya, M. (1999). Job Search and Employment-Related Issues in Athletic training programs. Journal of Athletic Training, 34(4), 368-73.

US Census. (2016). US Census Bureau Quick Facts. Retrieved from http://www.census.gov/quickfacts/table/PST045215/5414600,5411188,5455756

Western Reserve. (2011). John Holland's Theory of Career Choice. Retrieved from http://westernreservepublicmedia.org/careers/john_holland.htm

Yin, R.K. (2014). Case Study Research Design and Methods. (5 ${ }^{\text {th }}$ Ed.) Los Angeles, CA: SAGE Publications. 